\title{
COMPORTAMENTO DE CULTIVARES DE ARROZ DE SEQUEIRO EM DIFERENTES POPULAÇ,ÕES DE PLANTAS, COM E SEM IRRIGAÇÃO SUPLEMENTAR
}

\author{
ALEERTO BAETA DOS SANTOS \\ Engenheiro Agrónomo
}

\author{
Orientador: Prof. Dr. JOSE'DIAS COSTA
}

\begin{abstract}
Tese apresentada à Escola Superior de Agricultura "Luiz de eueiroz", da Universidade de São Paulo, para obtenção do título de "Doutor em Agronomia, Área de Concentração: Fitotecnia.
\end{abstract}

P I R A C I C A B A

Estrado de São Paulo - Brasil

-ezembro - 1990 
Ficha catalográfica preparada pela Seção de Livros dá Divisào de Biblioteca e Documentação - PCAP/USP

Santos, Alberto Baêta

S3itc Comportamento de cultivares de arroz de sequeiro em diferentes populaçōes de plantas, com e sem irrigação supiementar. Piracicaba, 1990.

ght ilus.

TE SE - ESALQ

Bibliografiá.

1. Arroz de sequeiro - Cultivar - Comportamento 2. Arroz de sequeiro - Irrigaçào 3. Arroz de seque ro - População - Efeito I.Escola Superior de Agri cultura "Luiz de Queiroz, Piracicaba.

$\operatorname{CDD} \quad 633.18$ 
COMPORTAMENTO DE CULTIVARES DE ARROZ DE SEQUEIRO EM DIFERENTES POPULAC,ÕES DE PLANTAS, COM E SEM IRRIGAC,ÃO SUPLEMENTAR

\section{ALBERTO BAÊTA DOS SANTOS}

Zipromada em: 04.12 .1990

romissão Julgadora:

Prof. Dr. Jose" Dias Costa

Pesq. Dr. Luis Fernando Stone

Pesq. Dr. Tomás Aquino Portes e Castro

Prof. Dr. Antonio Augusto Lucchesi

Prof. Ir. Jairo Teixeira Mendes Abrañäo ESALQ’/USP

\author{
ESALQ/USP \\ GNPAF /EMBRAPA \\ CNPAF $/$ EMBRAPA \\ ESALQ/USP
}

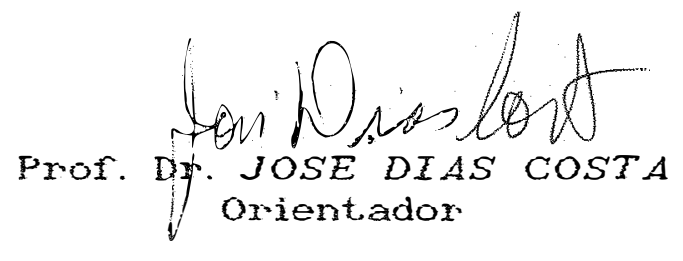




Wos meus pais, Nelson e Adelina,
pelo incentivo e pela dedicacão
de stras midas a mintya formacão
pessoal e profissional,
MINHA GRATIDÃO

If minga esposa, Vanderlúcia, aos metrs filbos, Eduardo, Renato e Talita, por reitetatem cotidianamente

a mintya espetatica be um futuro mais insto, com carinho, DEDICO 


\section{AGRADECIMENTOS}

$$
\text { Várias pessoas e instituições contribuiram, }
$$
de uma forma 5, de outra, para a realização deste trabalho. Entretarito, externamos, de maneira especial, os nossos agradecimentos:

$$
\text { A Empresa Brasileira de Pesquisa }
$$

Agropecuária (EMBRAPA), através do Gentro Nacional de Pesquisa de Arroz e Feijão (CNPAF), pelo auxilio e pela concessão do treinamento;

A Liscola Superior de Agricultura "Luiz de Queiroz" (ESALQ) e ao Departamento de Agricultura, pela oportunidade de realizar o curso de Pós-Graduação;

Ao Professor Dr. Jose Dias Costa, nosso profundo reconhecimento pela orientação e pela amizade;

$$
\text { Ao Pesquisador Dr. Francisco Jose }
$$

Pfeilsticker Zimmermann e à Professora Dra. Maria Gristina Stolf Nogueira, pelo auxilio na realização das análises estatísticas;

Ao Professor Dr. António Roberto Pereira e ao Pesquisador Dr. Tomás de Aquino Portes e Castro, pela eficiente colaboração recebida nas análises de 
crescimento das plantas;

Ao Conselho Nacional de Desenvolvimento Gientifico e Tecnológico (CNPq), pela concessão de bolsa de estudo por periodo parcial de realização do treinamento;

Aos professores do Departamento de Agricultura, pela contribuição em minha formação cientifica e pela amizade;

Aos companheiros de turma, pelo convivio e pela amizade;

Ao Técnico Agricola Odete Valadão c"in memorian"), pelo apoiō;

E principalmente a Deus que nos permitiu reunir todas as condições. necessárias para realização deste treinamento. 
LISTA DE FIGURAS

LISTA DE TABELAS

LISTA DE SIGLAS

RESUMO

SUMMARY

1. INTRODUĢÃO

2. REVISTOO DE LITERATURA

3. MATERIAL E MEtodos

4. RESULTAdOS E DISGUSSATO

5. GONGLUSOES

REFERENGIAS BIBLIOGRAFIGAS
Página

viii

$x i i$

xu

$x v i$

xix

1

4

15

23

82

84 
.viii.

\section{LISTA DE FIGURAS}

Figura

Página

01 Temperatura máxima, média e mínima e precipitação pluvial diárias e periodos em que as irrigações foram realizadas nos experimentos...

02 Evolução da produção da matéria seca total (MS) $\left(g . m^{-2}\right)$ dos cultivares de arroz de sequeiro Araguaia e Guarani, em função dos dif̄erentes espaçamentos e densidades, sem irrigação...

03 Evolução da produção da matéria seca total (MS) $\left(5 . m^{-2}\right)$ dos cultivares de arroz de sequeiro Araguaia e Guarani, em função dos diferentes espaçament.os e densidades, com irrigação...

04 Evolução do indice de área foliar (IAF) dos cultivares de arroz de sequeiro Araguaia e Guarani, em função dos diferent.es espaçamentos e densidades, sem irrigação...

05 Evolução do índice de área foliar (IAF) dos cultivares de arroz de sequeiro Araguaia e 
Guarani, em função dos diferentes espaçamentos e densidades, com irrigação...

06 Relação entre duração de área foliar (DAF) $\left(m^{-2} \cdot m^{-2} \cdot d i a\right)$ e rendimento de grãos $\left(k g \cdot h a^{-1}\right)$ do cultivar Guarani, sem e com irrigação, e dos cultivares Araguaia e Guarani, na análise conjunta...

07 Evolução da taxa de crescimento da cultura (TCG) (g.m $\mathrm{m}^{-2}$.dia ${ }^{-1}$ ) dos cultivares de arroz de sequeiro Araguaia e Guarani, em função dos diferentes espaçamentos e densidades, sem irrigação...

08 Evolução da taxa de crescimento sa cultura (TCG) (g.m $\mathrm{m}^{-2} \cdot \mathrm{dia}^{-1}$ ) dos cultivares de arroz de sequeiro Araguaia e Guarani, em função dos diferentes espaçamentos e densidades, com irrigação...

DQ Evolução da taxa de assimilação líquida (TAL) (s.m ${ }^{-2}$ folladia ${ }^{-1}$ ) dos cultivares de arroz de sequeiro Araguaia e Guarani, em função dos diferentes espaçamentos e densidades, sem irrigação...

10 Evolução da taxa de assimilação líquida (TAL) 
$\left(g . m^{-2}\right.$ folhadia $\left.{ }^{-1}\right)$ dos cultivares de arroz de sequeiro Araguaia e Guarani, em função dos diferentes espaçamentos e densidades, com irrigação...

11 Evolução da taxa de crescimento relativo (TGR) $\left(g . g^{-1} \cdot\right.$ dia $\left.^{-1}\right)$ dos cultivares de arroz de sequeiro Araguaia e Guarani, em função dos diferentes espaçamentos e densidades, sem irrigação...

12 Evolução da taxa de crescimento relativo (TCR) $\left(g . g^{-1} \cdot\right.$ dia $\left.^{-1}\right)$ dos cultivares de arroz de sequeiro Araguaia e Guarani, em função dos diferentes espaçmentos e densidades, com irrigação...

13 Evolução da razão da área foliar (RAF) $\left(\mathrm{dm}^{2} \cdot \mathrm{g}^{-1}\right.$ ) dos cultivares de arroz de sequeiro Araguaia e Guarani, em função dos diferentes espaçamentos e densidades, sem irrigação...

14 Evolução da razão da área foliar (RAF) $\left(\mathrm{dm}^{2} \cdot \mathrm{g}^{-1}\right)$ dos cultivares de arroz de sequeiro Araguaia e Guarani, em função dos diferentes espaçamentos e densidades, com irrigação... 
(TCFR) $\left(m^{2} \cdot m^{-2} \cdot d i a^{-1}\right)$ dos cultivares de arroz de sequeiro Araguaia e Guarani, em função dos diferentes espaçamentos e densidades, sem irrigação...

16 Evolução da taxa de crescimento foliar relativo (TCFR) $\left(\mathrm{m}^{2} \cdot \mathrm{m}^{-2} \cdot \mathrm{dia} \mathrm{a}^{-1}\right)$ dos cultivares de arroz de sequeiro Araguaia e Guarani, em função dos diferentes espaçamentos e densidades, com irrigação...

17 Evolução do número de perfilhos.m ${ }^{-2}$ dos cultivares de arroz de sequeiro Araguaia e Guarani, em função dos diferentes espaçamentos e - densidades, sem irrigação...

18 Evolução do número de perfilhos.m ${ }^{-2}$ dos cultivares de arroz de sequeiro Araguaia e Guarani, em função dos diferentes espaçamentos e densidades, com irrigação...

19 Relação ent.re indice de colheita (IC) e rendiment.o de srãos $\left(\mathrm{kg}_{\mathrm{h}} \mathrm{ha}^{-1}\right)$ do cultivar Guarani, sem irrigação, e dos cultivares Araguaia e Guarani, na análise conjunta... 
1 Caracteristicas quimicas das amostras do solo coletadas na camada de $0-20 \mathrm{~cm}$ de profundidade, na área experimental.

2 Equações das funções exponenciais quadráticas, $M S=e^{\left(a+b t+c t^{2}\right)} e$ IAF $=e^{\left(a_{1}+b_{1} t+c_{1} t^{2}\right)}$, selecionadas para descrever o acúmulo de matéria seca e o Indice de área foliar em função dos tratamentos, do cultivar Araguaia, sem e com irrigaçã̃o.

3 Equações das funções exponenciais quadráticas, $M S=e^{\left(a+b t+c t^{2}\right)} e$ IAF $=e^{\left(a_{1}+b_{1} t+c_{1} t^{2}\right)}$, selecionadas para descrever o acúmulo de matéria seca e o indice de área foliar em função dos tratamentos, do cultivar Guarani, sem e com irrigação.

4 Resumo das análises da variância, expresso em quadrados médios, das caract.erísticas biométricas e de alguns indices fisiológicos dos 
cultivares Araguaia e Guarani, sem e com irrigação.

5 Resumo das análises da variância, expresso em quadrados médios, da análise conjunta das caracteristicas biométricas e de alguns indices fisiológicos dos cultivares Araguaia e Guarani.

6 Efeitos significativos da interação entre espaçamento e densidade sobre a produção de matéria seca total $\left(g . \mathrm{m}^{-2}\right)$ do cultivar Araguaia, com irrigação.

7 Efeitos significativos dos espaçamentos e das densidades sobre as caracteristicas biométricas e alguns índices fisiológicos dos cultivares Araguaia e Guarani, na análise conjunta.

8 Efeitos significativos dos espaçamentos e das densidades sobre as caracteristicas biométricas e alguns indices fisiológicos do cultivar Araguaia, sem e com irrigaçăo.

9 Efeitos significativos dos espaçamentos e das densidades sobre as características biométricas e alguns indices fisiolégicos do cultivar 
Guarani, sem e com irriğação.

10 Efeitos significativos da int.eração entre espaçamento e densidade sobre o número de perfilhos por $\mathrm{m}^{2}$ do cultivar Araguaia, sem irriğação e na análise conjunt.a.

11 Efeitos significativos da interação entre espaçamento e densidade sobre o rendiment.o grãos $\left(k g . h a^{-1}\right)$ do cultivar Guarani, análise conjunta. 


\title{
COMPORTAMENTO DE CULTIVARES DE ARROZ DE SEQUEIRO EM DIFERENTES POPULACÕES DE PLANTAS, COM E SEM IRRIGACÁAO SUPLEMENTAR
}

\author{
Autor: ALBERTO BAETA DOS SANTOS \\ Orientador: PROF. DR. JOSE'DIAS COSTA
}

RESUMO

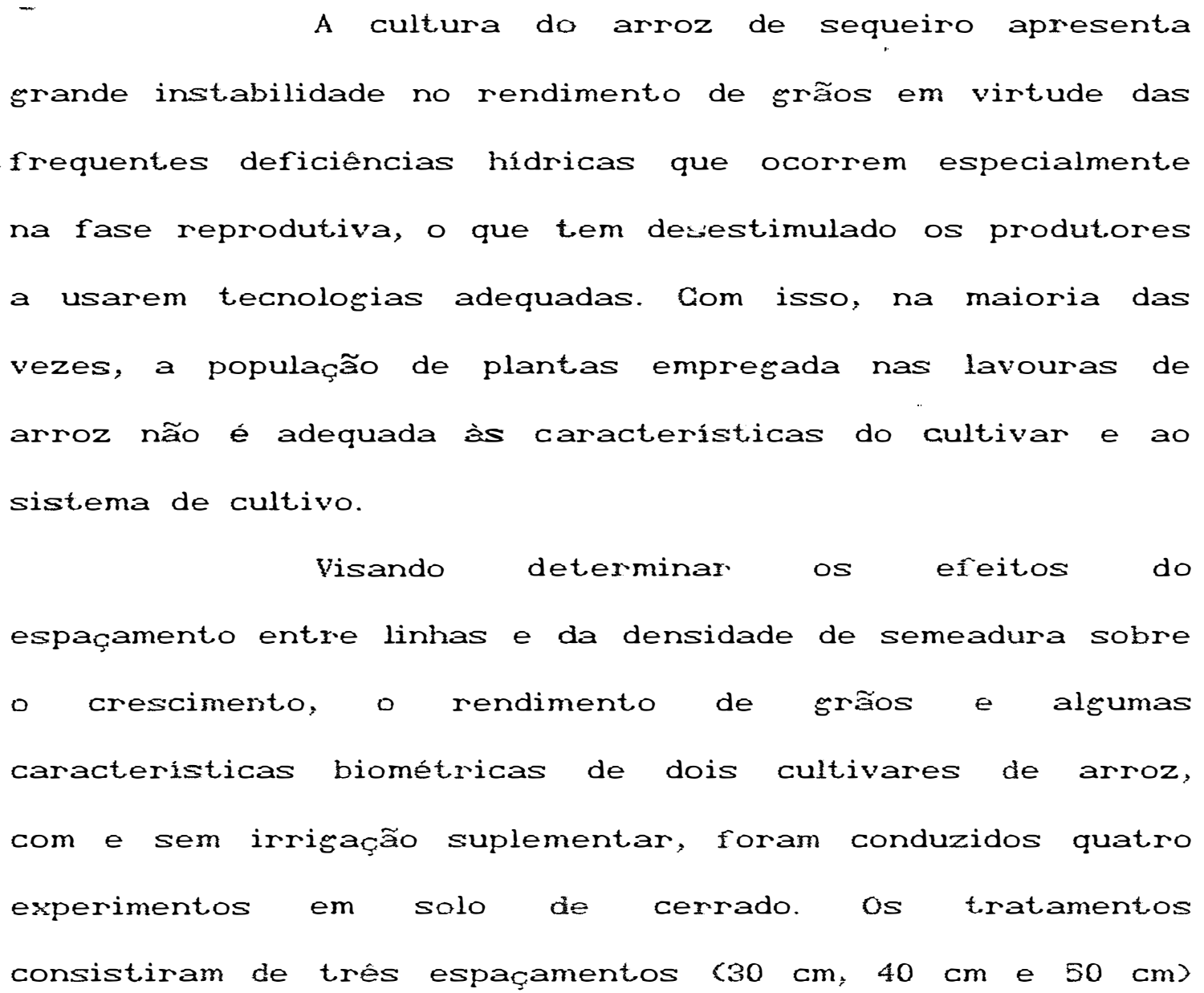


combinados com três densidades 450,100 e 150 sementes por $\mathrm{m}^{2}$ ) com os cultivares Araguaia (ciclo médio) e Giuarani (ciclo curto).

o delineament.o experimental foi o de blocos ao acaso, em arranjo ratorial (3X3), com quatro repetições. As curvas de crescimento do indice de área foliar (IAF) e da matéria seca total (MS) foram ajustradas at.ravés da utilização de funções matemáticas, com equações exponenciais quadráticas.

A irrigação propiciou incremento de 90 e $35 \%$ no rendimento de grãos dos cultivares Araguaia e Guarani, respectivamente. Influeñciou significativamente todas as caracteristicas biométricas estudadas, exceto o número de perfilhos por $\mathrm{m}^{2}$ no cultivar Araguaia. Aumentou a MS, O IAF, a taxa de crescimento da cultura (TCC) e a duração da área foliar (DAF) nos dois cultivares. O cultivar Guarani teve maior MS, pois apresentou maiores valores de TCC, taxa de assimilação líquida (TAL) e traxa de cresciment,o relativo (TCR), parâmetros indicativos de capacidade de acúmulo de biomassa. Atingiu rapidamente o ponto de máximo IAF, com alta capacidade de aproveitamento da área disponível.

o cultivar Guarani apresentou maior produção de grãos no menor espaçamento e na população de 130 plantas por $\mathrm{m}^{2} ; e, 0$ seu $\mathrm{lC}$ foi correlacionado linear. e positivamente com o rendimento de grãos, independente do 
uso da irrigação. No cultivar Araguaia o maior rendimento de grãos foi observado no espaçamento de $40 \mathrm{~cm}$, independente da irrigação e da densidade de semeadura. E, nesta distáncia entre linhas, maiores valores de MS, IAF e TCC neste cultivar foram obtidos na população de 150 plantas por $\mathrm{m}^{2}$, nas condiçŏes irrigadas, e com 100 e 150 plantas por $\mathrm{m}^{2}$, sem irrigação.

- Guarani mostrou ser um cultivar mais competitivo que o Araguaia, apresentando menor IC e maior influência da população de plantas sobre o rendimento de grãos. 


\title{
PERFORMANCE OF UPLAND RICE CULTIVARS IN DIFFERENT PLANT POPULATION UNDER AND WITHOUT SUPPLEMENTAL IRRIGATION
}

\author{
Author: ALBERTO BAETA DOS SANTOS \\ Adviser: PROF: DR. JOSE'DIAS COSTA
}

\section{SUMMARY}

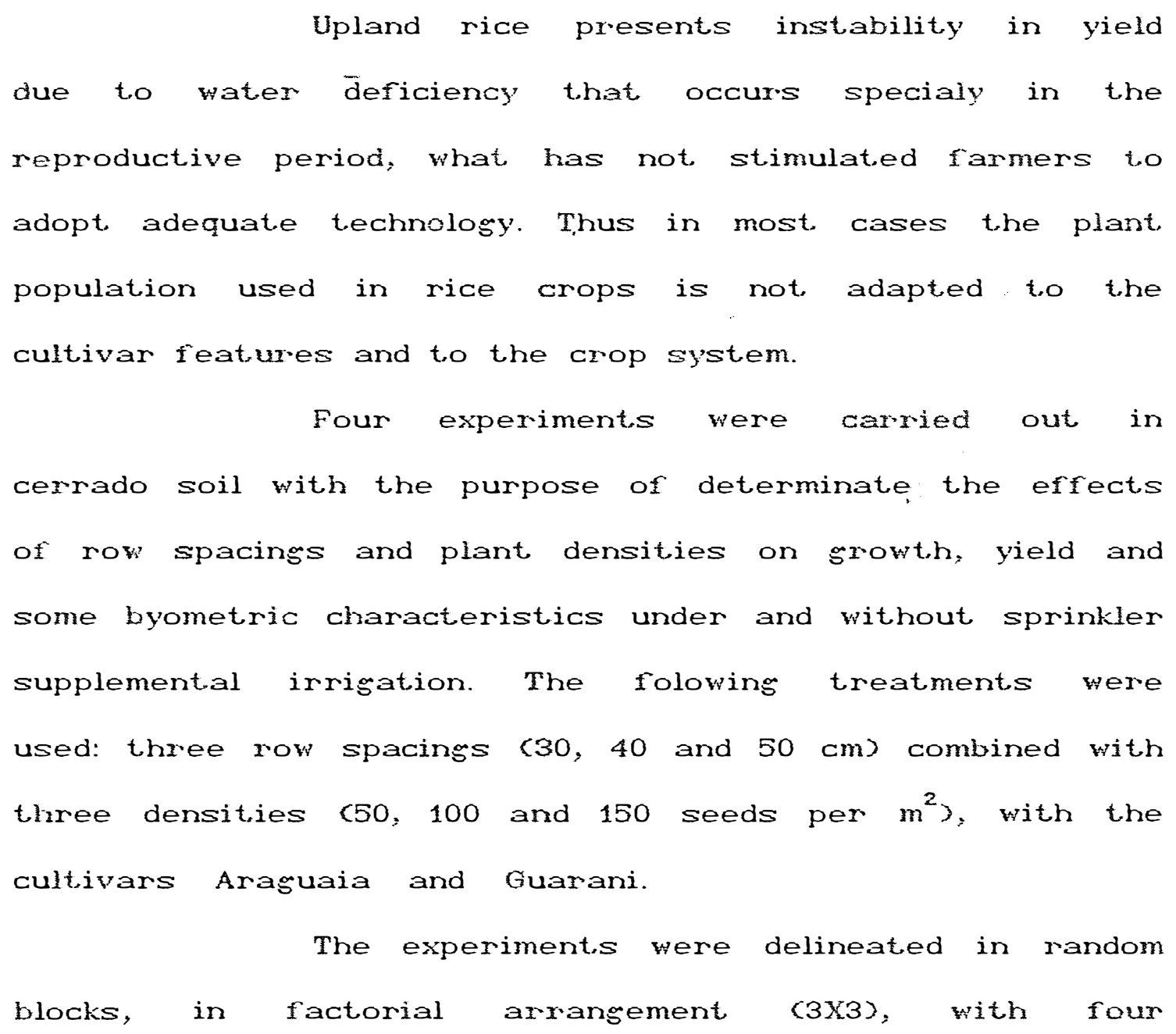


replications. The growth rates of leaf area index (LAI) and total dry matter (DM) were fitted by square regressions.

Irrigation enhanced in 90 and $35 \%$ yield of cultivars Araguaia and Guarani respectively. Irrigation significantly effects biometric characteristics excepting the tiller number of the cultivar Araguaia. Irrigation enhanced total dry matier (DM), leaf area index (LAI), crop growth rate (CGR) and leaf area duration (LAD) in both cultivars. The cultivar Guarani had hioher total dry matter production, presenting higher values of CGR, net assimilation rate (NAR) and relative growth rate (RGR), parameters of biomass accumulation capacity. This cultivar fastly reached the maximum LAI, with high capacity to exploit the available surface.

The highest, yield of cultivar Guarani was obtained with $30 \mathrm{~cm}$ row spacing and density of 130 plants per $\mathrm{m}^{2}$, and its $\mathrm{HI}$ was linearly and positively correlated with yield, independently of irrigation. The highest yield of cultivar Araguaia was obtained with $40 \mathrm{~cm}$ spacing: independently of density and presence of irrigation, and in this spacing higher DM, LAI and CGR were observed under densities of 150 plants pex $\mathrm{m}^{2}$ under supplemental irrigation, and 100 and 150 plants per $\mathrm{m}^{2}$ whithout irrigation. 


\section{INTRODUCÃ̃O}

Cerca de $60 \%$ da produção brasileira de arroz provém do sistema de cultivo de sequeiro. Neste sistema são reconhecidas duas sitụaçöes distintas em termos de risco de ocorrência de deficiência hídrica em arroz de sequeiro. As regiōes com menor e maior risco foram caracterizadas como favoráveis e não favoráveis, respectivamente, para o cultivo de arroz CSTEINMETZ et alii, 1984).

$$
\text { Em áreas sujeitas à ocorrência de veranico }
$$

são observados frequentes insucessos, ocasionando rendimentos não compensadores de arroz, o que tem desestimulado as produtores a usarem tecnologias adequadas. Consequentemente, no sistema de cultivo tradicional de sequeiro, há uma instabilidade na produção devido aos baixos rendimentos de grãos obtidos.Com isso, o produtor limita seus investimentos permanecendo num baixo nivel de utilização de tecnologia, propiciando a existência de um círculo vicioso: não se investe porque a cultura é de alto risco e esse permanece alto pela não adoção de técnicas culturais que o diminuam. Entretanto, 
com o emprego de irrigação suplementar por aspersão, essas áreas tornam-se viáveis à exploração agricola intensiva, permitindo a utilização de niveis mais elevados de tecnologias, com menores riscos."

A competição intra-especifica, ou seja, entre plantas de mesma espécie, determina, para cada cultivar, a população de plantas que propicia maior rendimento e melhor aproveitamento dos recursos disponíveis. Na maioria das vezes, a população de plant.as empregada nas lavouras de arroz não é adequada às características do cultivar e ao sistema de cultivo. Dado - baixo nivel de tecnologia habit.ualmente empregado na cultura de arroz de sequeiro, devido aos riscos a ela inerentes, é comum a ocorrência de lavouras com baixa população de plantas ou com limitado crescimento da área roliar. Os efeitos desses fatores no decréscimo da produção potencial dos cultivares de arroz de sequeiro são normalmente subestimados, ou não são sequer considerados (PINHEIRO \& GUIMARÃE, 1990$).$

Vários são os estudos CANDRADE et alii, 1971; OLIVEIRA et aiii, 1977; BUENO et alii, 1981; EMPRESA DE PESQUISA AGROPECUARIA DO ESTADO DO MATO GROSSO, 1982; $-$ SOBRAL \& OLIVEIRA, 1982; SANTOS et aiii, 1988) sobre os efeitos do espaçamento entre linhas e da densidade de semeadura no rendimento do arroz de sequeiro. Entretanto, os resultados são bästante genéricos, pois dependem da 
capacidade de perfilhamento e do ciclo do cultivar, da susceptibilidade à brusone (Pyricularia oryzae cav.) e da disponibilidade de água, além do nivel de fertilidade do solo. A grande maioria dos trabalhos relacionados com a população de plantas de arroz de sequeiro por área não se preocupou com a disponibilidade de água, bem como as pesquisas foram desenvolvidas com cultivares susceptiveis à brusone. Ademais, foram considerados apenas os efeitos sobre a produção de grãos e algumas características biométricas dos cultivares est.udados, não dispondo, portanto, de informações relacionadas ao crescimento das plant.as.

o objetivo deste estudo foi determinar os efeitos do espaçamento entre linhas e da densidade de semeadura sobre o crescimento, o rendimento de grãos e algumas caracteristicas biométricas dos cultivares de arroz Araguaia e Guarani, em condições de irrigação suplementar por aspersão e sem irrigação. 


\section{REVISÃO DE LITERATURA}

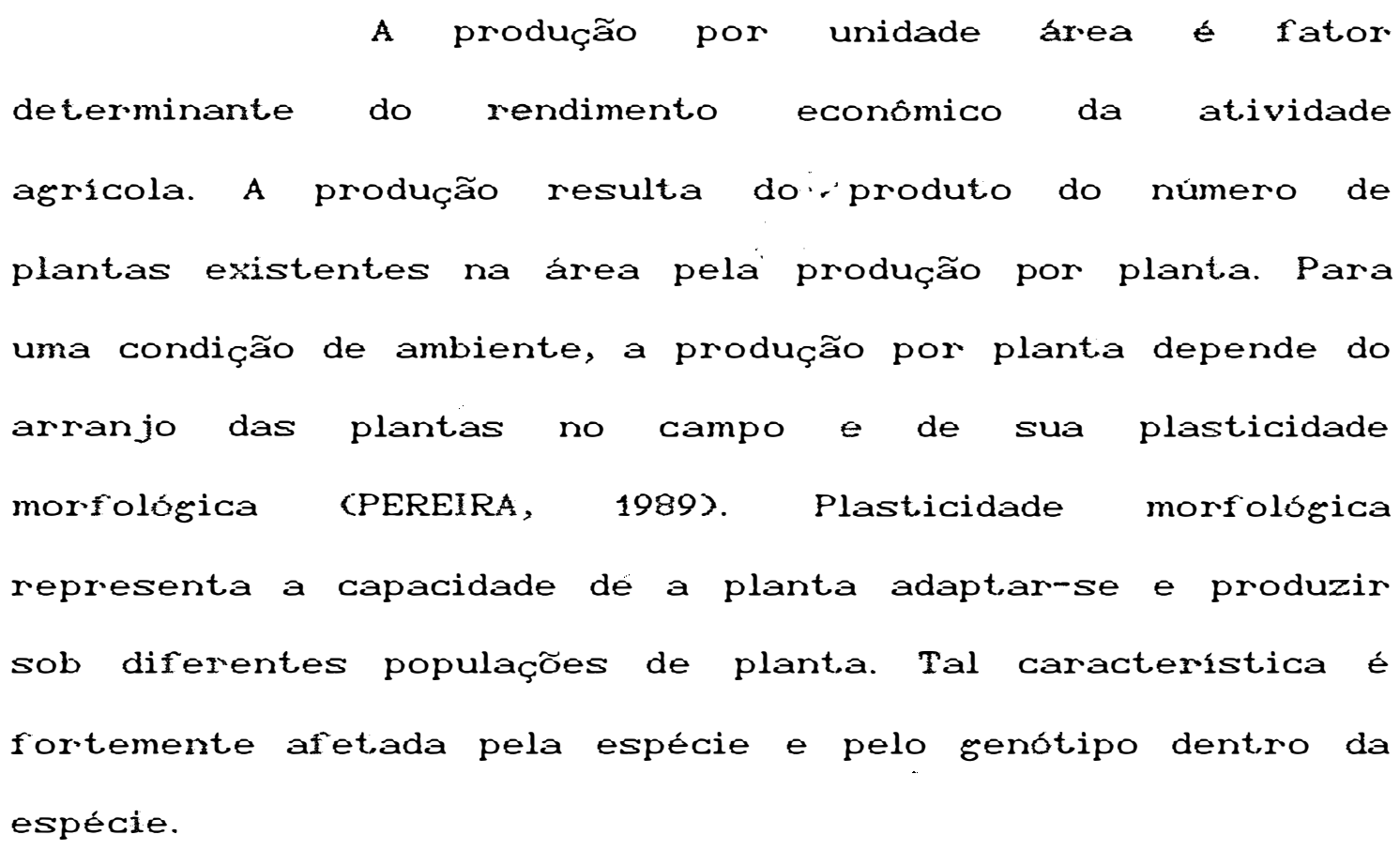

Vários autores CDUNCAN, 1958; DONALD, 1963;

CHANDLER JUNIOR, 1969; WILEY \& HEATH, 1969; YOSHIDA, 1977; ANDRADE et alii, 1971) tem relatado a relação negativa existente entre o número de plantas por área e a produção por planta. Em populações menores, a produção por planta é máxima, embora por área seja baixa. Aumentando-se a população, a produção por planta decresce, havendo, no entanto, aumento no rendimento. O decréscimo individual é compensado pelo aumento no número de individuos por área. 
A curva da produção por unidade de área passa por um máximo onde a população e ideal. A partir dal, o decréscimo na produção individual não é compensado pelo aumento na população de plantas (PEREIRA, 1989). Em culturas, cujo produto de valor económico é apenas partee da planta, HOLIDAY (1960) veriricou que a relação entre a produção e o número de plantas por área é parabólica. Há incremento na produção por área à medida que cresce o número de plantas até um valor máximo, reduzindo em seguida (DUNCAN 1958, 1984). A população de plantas adequada é aquela que corresponde ao máximo rendimento. 0 rendimento máximo de um determinado cultivar é obtido com maior ou menor população de plant.as, dependendo da disponibilidade de ásua e nutrientes.

Em geral, a produção econômica de cultuxas que apresentam um orgão especifico com import.ancia comercial é máxima numa faixa de população de plantas, e, para cereais, a faixa adequada tende a ser mais variśvel por causa de sua capacidade de perfilhar CSNYDER \& GARLSON, 1984). O pico de produção de grãos coincide com a população que determina a estrabilização de crescimento de produção biológica (MITCHELL, 1979).A produção biológica deșsas espécies apresenta relação assintótica quando relacionada com a população de plantas CDONALD \& HAMBLIM, 1976). Como a produção econômica é uma txação variável da produção biológica, esta fração representa o indice de 
colheita (DONALD, 1962). Os termos produção biológica

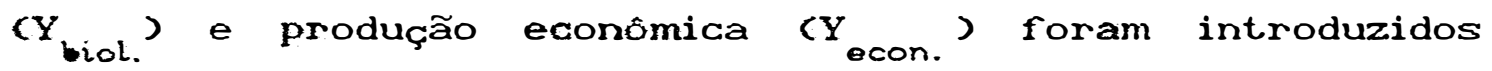
por NICHIPOROVICH (1960). Estes termos referem-se à produção total de matéria seca e a parte útil economicamente da produção biológica, respectivamente. Essas duas produções podem ser relacionadas por um parâmetro ( $\left.K_{\text {econ. }}\right)$, que foi originalmente chamado de "coeficiente de eficácia de formação da parte econômica da produção total" (NICHIPOROVICH, 1960), coeficiente de migração (ENGLEDOW \& WADHAM, 1923; TSONODA, 1959) e atualmente amplamente conhecido como "indice de colheita" (DONALD, 1962).

$$
Y_{\text {econ. }}=K_{\text {econ. }} \times Y_{\text {biol }}
$$

Esta equação indica que a produção económica pode ser aumentada tanto pelo aumento na produção total de matéria seca como pelo aumento do indice de colheita.

Em cereais, o aumento na produção econômica resultou da seleção de plantas menos competitivas, com maior capacidade de formação de grãos, ist.o é, com maior indice de colheita CDONALD, 1968; JENNINGS \& AQUINO, 1968). Quanto mais competitiva for a planta, menor será o indice de colheita e maiores serão os efeitos do aumento da população de plantas sobre a produção individual (PEREIRA, 1989). A relação entre produção por área e competitividade das plantas de axroz é negativa, ou seja, 
plantas mais competitivas investem mais na produção de colmos e folhas e menos em grãos, apresentando, portanto, menor indice de colheita (JENNINGS \& JESUS, 1968). Estudos realizados por SING \& STOSKOPF (1971) indicaram que considerável melhorament? na produção de grãos em cereais pede ser obtido através da seleção de maiores indices de colheita.

Dentre outros fatores que influem diretamente no rendimento do arroz está o arranjo das plantas no campo, pois a mesma população de plantas pode ter diferentes arranjos. A medida que plantas menos competitivas são selecionadas, menor pode ser o espaçamento entre as linhas. Para determinada condição de solo, clima, cultivar e tratos culturais, existe um número de plantas por unidade de área que conduz à mais - alta produção por área (YOSHIDA, 1977 ).

A população excessiva de plantas acarreta o rápido esgotamento das reservas de água do solo por evapotranspiração, causa autossombreamento, com consequente atraso no perfilhamento e na absorção de nitrogênio, acamamento e redução da matéria seca cYoSHIDA, 1977). Enquanto que a população de plantas aquém da ideal favorece o crescimento de plantas invasoras, com consequente redução da capacidade produtiva dos solos, levando à formação de perfilhos improdutivos CGASTAL, 1974; SOARES et alii, 1979). A interação entre as plantas 
de culturas anuais se dá pela competição por luz que se instala rapidamente sendo, portanto, desejavel um rápido cresciment.o da área foliar e uma arquitetura foliar que reduza ao máximo o autossombreament.o (BERNARDES, 1987 ).

Maior uniformidade ent.re plantas de uma comunidade vegetal permit.e maiores populaçães sem que ocorra grande número de plantas suprimidas pela competição (DUNCAN, 1969).

O espaçament.o entre sulcos de semeadura t.em destacada import.ância no balanço competitivo cult.ura máto, pois determina a velocidade e a intensidade do sombreamento provocado pela cultura CSARKAR, 1979; YAMAGUISH et alii, 1976), auxiliando na éficiência das medias de controle empregadas KKIM \& MOODY, 1980; MERCADO E LUBIGAM, 1979), pelo efeito supressivo no crescimento das plantas invasoras. Efieitos do espaçamento entre linhas na competiçăo por nutrientes pelas plantas daninhas com a cultura de arroz de sequeiro foram observados por PITELLI et alii (1984). Os efeitos das plantas daninhas sobre a composiçäo quimica das plantas de arroz foram mais acentuados no espaçament.o de $60 \mathrm{~cm}$, do que em $40 \mathrm{~cm}$.

A população de plantas influencia a inciderrcia e a severidade da brusone, a qual e uma das principais doenças da cultura do arroz. O sistema de cultivo de sequeiro está sujeito a maiores danos decorrentes da brusane. Todas as medidas para aumentar a 
população de plantas por área favorecem o rápido desenvolviment.o da doença nas folhas. RIBEIRO (1982) verificou redução na intensidade dos sintomas de brusone nas folhas com o aumento do espaçamento, diferindo de nivel entre cultivares, em função do grau de susceptibilidade de cada um.

Trabalhos desenvolvidos nos Estados do Paraná (INSTITUTO AGRONómICO DO PARANA, 1980) e de Goiás (BUENO et alii, 1981), no sistema de cultivo tradicional "

de sequeiro, mostraram que o rendimento de grãos é -nffluenciada diretamente pela população de plantas e pela rrecipitação pluvial. Em condições de boa disponibilidade de água, as produçóes mais elevadas foram obtidas com maiores populações de plantas por área, sendo observado o inverso sob condições de estiagem prolongada durante a fase de crescimento das plantas de arroz.

Exist.em poucas informações sobre a influência da população de plantas no rendimento da cultura do arroz, com irrigação suplementar por aspersão, em regiōes com maior risco de ocorrência de deficiência hidrica, bem como, naquelas caracterizadas como favoráveis ao cultivo desta espécie. No Estrado de Minas Gerais, OLIVEIRA et aiii, (1977), empregando irrigação supplementar por aspersão, verificaram que os rendimentos dos cultivares IAG 1246 e Batatais aumentaram na medida em que - espaçament.o foi reduzido até $30 \mathrm{~cm}$. Quanto à densidade 
de semeadura, os cultivares comportaram-se de maneiras diferentes, sendo que, para o IAG 1246 a produção declinou linearmente e, para o Batat.ais, a resposta foi quadrática, ao aument.o do número de plantas por área, sendo o máximo rendimento de grãos estimado com densidade pouco superior a 100 sementes por $\mathrm{m}^{2}$. Determinando os efeitos da população de plantas e do controle de pragas sobre o rendimento de grãos e algumas caracteristicas biomét.ricas do cultivar IAG 165, em condições de irrigação suplement.ar ' $r$ '

por aspersão, SANTOS et alii (1988) verificaram que, sem inseticida a produção de grãos aumentou quando o espaçamento ou a densidade de semeadura cresceram. Enquanto que, com emprego de inseticidas há int.eração entre espaçamento e densidade, e o rendimento é maior na distância de $50 \mathrm{~cm}$ entre linhas e 200 sement.es viáveis por $m^{2}$. Verificaram tambem que hä reducăo na percentagem de plant.as acamadas em espaçamentos mais amplos. Trabalhos conduzidos em regiōes com menor risco de ocorrência de deficiencia hidrica CEMPRESA DE PESQUISA AGROPECUARIA DO $\theta$

ESTADO DO MATO GROSSO, 1982; SOBRAL \& OLIVEIRA, 1982) evilenciaram que os maiores rendimentos de gãos do cultivar IAG 47 foxam obtidos com a densidade de 50 a 70 sementies por metro linear, no espaçamento de 50 cm entre linkas.

A relação ent.re o ambiente e a produção de arroz è complexa, pois a produçäo ؛ o resultsdo global do 
crescimento, e este é um fenômeno resultante da interação ent.re o ambiente, cuitivar e técnica cultural.

A análise quantitativa do crescimento é o meio mais acessivel e bastante preciso para avaliar o crescimento e inferir a contribuição de diferentes processos fisiológicos sobre o comportamento vegetal. E um método de grande valor na avaliação das diferenças int.ervariet.ais e interespecificas das diversas caracteristicas que definem a capacidade da planta, sendo $\because$

usado para investigação do efeit.o de fenômenos ecológicos sobre o crescimento, como a adaptabilidade de espécies em ecossist.emas diversos, efeitos de competição, diferenças genotipicas da capacidade produtiva e influência de práticas agronômicas sobre o crescimento, além de fatores intrinsecos que estão associados com a fisiologia da planta (MAGALHÃES, 1985).

As técnicas de análise de crescimento e seus conceitos foram compilados por WATSON (1952) em longo trabalho de revisão. A utilização dos parâmetros de Q cresciment.o vegetal, como um tipo de análise, teve inicio no começo do século com fitorisiologistas como BLACkMAN (1919) e BRIGS et alii (1920a, 1920 ${ }_{b}$ ) passando então a ser usado como método básico para se calcular estimativa da produção biolóğica das comunidades vegetais. E, segundo RADFORD (1967), este método cont.inuaráa a ser usado particularmente quando se deseja uma forma precisa de 


\begin{abstract}
avaliação do crescimento da planta, sendo basicament.e requeridas duas medidas periódicas para execução de uma simples análise de crescimento: a biomassa cmatéria seca tot.al) e o tramanho do aparelho fotossintetizant.e cárea foliars.
\end{abstract}

A população de plantas influencia os estádios iniciais do crescimento das culturas, pois determina a área foliar disponivel para a interceptação máxima de radiação (WATSON, 1952; DONALD, 1963). Aumento na densidade pode também influenciar a distribuição da radiação, independente da cobertura foliar, por apresentar uma orientação mais vertical das folhas e por mudar o tamanho e forma das folhas (NEWTON \& BLACKMAN, 1970 ).

A matéria seca total est.á relacionada ao rendimento de srãos pelo indice de colheita. Este tende a decrescer à medida que a produção de matéria seca t.otal aumenta, pois em altas populaçöes alsumas plantas não reproduzem e constituem uma perda na produção econômica. Perdas adicionais na eficiência ocorrem quando a competição te t.ão severa que alsuns perfilhos ou plarıtas morrem.

As variações da quantidade de biomassa e da
área foliar são utilizadas, com o tempo, na estimativa de
vários indices fisiológicos, tais como: taxa de
crescimento da cultura (TCC), taxa de crescimento relativo
(TCR), taxa de assimilação líquida (TAL), indice de área


foliar (IAF). Tais indices podem, então, serem comparados, na tent.ativa de explicar as diferenças na produção econômica de diferentes cultivares ou de um mesmo cultivar submetidos a diferentes t.ratamentos.

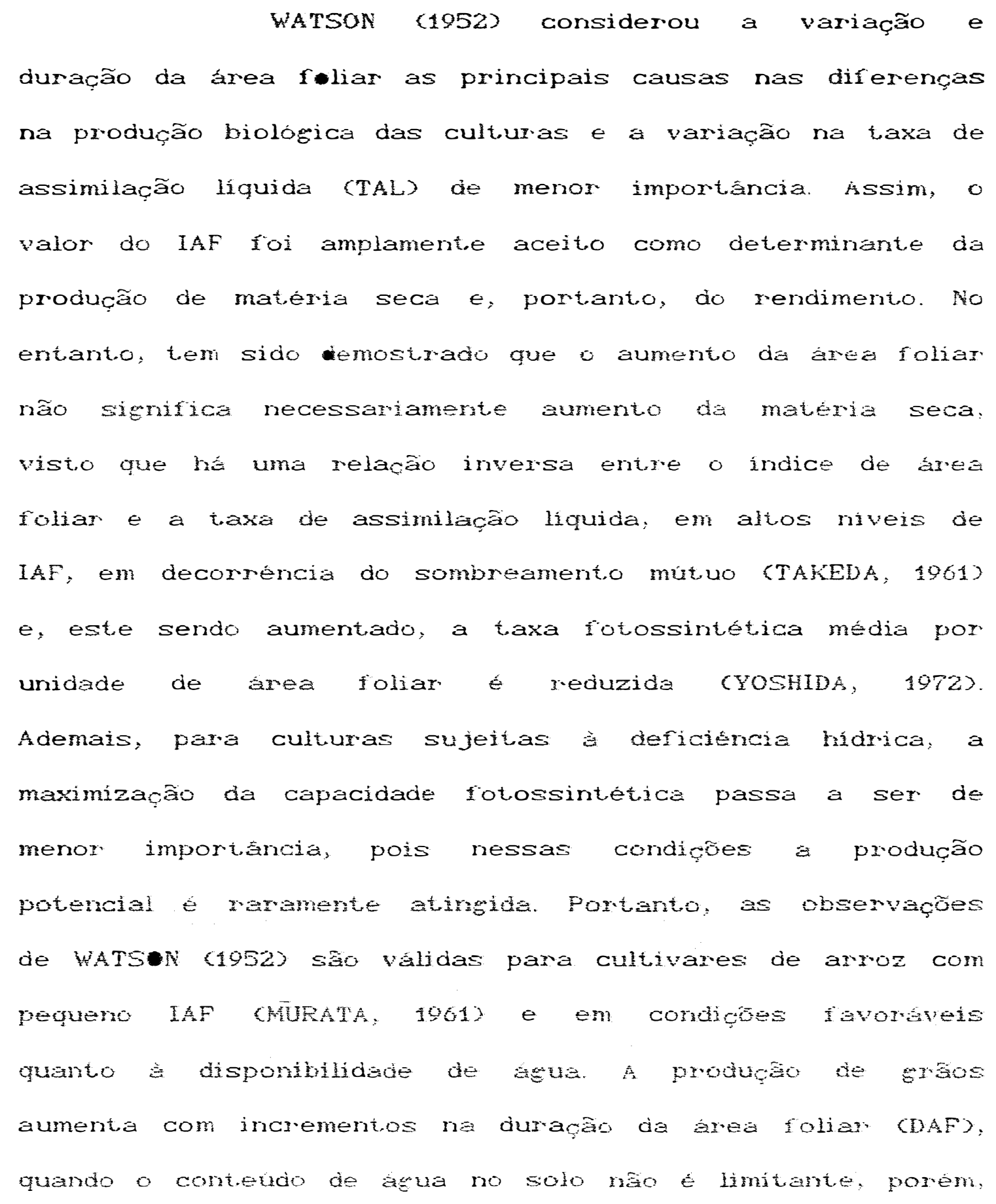


em condições de deficiência hídrica, pode haver redução no rendimento de arroz CSTONE \& STEINMETZ, 1979; STONE et alii, 1979; PINHEIRO \& GUIMARTES, 1990). No entanto, valores muito baixos do IAF (inferiores a 2,0 ), apesar de minimizarem o risco de pexda por deficiência hídrica, restringem o potencial produtivo CPINHEIRO \& GUIMARTES, 19902.

O IAf areta a produção de grãos pela relação negativa com a fertilidade das espisuetas, quando há deficiência hídrica no periodo reprodutivo do arroz (PINHEIRO et alii, 1990). Na ausência de deficiência hídrica, um alto IAF não é garantia de alto rendimento. Quando associada a condições de alta pluviosidade e dias encobertos no periodo reprodutivo, a depressão do rendimento se dá via redução do número de espiguetas. Esses mesmos autores concluiram que no melhoramento dos cultivares tradicionais de arroz de sequeiro, e possivel buscar aumento do número de perfilhos, sem redução da resistência à seca, desde que a área foliar por perfilho seja reduzida." 


\section{MATERIAL E MÉTODOS}

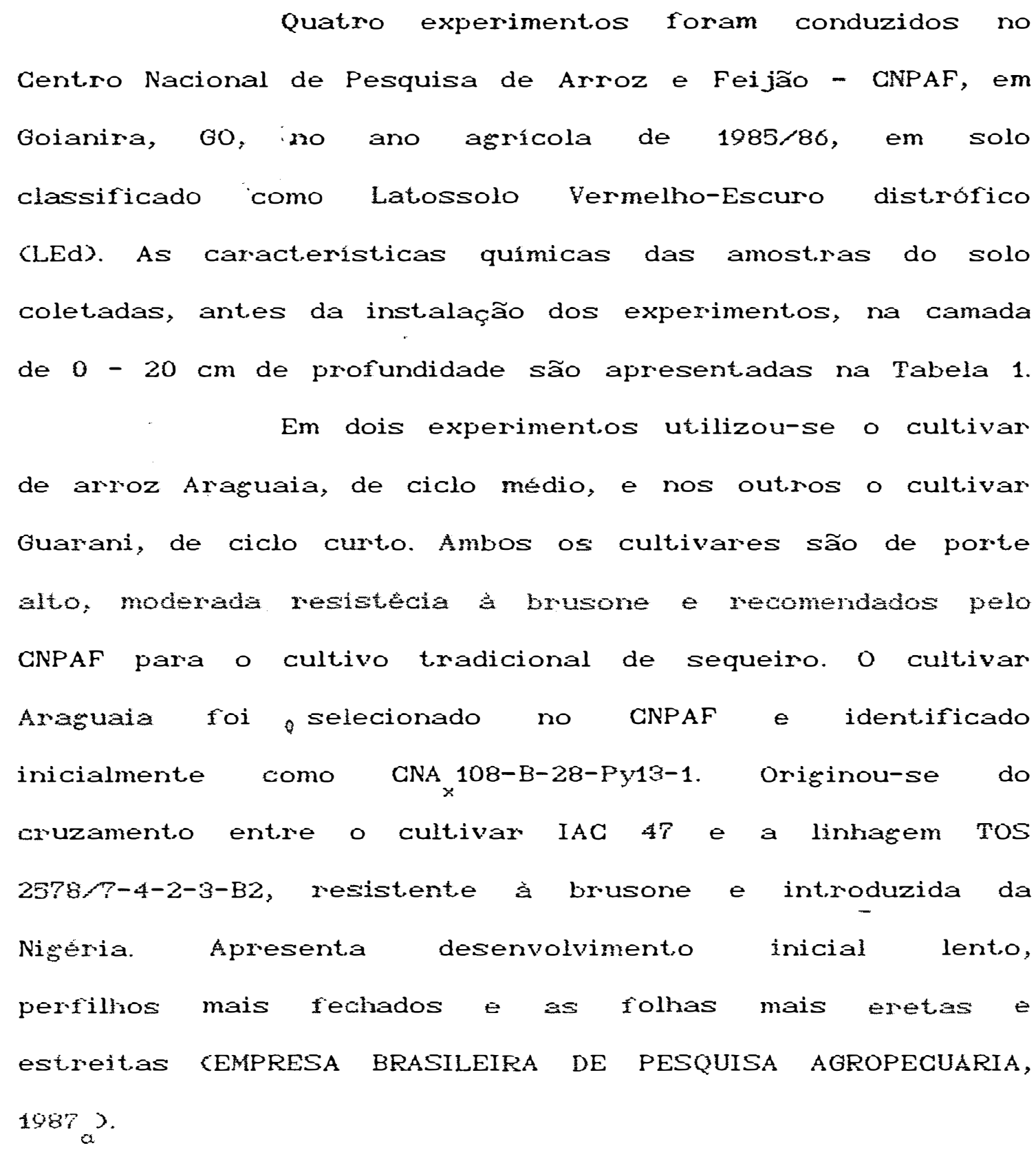


Tabela 1 - Garacteristicas quimicas das amostras do solo coletadas na camada de $0-20 \mathrm{~cm}$ de profundidade, na área experimental ${ }^{1}$.

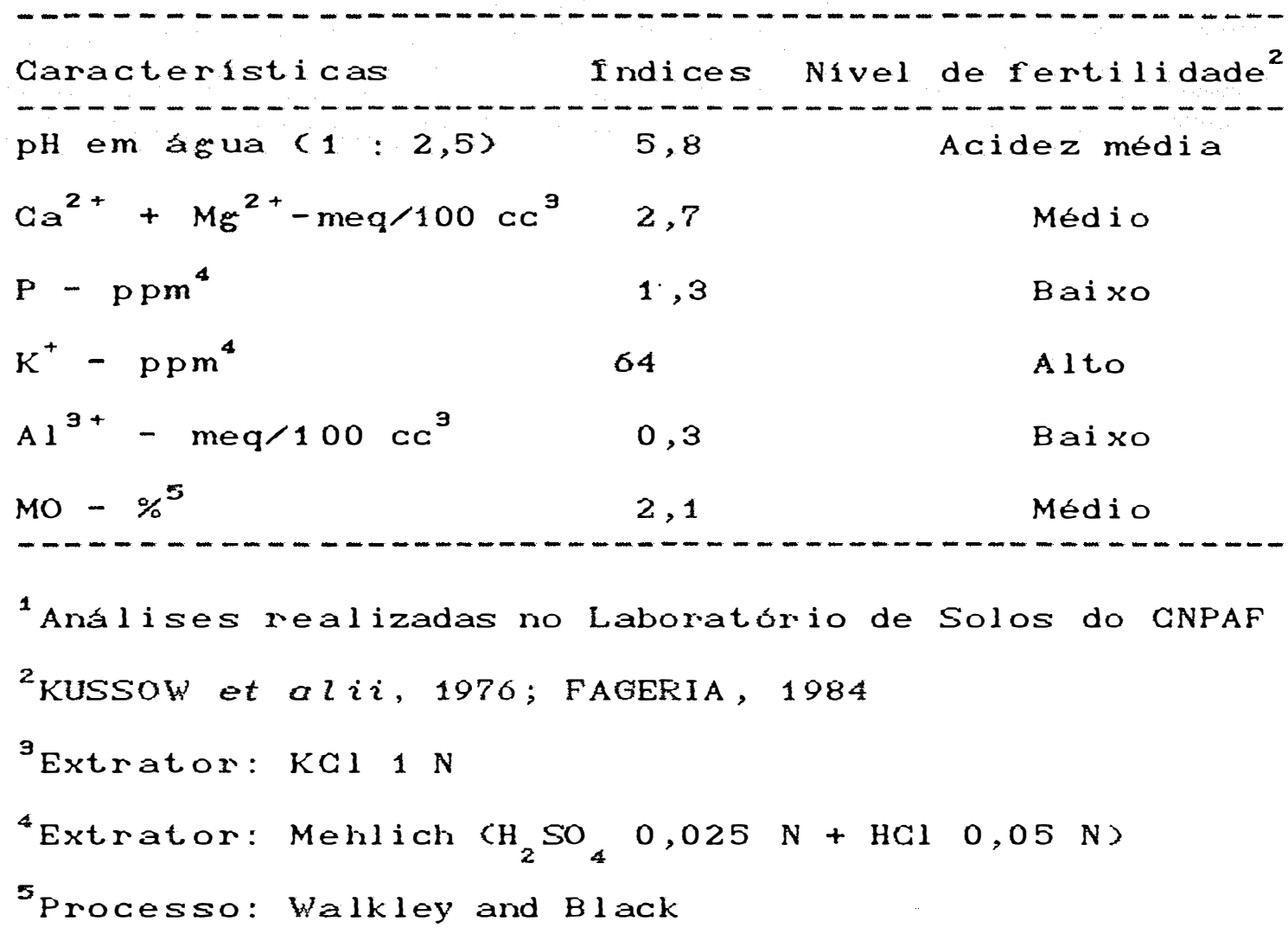

- cultivar Guarani, inicialmente identificado como a linhagem CNA 095-BM30-BM9-28, teve como material básico a variabilidade sonética proveniente do cruzamento CNA 095 que foi realizado também no CNPAF, e envolveu como progenitor feminino a linhagem nigeriana 63-83 e como progenitor masculino o cultivar brasileiro IAC 25. O cultivar Guarani apresenta duas caracteristicas relevantes que săo a boa resistencia à brusone e à mancha 
dos grãos CDrechslera oryzae syn. Helminthosporium oryzae e Phoma sorghina) (EMPRESA BRASILEIRA DE PESQUISA AGROPECUARIA, $1986_{b}$; GUIMARAES et alii, 1989). Embora, atualmente tem-se observado ocorrência de brusone no cultivar Guarani, neste trabalho nenhum dos cultivares est.udados apresentaram sintomas dessa doença em níveis elevados.

Com cada cultivar, um experimento foi conduzido sem irrigação, ou seja, o fornecimento de água foi provenient,e apenas das precipitaçỡes pluviais, e no outro foi empregada irrigaçăo por aspersão, possibilitando suplementar a necessidade de água nos períodos de estiagem. Para isso, estabeleceu-se que após três dias sem a ocorréncia de chuvas, o experimento seria irrigado, procurando, levar o solo à sua capacidade de campo. Os periodos $\mathrm{em}$ que as irrigaçōes foram realizadas, as temperaturas minimas, médias e máximas e os dados diários de chuvas registrados durante a permanéncia dos experimentos no campo constam da Figura 1.

Em todos os experimentos foram testrados os espagamentos de $30 \mathrm{~cm}, 40 \mathrm{~cm}=50 \mathrm{~cm}$ ent.re sulcos e as densidades de 50,100 e 150 sementes por $\mathrm{m}^{2}$. A adubação empregada foi $200 \mathrm{~kg} / \mathrm{ha}$ do formulado 5 - 30 - 15 CFAGERIA, 19843, no sulco mist.urado com o solo antes da semeadura.

Por ocasião da diferenciação do primórdio floral, efetuou-se a adubação nitrogenada à base de 30 


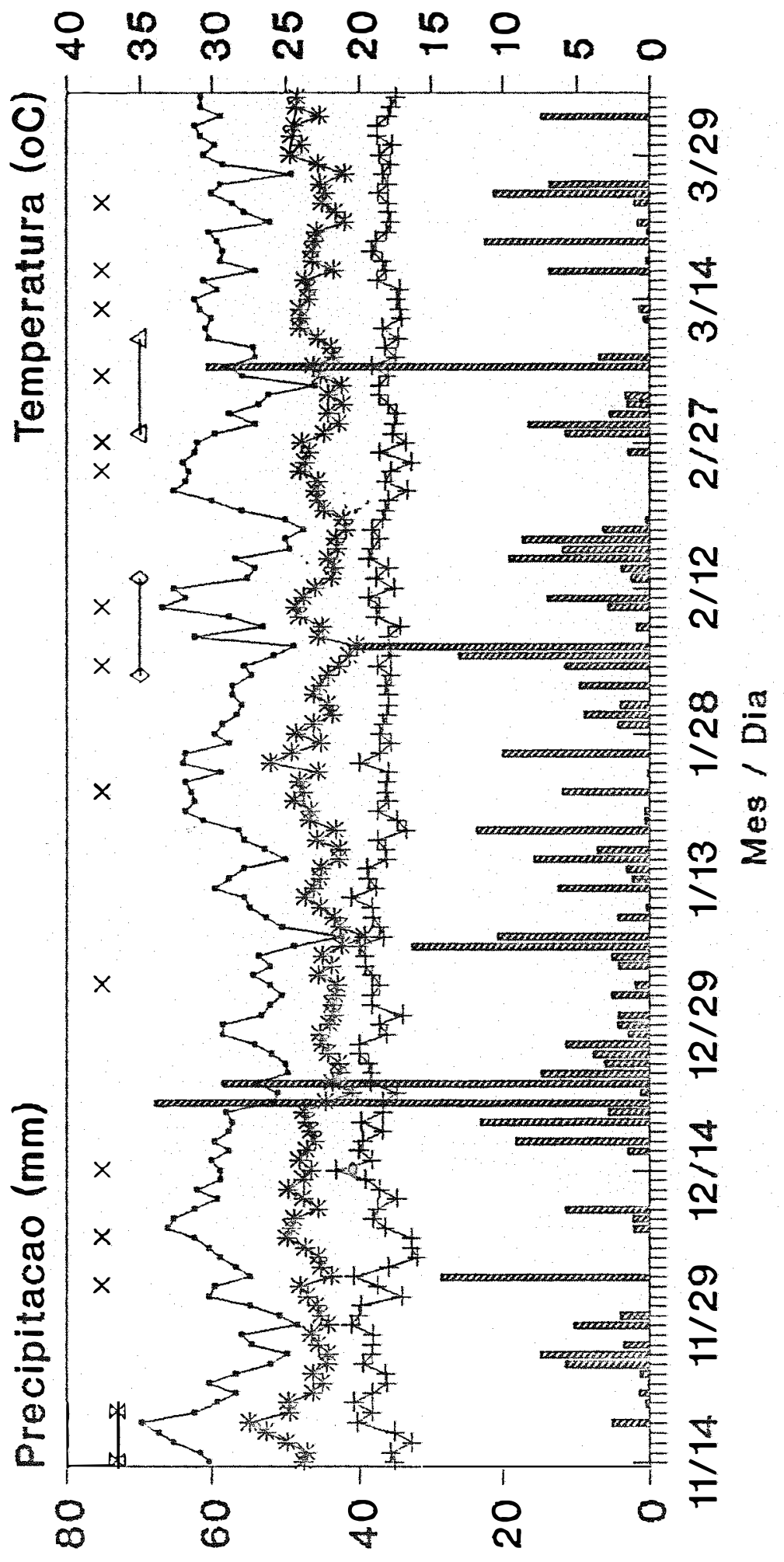

()

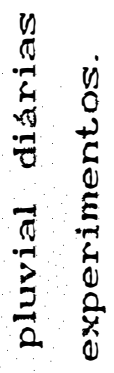

$\log _{0}^{0}$

(4) $c$

$\stackrel{n}{2} \quad \frac{\pi}{2}$

a)

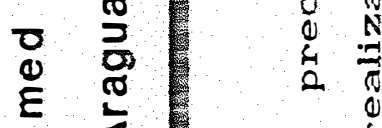

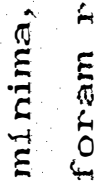

a

E

必姃 0

(1) 0

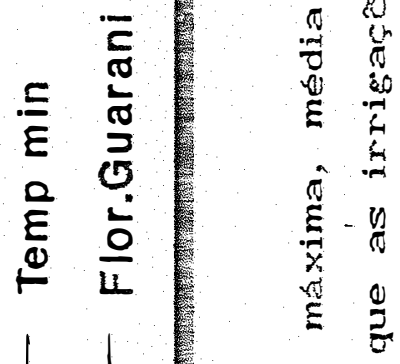

$+\phi$

ह 5

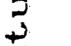

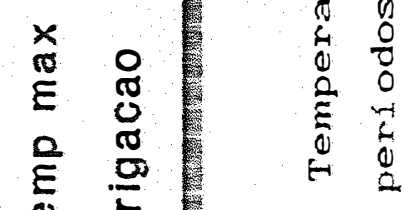


kg/ha de $N$, em cobertura, na rorma de sulfato de amónio, apenas no cultivar Araguaia. O cultivar Guarani recebeu fertilizante nitrogenado soment.e por ocasião da semeadura, pois apresenta maior tendência de acamamento, quando ocorre elevado crescimento veget.ativo.

o delineament.o experiment.al foi o de blocos ao acaso, em arranjo fatorial ( $3 \times 3$, com quatro repetiçَes. Cada parcela foi constituida de treze, dez e oito linhas de $6 \mathrm{~m}$ de comprimento para os espaçament.os de $30 \mathrm{~cm}, 40 \mathrm{~cm}$ e $50 \mathrm{~cm}$, respectivament.e, correspondendo a $8,40 \mathrm{~m}^{2}, 8,00 \mathrm{~m}^{2}$ e $8,00 \mathrm{~m}^{2}$ de área út.il. A compet.ição com as plantas invasoras foi prevenida com aplicação de 1,5 kg/ha do herbicida Pendimethalin, em pré-emergência, e uma capina à errxada.

$$
\text { Para as análises de crescimento, }
$$
realizaram-se amostragens semanais da part.e aerea de dez perfilhos em cada parcela, em todos experiment.os, começando aos 20 dias apús a emergếncia das plẩntulas at.é por ocasião da colheita. A área foliar foi determinada nesses perfilhos utilizando-se um medidor automát.ico modelo LI 3000 da "Lambda Instruments Corporation". Ao mesmo tempo, foi contado o número de perfilhos em 2 metros lineares, previamente demarcados em cada parcela. Apús a secagem a $75 \circ \mathrm{C}$ em estutia com circulação forçada de ar, determinou-se a massa da parte aérea dos perfilhos. o indice de sirea follar foi obtido pela multiplicaça da 
área foliar média de um perfilho, em $\mathrm{m}^{2}$, pelo número de perfilhos por $\mathrm{m}^{2}$. As curvas de crescimento do índice de área foliar (IAF) e da matéria seca (MS) foram ajustadas por equações de regressão, testando-se modelos lineares, quadráticos e cúbicos. Os melhores ajustes em função do tempo foram obtidos pelas equações exponenciais quadráticas. Estes modelos foram utilizados em análises de crescimento de plantas de culturas anuais, como soja (BUTTERY, 1969) e feijoeiro (STONE et alii, 1988). Os modelos selecionados mostraram-se bem ajustados, sendo os menores valores de $R^{2}$ iguais a 0,95 e 0,97 para $M S$ e 0,93 e 0,92 para IAF para os cultivares Araguaia e Guarani, respectivamente; altamente significativos pelo teste de F; e, biologicamente explicaram as variações ocorridas nestes parâmetros, em runção do tempo.

$$
\begin{aligned}
& \text { MS }=e^{\left(a+b t+c t^{2}\right)} \\
& I A F=e^{\left(a_{1}+b_{1} t+c_{1} t^{2}\right)} \\
& \text { Os coeficientes foram estimados atraves de }
\end{aligned}
$$
análise de regressão, após transformação das equaçŏes para a forma logaritmica.

A ut.ilização de funções matemát.icas na análise de crescimento tem sido recomendada por diversos autores CVERNON \& ALIISON, 1963; RADFORD, 1967; BUTTERY, 1969; KVET et alii, 1971; HUNT, 1982; PEREIRA \& MACHADO, 1987; PEREIRA \& ARRUDA, 1987; CASTRO JUNIOR \& PORTES \& CASTRO, 1990). 
Para determinação dos valores instrantâneos da taxa de crescimento da cultura (TCG), em g.m ${ }^{-2}$ terrno.dia ${ }^{-1}$, empregou-se a derivada da equação ajustada da matéria seca, em $\mathbf{g} \cdot \mathbf{m}^{-2}$, em relação ao tempo, pois, TCC $=d M S / d t$, ou seja:

$$
T C C=(b+2 c t) e^{\left(a+b t+c t^{2}\right)}
$$

Os valores instantâneos da taxa de crescimento relativo (TCR), em $\mathrm{g} \cdot \mathrm{g}^{-1} \cdot \mathrm{dia}^{-1}$, foram obtidos pela fórmula $\mathrm{TCR}=\mathrm{TCG} / \mathrm{MS}$, pois, $\mathrm{TGR}=1 / \mathrm{MS} *(\mathrm{dMS} / \mathrm{dt})$; $T C R=d(\ln M S) / d t$, onde:

$T C R=b+2 c t$

Os valores instantâneos da traxa de crescimentio foliar relativo (TCFR), em $\mathrm{m}^{2} \cdot \mathrm{m}^{-2} \cdot \mathrm{dia}^{-1}$, foram determinados pela fórmula $\mathrm{TCFR}=1 / \mathrm{IAF} *(\mathrm{dIAF} / \mathrm{d} \mathrm{t}) ; \mathrm{TCFR}=$ $\mathrm{d}(\ln I \mathrm{AF}) / \mathrm{dt}$, sendo:

$$
\text { TCFR }=b_{1}+2 c_{1} t
$$

No cálculo da traxa de assimilação liquida (TAL), em $5 . \mathrm{m}^{-2}$ folhadia ${ }^{-1}$, os valores inst.antâneos de TCC e IAF foram empregados na equação TAL = TCC/IAF, pois, $\mathrm{TAL}=(\mathrm{dMS}, \mathrm{dt},) / \mathrm{IAF}$, sendo:

$$
\begin{aligned}
& \text { TAL }(b+2 c t) e^{\left(a-a_{1}\right)+\left(b-b_{1}\right) t+\left(c-c_{1}\right) t^{2}} \\
& \text { Os valores instantâneos da razão da área }
\end{aligned}
$$
foliar (RAF), em $\mathrm{dm}^{2} \cdot \mathrm{s}^{-1}$, foram determinados pela fórmula $\mathrm{RAF}=\mathrm{IAF} / \mathrm{MS}$, sendo, portanto:

$$
R A F=e^{\left(a_{1}-a\right)+\left(b_{1}-b\right) t+\left(c_{1}-c\right) t^{2}}
$$


A duração da area foliar (DAF), expressa em $m^{2} m^{-2}$.dia, foi obtida pela integração da curva do IAF em função do tempo, ou seja:

$$
D A F=\int_{t_{1}}^{2} \text { IAF.dt. }
$$

- Indice de colneita (IC) foi obtido pela relação entre a produção de grãos e a de matéria seca total em $1 \mathrm{~m}^{2}$, em cada parcela.

Em t.odos os experimentos; ' foram determinados, por ocasião da colheita, o número de perfilhos e de paniculas por $\mathrm{m}^{2}$, a número de grãos $e$ de espiguetas vazias por panícula, a massa de 100 grãos, a altura de plant.as e a produção de grãos, a qual foi expressa em kg.ha-1, após ajustada em $13 \%$ de umidade. 


\section{RESULTADOS E DISCUSSĀO}

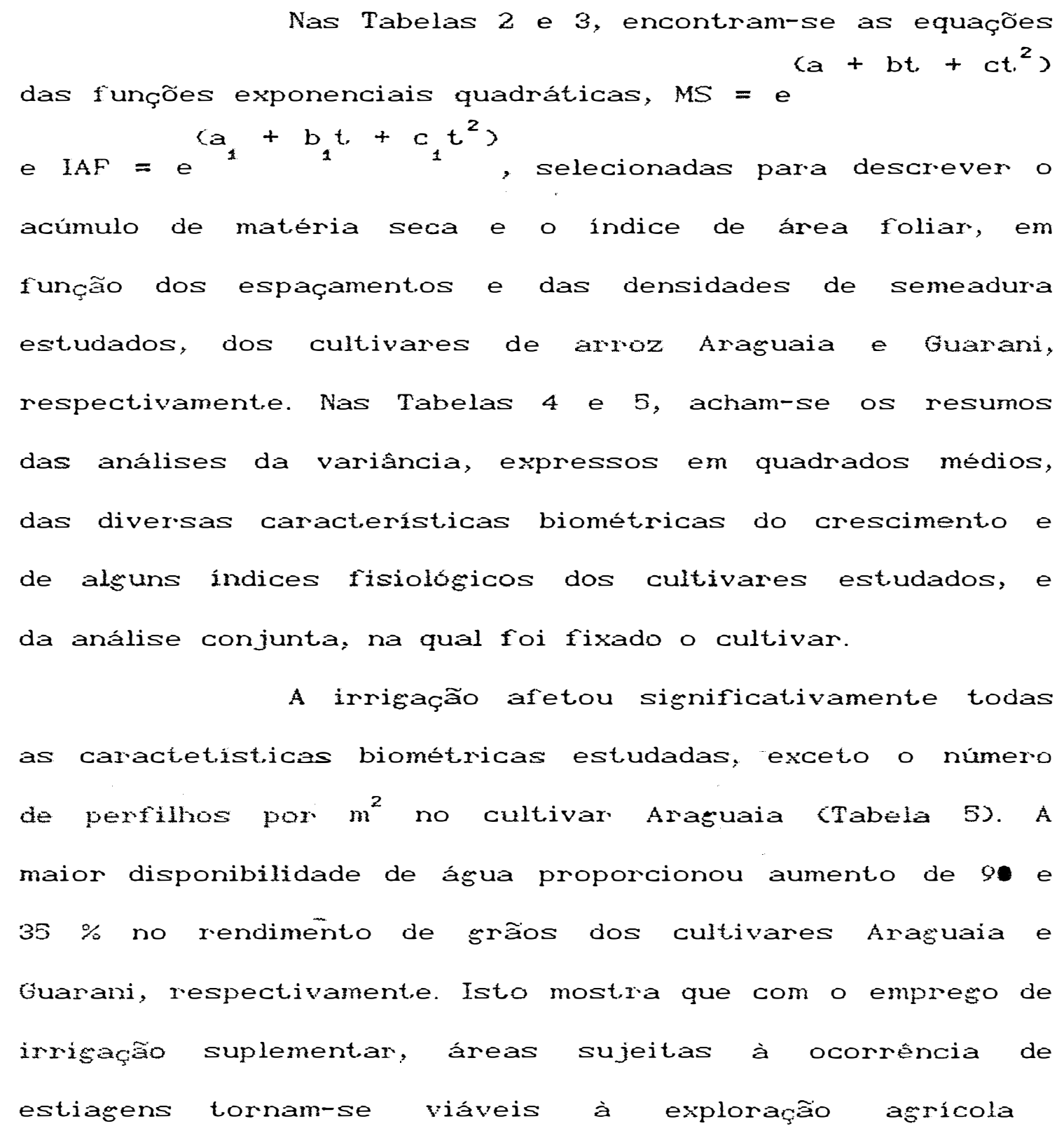




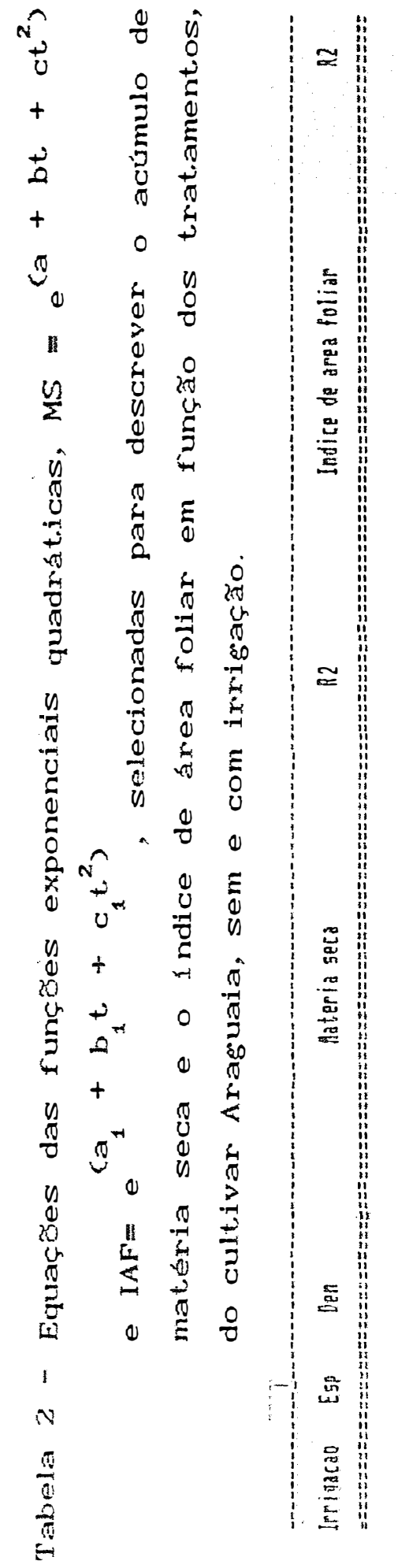

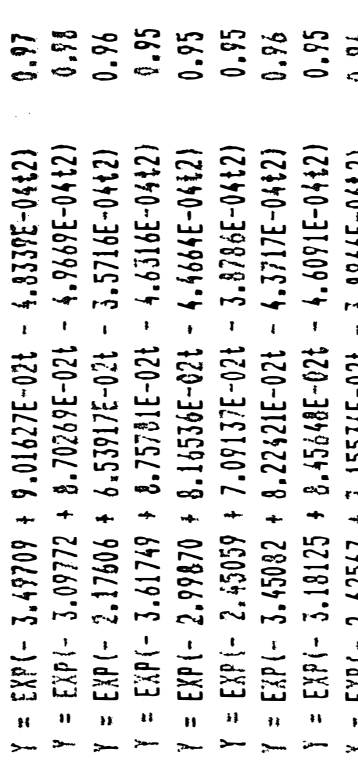

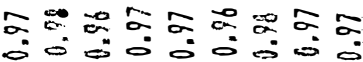

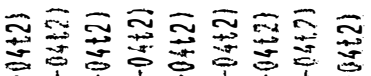

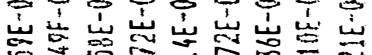

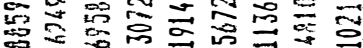

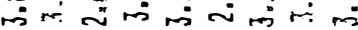

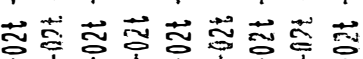

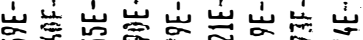

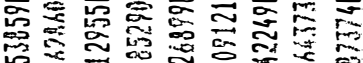
nर $++++++1-$

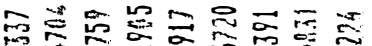

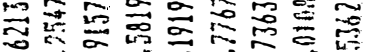

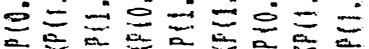

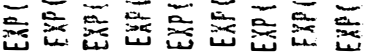
" " " " " " "

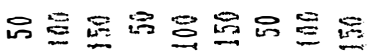

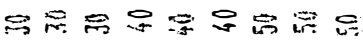
胥

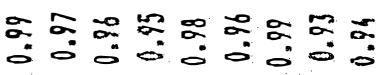

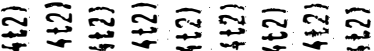

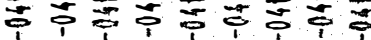

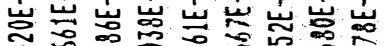

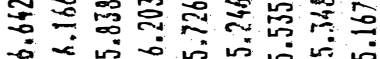

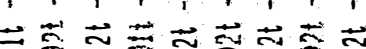
훙ㅎㅇ항ㅎㅇ

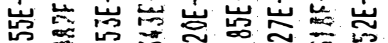

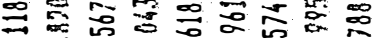
$\therefore \alpha 0-200$ o 0 $++++++++$

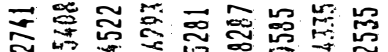

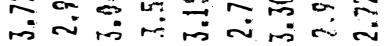

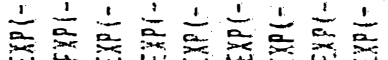
" " " " " " " $->-\infty>-1$

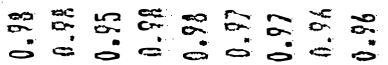

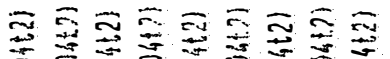

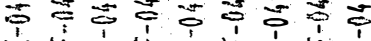

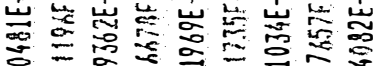

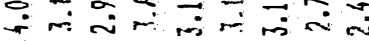

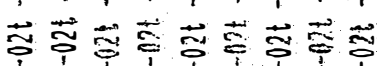

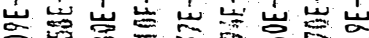

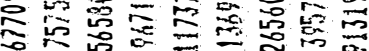

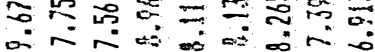
$+++++\ldots+$

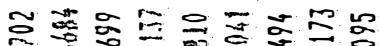

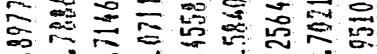

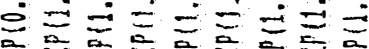

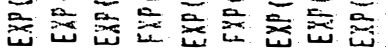
" " " " " " " " " " " "

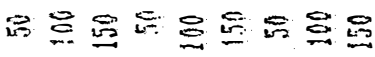

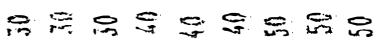
홍 


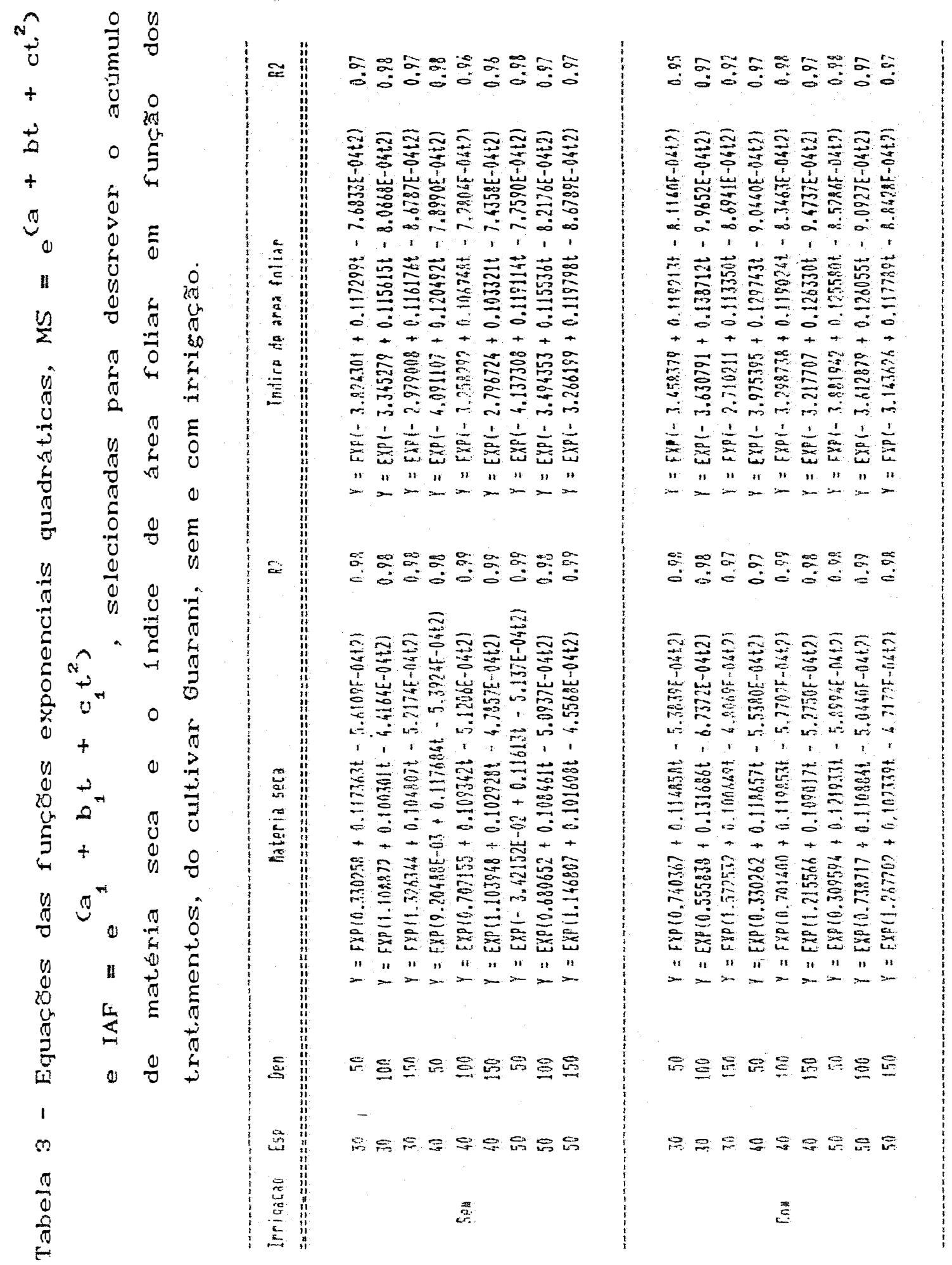




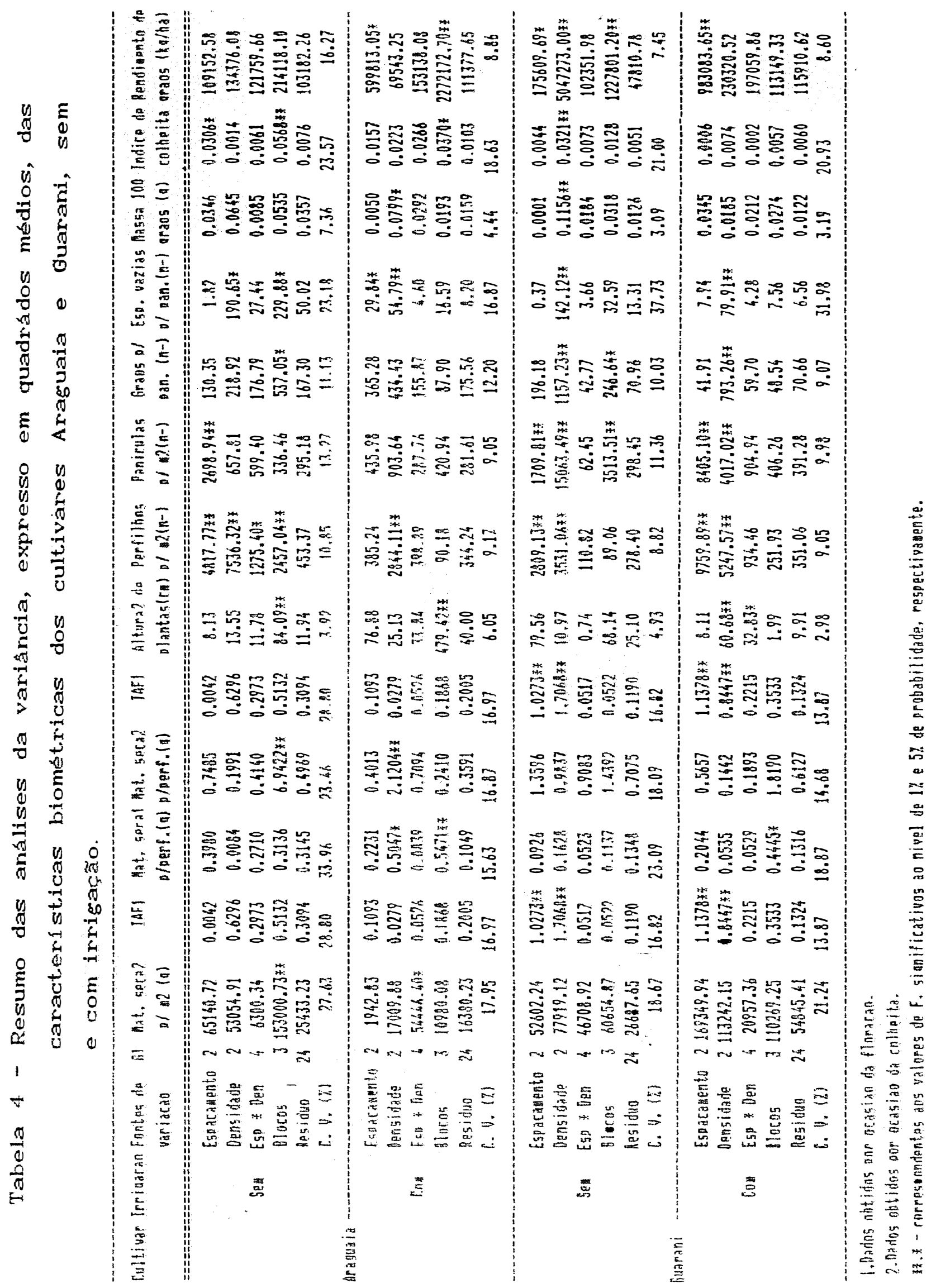




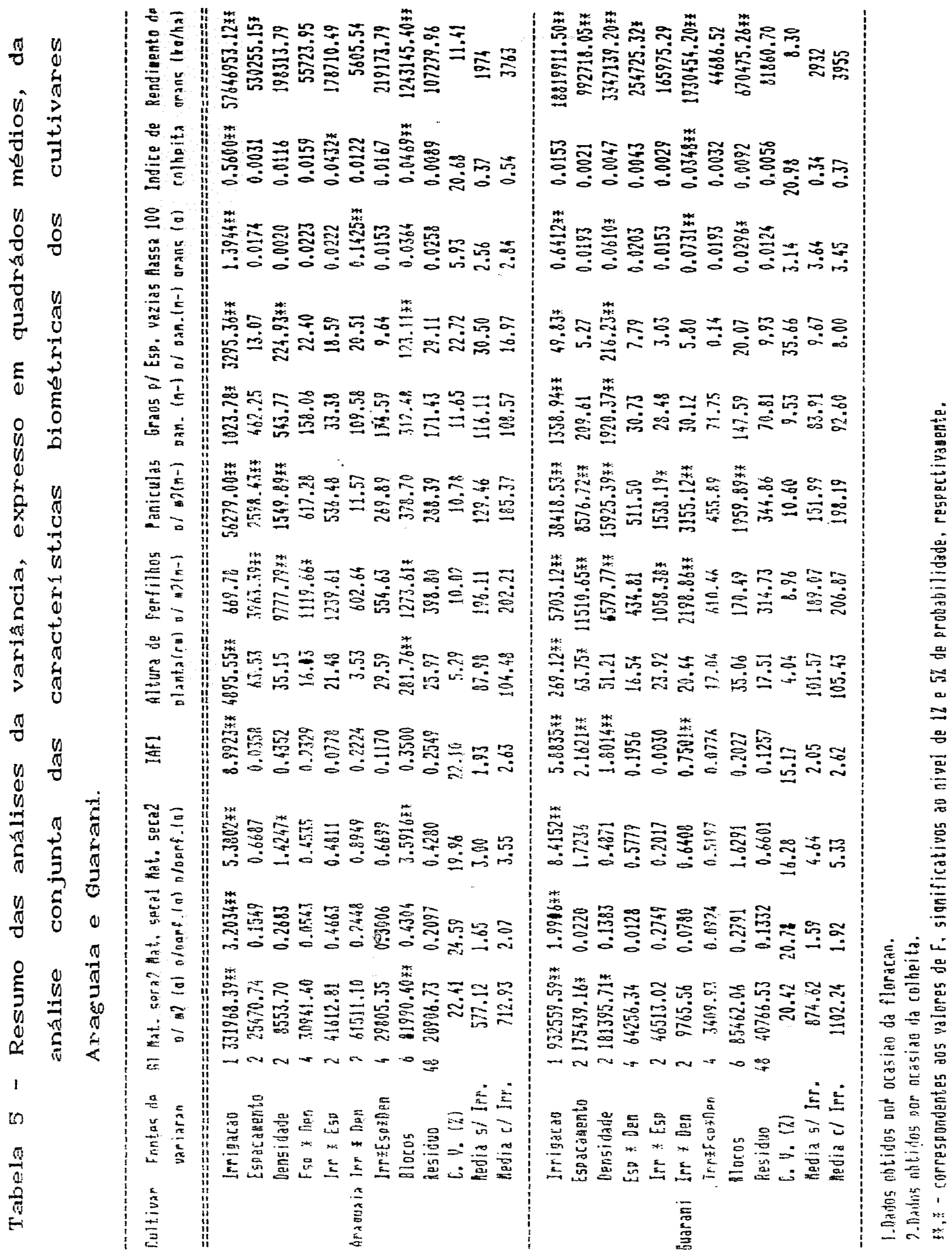


intensiva, possibilitando a adoção de niveis mais elevados de tecnologias. Além disso, a suplementação hidrica propiciou maiores valores para: produção de matéria seca total, indice de área foliar, taxa de crescimento da cultura, duração da área foliar nos dois cultivares, e não teve influência sobre a taxa de assimilação líquida, taxa de crescimento relativo, razão de área foliar e a taxa de crescimento foliar relativo. Com isso, observa-se que os indices fisiológicos obtidos por área foram influenciados pelo emprego da irrigação, enquant.o que aqueles determinados por perfilho não sofreram influéncia, ou seja, o desenvolvimento de cada perfilho individual não foi alterado, apenas o número de perfilhos por área. Isto se deve ao efeito do autossombreamento.

No periodo entre 35 dias antes e 10 dias após o início do florescimento, periodo este considerado por MATSUSHIMA (1968) como o de maior susceptibilidade das plantas de arroz à deficiência hídrica, as chuvas foram escassas (Figura 1), afetando o crescimento e o desenvolvimento das plantas.

A evolução dos principais parămetros de avaliação da análise de cresciment,o vegetal, quais sejam: produção de matéria seca total (MS), em s.m. ${ }^{-2}$; indice de área foliar (IAF); duração da area foliar (DAF), em $\mathrm{m}^{2} \cdot \mathrm{m}^{-2}$.dia; taxa de crescimento da cultura (TCG), em $5 \cdot \mathrm{m}^{-2}$ 
terieno.dia ${ }^{-1}$; taxa de assimilą̧ăo liquida (TAL), em

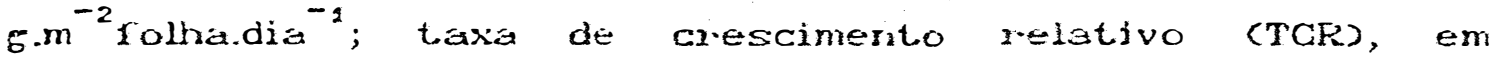
$6 \cdot 6^{-1} \cdot d i a^{-1} ;$ taxe de crescimento roliar selativo (TCFF), $\mathrm{em} \mathrm{m}^{2} \cdot \mathrm{m}^{-2} \cdot \mathrm{di} \mathrm{a}^{-1} ;$ raz̧̄o de ares foliar (RAF), em $\mathrm{dm}^{2} \mathrm{o}^{-1}$, pode ser observada, para cada cultivar estudada, sob a imfluencia dos diferentes ixatamerios, atraves das Fieruras $2=10$

0 acumulo de materia sece total dos dois cultivares ammeritou com o emprego de irrazgä em todos espaçamentos e dersidades de semeadure sstudabos cFieuras 2 e 3). De modo seral, a evoluga do evumulo de materis seca em relaç0 as mudengas ontogentidas nostrou que a

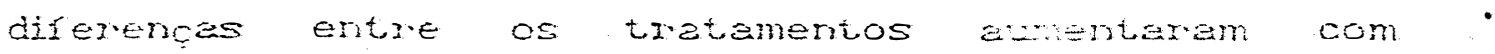

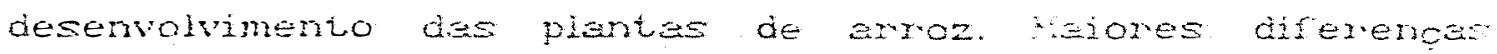

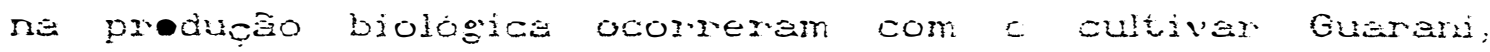
especialmente ros merores especementos. Fos dois cultivares; 2 materia seda eumentou = medidi que a dersidade de semeadure cisscen. mroperdente do

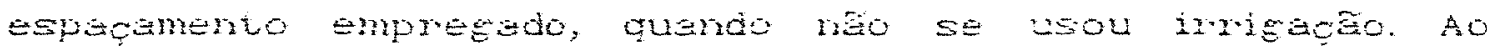

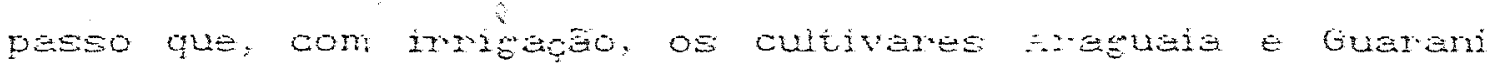
tiverem meiox producao de matexie sto no espegamento de

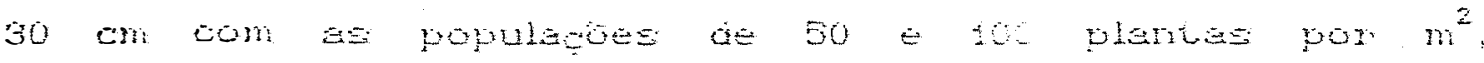

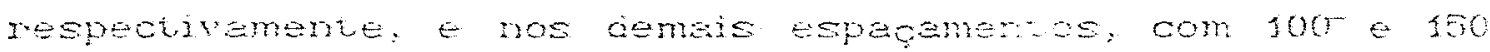

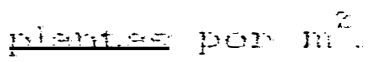

\footnotetext{
Obsempando-se es curve de meteria seca:

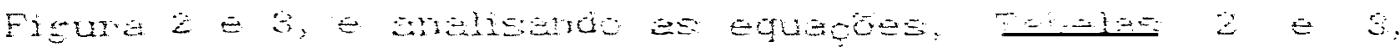



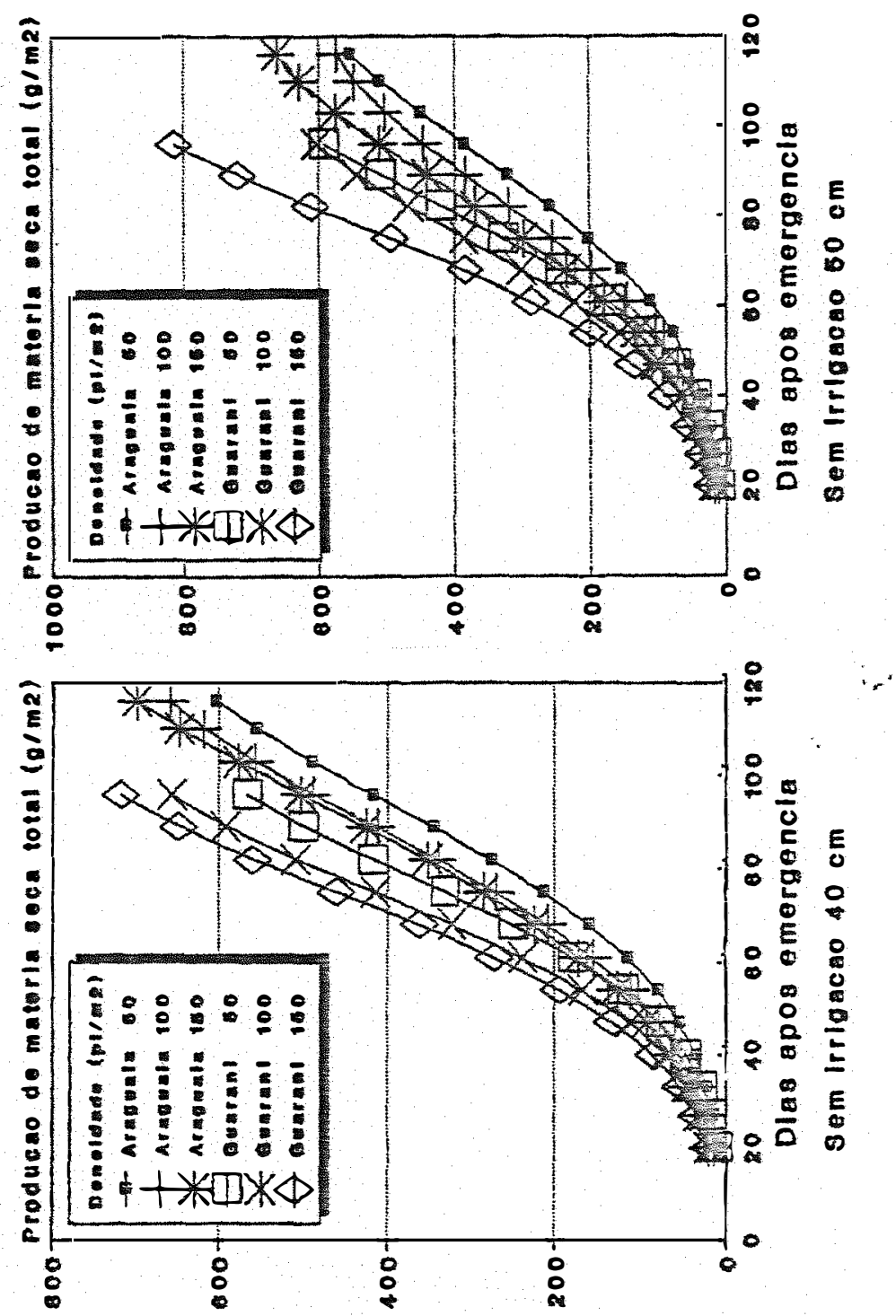

U

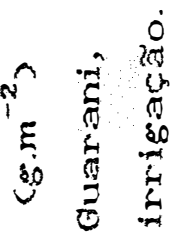

ถ

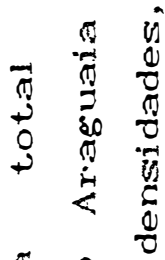

$\begin{array}{lll}\pi & 0 & 0 \\ 0 & 4 & 0 \\ 0 & 0 & 0 \\ & 2 & 0 \\ 0 & 0 & 0 \\ 0 & 0 & 0 \\ 0 & 0 & 0 \\ 0 & & 0 \\ 0 & 0 & 0 \\ \vdots & 0 & 0 \\ 0 & & 0 \\ 0 & & 0\end{array}$

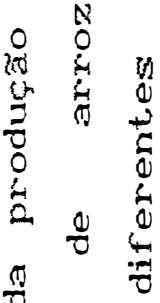

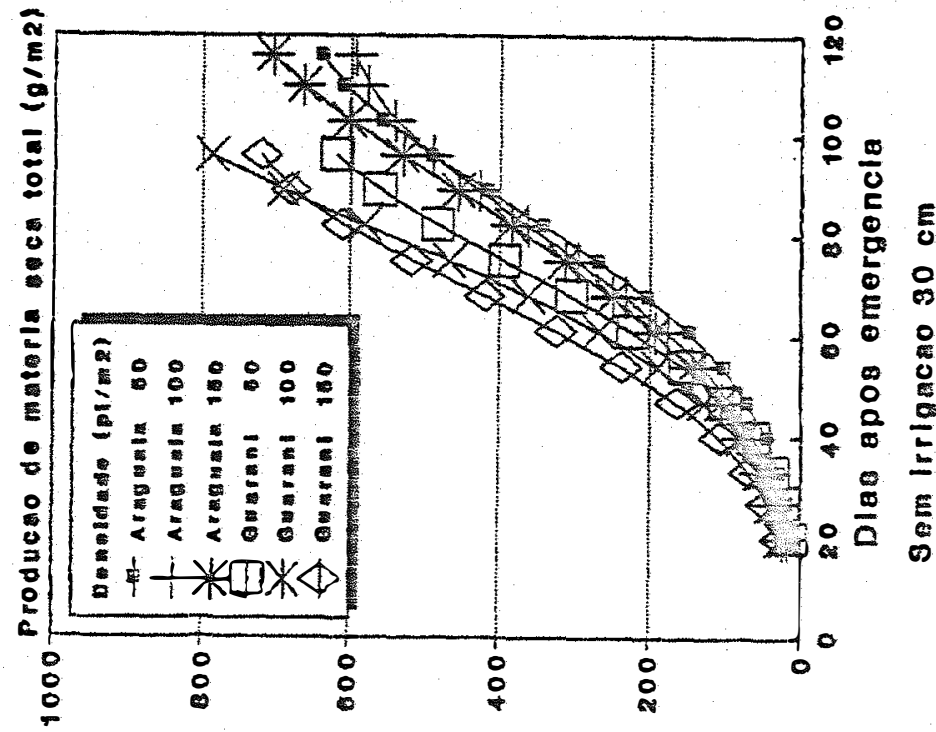

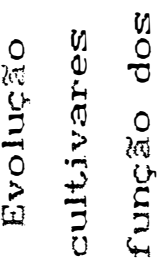

$\underset{7}{*}$ 


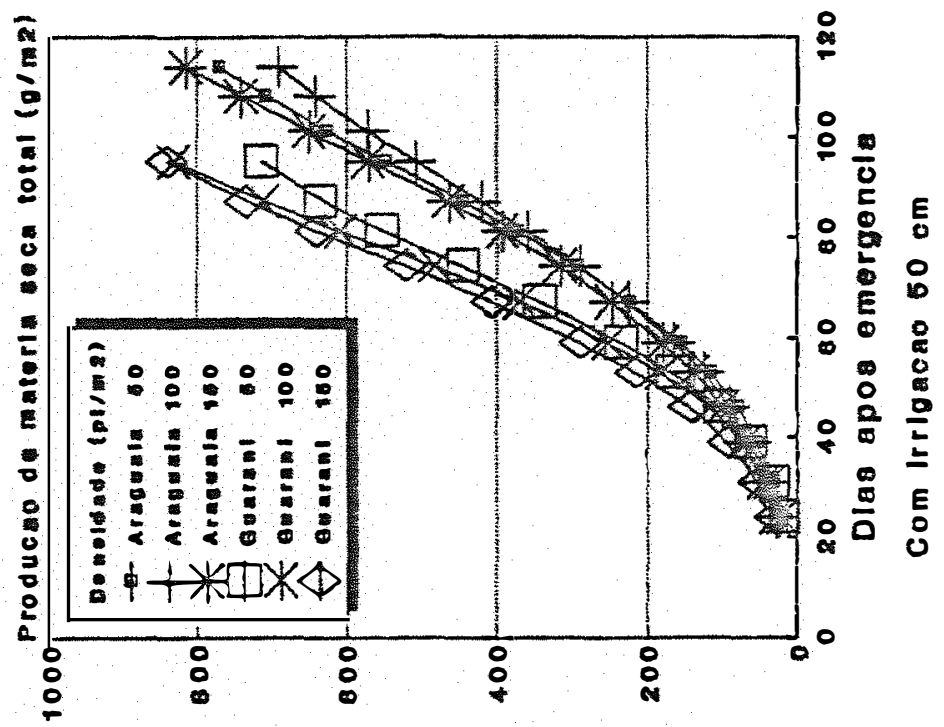

$\begin{array}{ll}n & 0 \\ 0 & 0\end{array}$
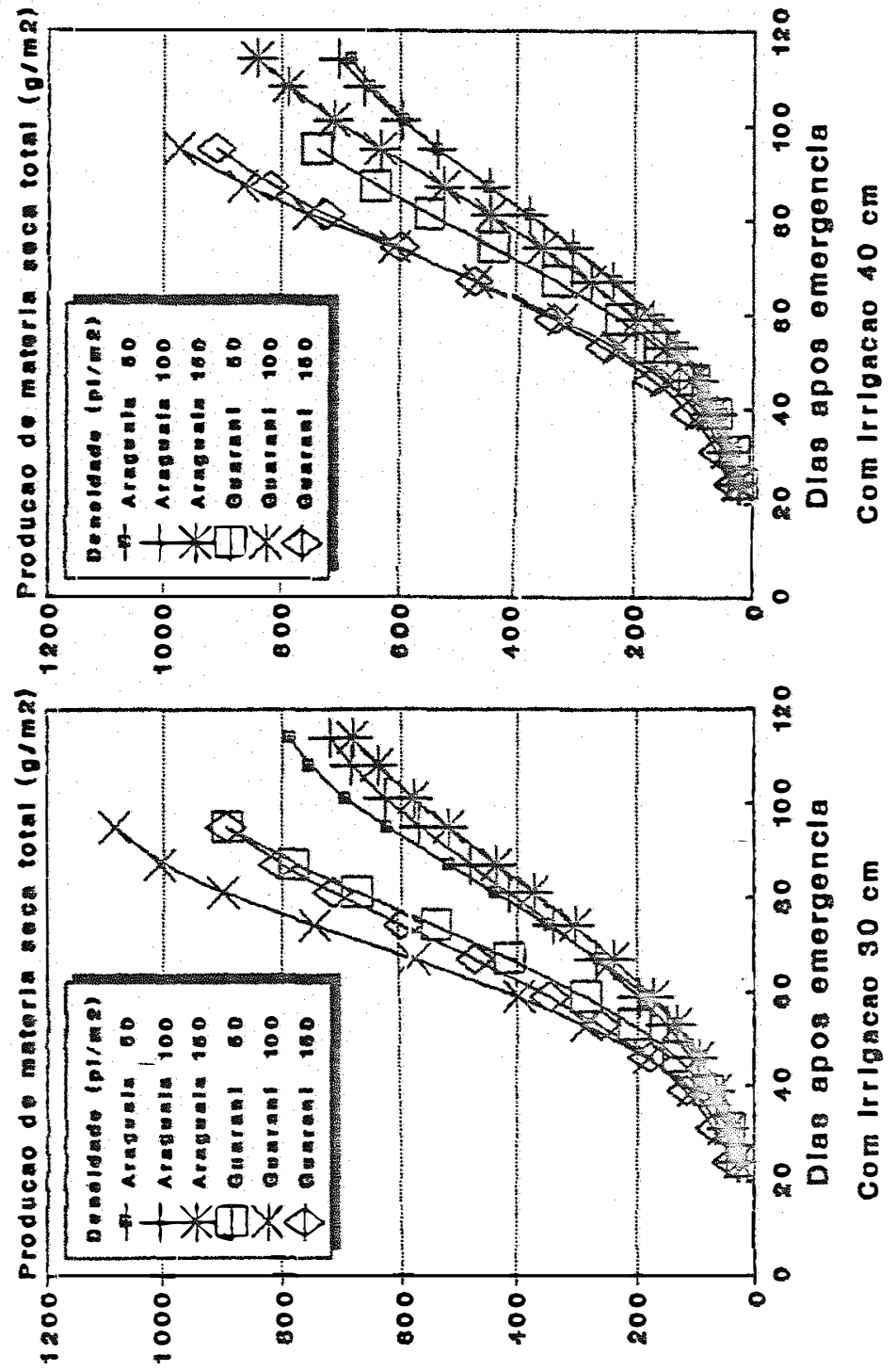

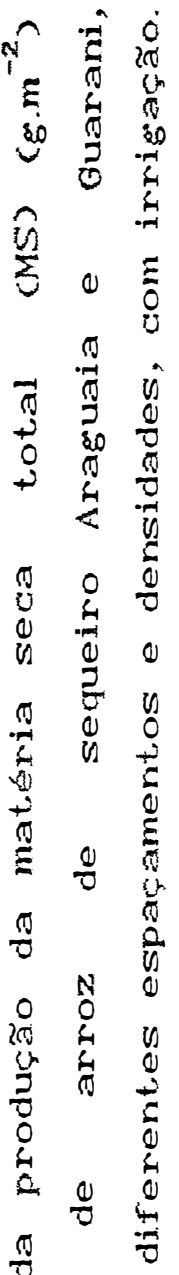

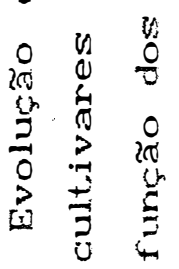

5 
verificam-se que os pontos máximos são estimados entre 119 e 143 dias após a emergéncia das plántulas do cultivar Araguaia, e entre 97 e 113 dias no cultivar Guarani.

O cultivar Araguaia foi mais influenciado

pela deficiéncia hídrica que o Guarani, devido este ser de ciclo curto o que possibilitou o escape ao déricit hidrico e, consequentemente maior produção de matéria seca total. Em condiçäes irrigadas, a menor produção de matéria seca total apresentada pelo cultivar Araguaia no menor espaçament.o provavelment.e se deve à menor concentração do fertilizante no sulco de semeadura nesta dist.áncia entre linhas, visto que a adubação foi baseada por área e não por metro linear de sulco, e esse cultivar é mais exigente a niveis mais elevados de fertilidade do solo, em comparação com o Guarani.

$$
\text { Pela análise da variância da produção de }
$$

matéria seca total det.erminada por ocasião da colheita, verificou-se efeito significativo da interaça entre espaçamento e densidade de semeadura com - cultivar Araguaia, quarido a irrigação foi emprégada (Tabela 4 ). Desdobrando o efeito da interação dos tratamentos sobre a produção de matéria seca t.otal do cultivar Araguaia em condiçóes irrigadas, verifica-se, na Tabela 6 , que no espaçament.o de $30 \mathrm{~cm}$ a matéria seca reduziu à medida que as densidades de semeadura cresciam, no espaçamento de 40 $\mathrm{cm}$ aument.ou linearmente e no de $50 \mathrm{~cm}$ não houve efeit.o 


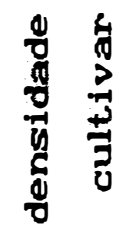

- 0

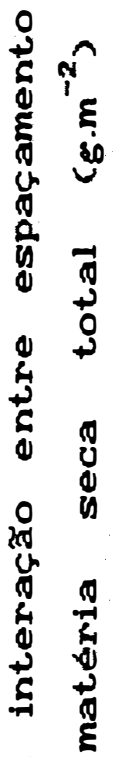

II

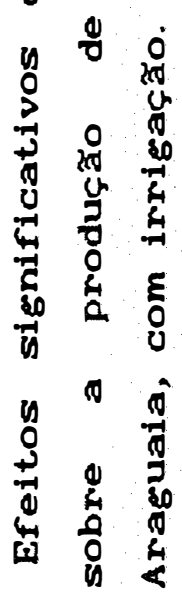

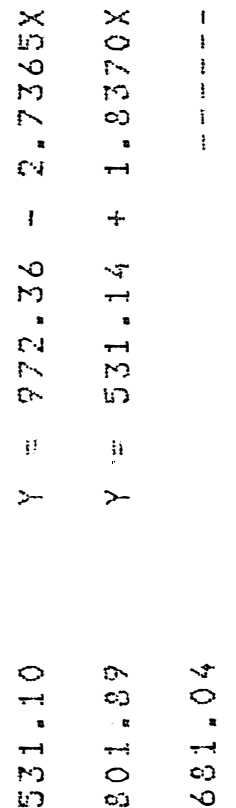

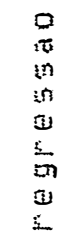

$\begin{array}{ll}11 & \\ 11 & \\ 11 & \\ 11 & 0 \\ 11 & 0 \\ 11 & 0 \\ 11 & \\ 11 & \\ 11 & \end{array}$

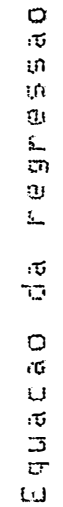

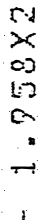

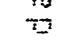

0
0
0
3
3
0
0
0

a

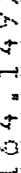

$2 \quad 4$

$\stackrel{5 . d}{E}$

문

$\begin{array}{cc}\Sigma & \\ E & 0 \\ \text { iai } & 0 \\ \text { in } & \end{array}$

rid

5. is 1

$\begin{array}{lll}2 & 0 & m \\ i & n & m\end{array}$

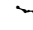

$\frac{3}{5}$
$\vdots$
$\vdots$
0

$\begin{array}{lll}0 & 0 & 21 \\ 1 & 4 & 0\end{array}$

$\begin{array}{lll}\pi & 0 & 17 \\ 0 & =\pi & \pi\end{array}$

$\begin{array}{lll}m & m & 4 \\ m & m & 0 \\ H & m & 0 \\ H & m & 0\end{array}$

$\tilde{E}$

$=\quad 0$

$\begin{array}{lll}0 & 0 \\ -1 & 0\end{array}$

$\begin{array}{lll}0 & 0 & 0 \\ 0 & m & 0 \\ 0 & 0 & 0\end{array}$

$\begin{array}{lll}0 & \cdots & 0 \\ m & 0 & -1 \\ 0 & 0 & = \\ 0 & 0 & m\end{array}$

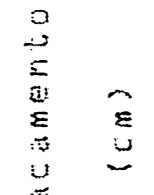

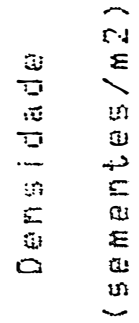


significativo. Nas populaçöes de 50 e 100 plantas por $\mathrm{m}^{2}$ a produção de matéria seca não foi influenciada significativamente, enquanto que na população de 150 plantas por $\mathrm{m}^{2}$ o aumento do espaçamento resultou em resposta quadrática, obtendo-se um valor máximo estimado de $809 \mathrm{~g} / \mathrm{m}^{2}$ com o espaçamento de $42 \mathrm{~cm}$ entre linras.

Na análise conjunta, os espaçamentos e as densidades de semeadura influenciaram significativamente a produção de matéria seca apenas do cultivar Guarani (Tabela 5). As análises de regressão mostraram que houve correlação linear nesativa significativa entre a produção de matéria seca e os espaçamentos e, linear positiva, entre a matéria seca e as densidades de semeadura cTabela 7). Ex̂etuaram-se as análises da variância da matéria seca por perfilho obtida por ocasião da floração e na colheita. Em ambas determinações, no cultivar Araguaia, em condições irrigadas, houve efeito significativo da densidade (Tabela 4), e a matéria seca por perfilho declinou linearmente com - aumento da densidade de semeadura (Tabela 8).

$$
\mathrm{Na} \text { análise conjunta (Tabela 5), efeito }
$$

simnificativo foi observado apenas da densidade na determinação efetuada por ocasião da colheita do cultivar Araguaia. Nesta análise, o aumento da densidade também propiciou redução na matéria seca por perfilho (Tabela 7 ).

As curvas ajustadas do indice de área foliar em função da idade das plantas de arroz, em 


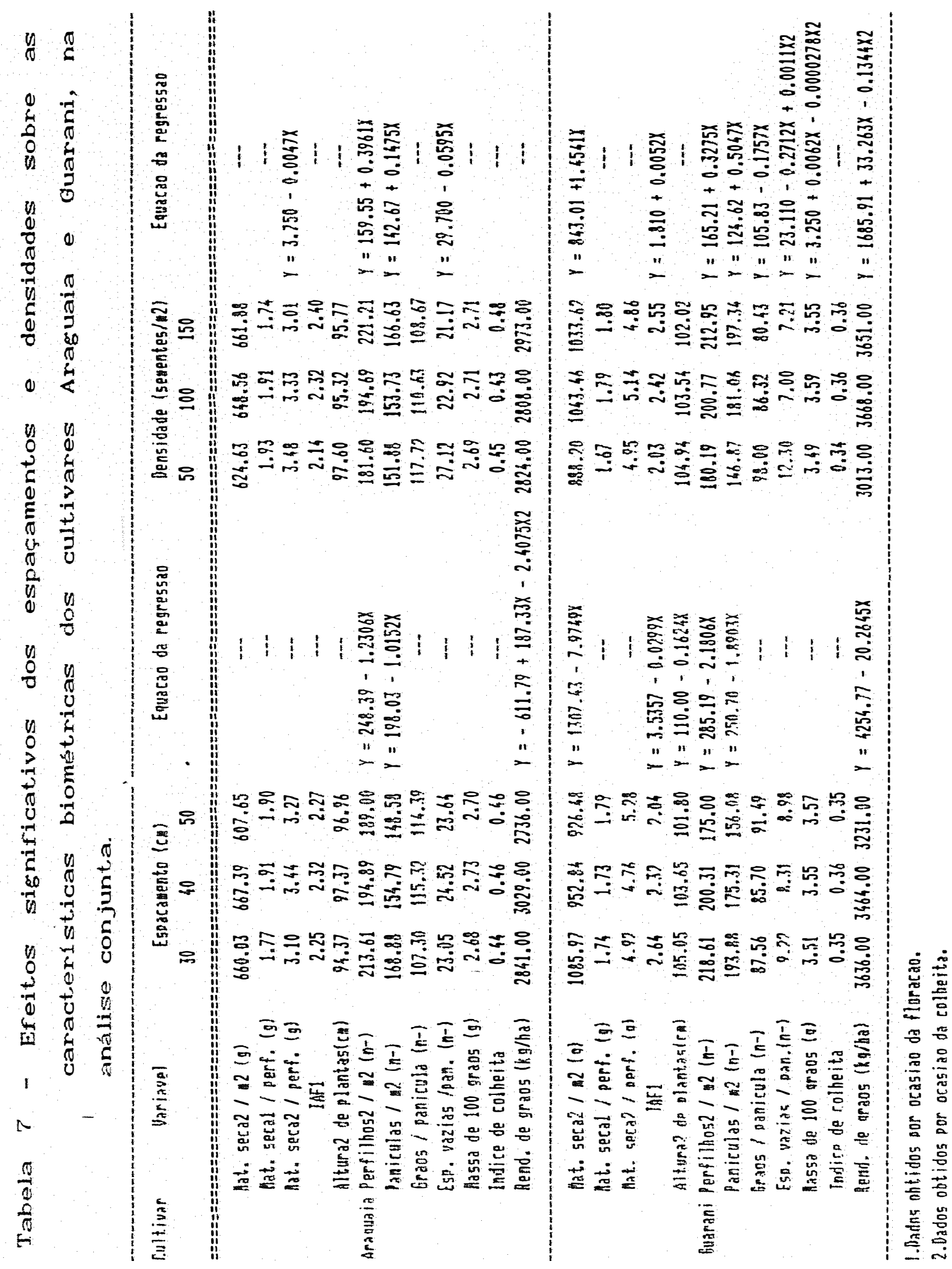




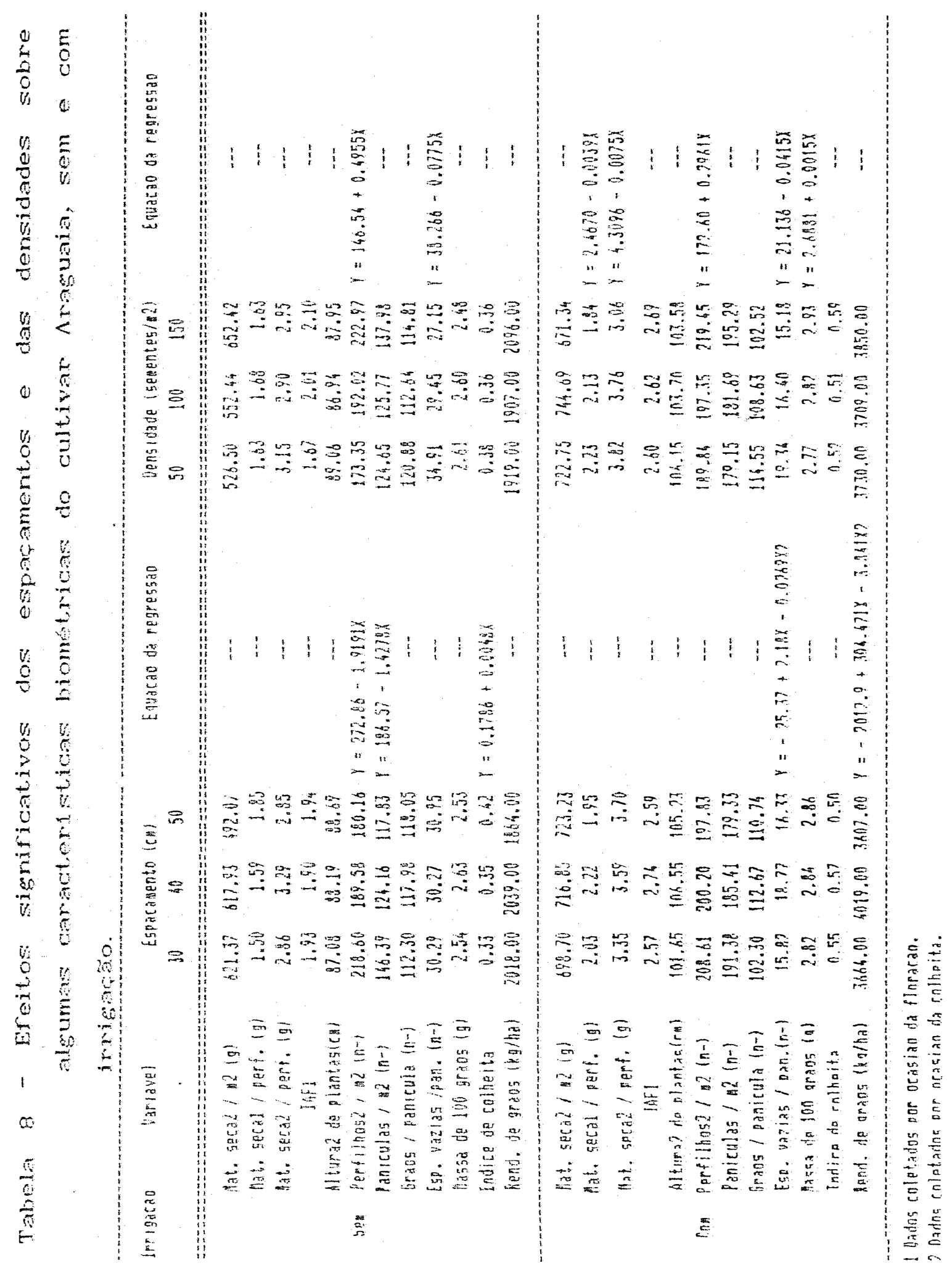




\begin{abstract}
diferentes espaçamentos e densidades de semeadurá, sem e com irrigaçäo, tem suas tendências graficamente representadas nas figura 4 e 5 . O conceit.o de indice de área roliar (IAF) foi introduzido por WATSON (1947) sendo derinido como a área roliar por unidade de área de termeno. Este indice avalia a capacidade com que a axea roliar cobre o terreno disponível a planta, ou seja, a capacidade que a comunidade vegetal tem em explorar o espaço disponivel.
\end{abstract}

Os indices de área foliar dos dois cultivares apresentaram valores maiores nos tratamentos com irrigação do que naqueles em que o fornecimento de agua às plantas roi proveniente apenas das precipitaçöes pluviais. Os valores maximos do IAF para os tratamentos irrigados ocorreram 8 e 3 dias antes nos cultivares Araguaia e Guarani, respectivamente, em relaçăo aos não irrigados. Isto mostra que a maior disponibilidade de asua possibilita às plantas dos dois cultivares cobrir o espaço a elas disponivel com maior rapidez, em comparaço às condições não irrigadas, aproveitando, desta maneira, mais eficientemente o terreno por maior periodo de tempo.

De modo geral, houve uma tendêraia dos välores máximos de IAF reduzirem com o aumento do espaçamento em ambos os cultivaxes, independente do uso da irrigaço, com exceça do cultivar Araguaia ha populaça de 150 plantas por $\mathrm{m}^{2}$. Como era de se esperir, em cada 


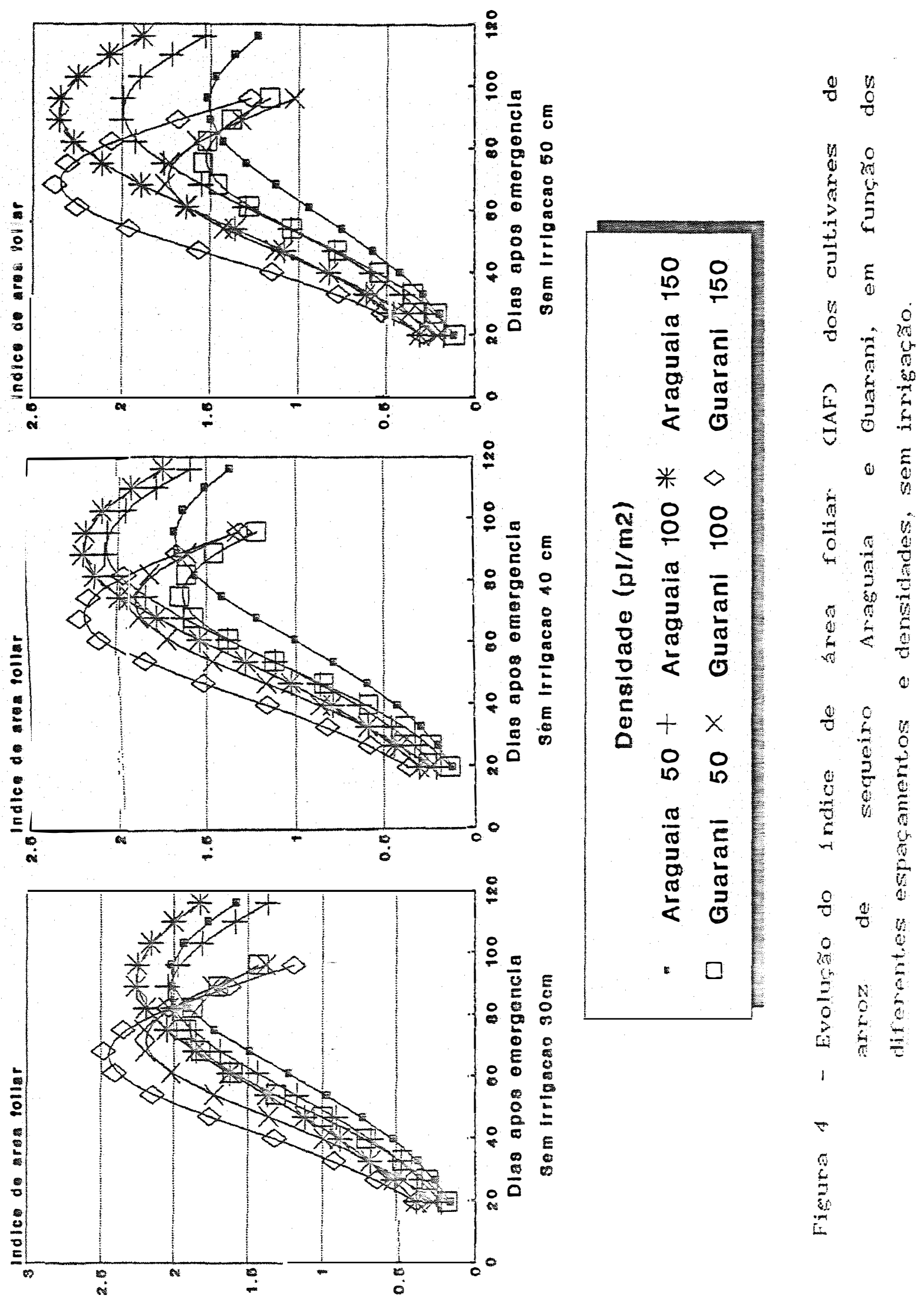



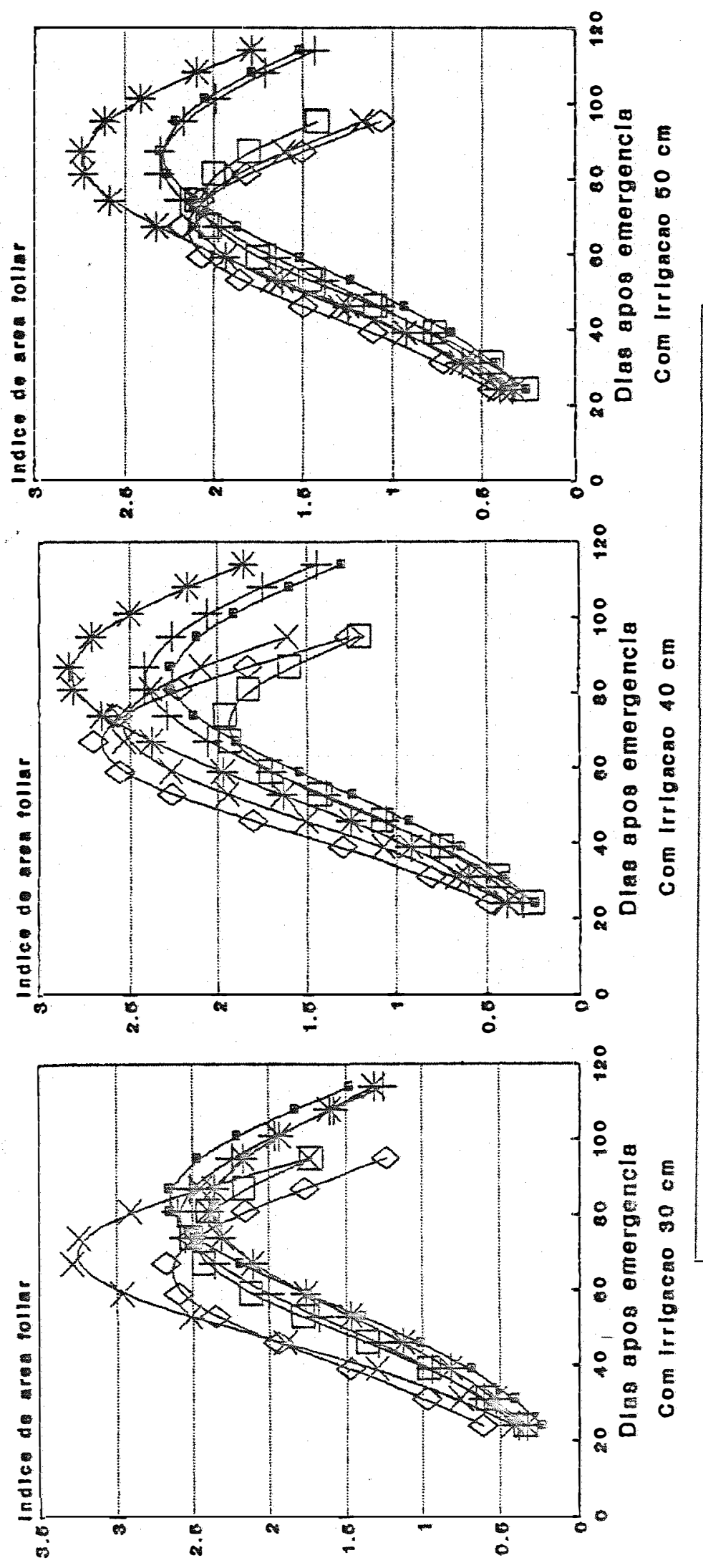

ช. $\frac{1}{0}$

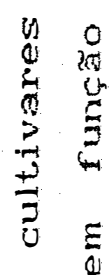

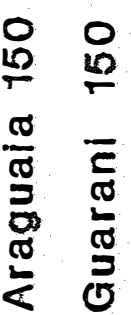

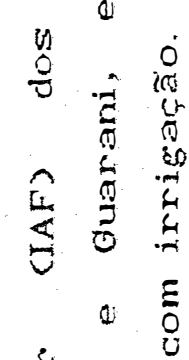

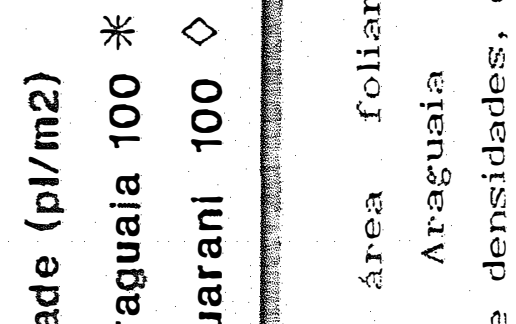

의

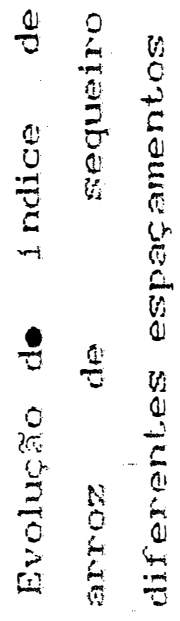

(1)

3 


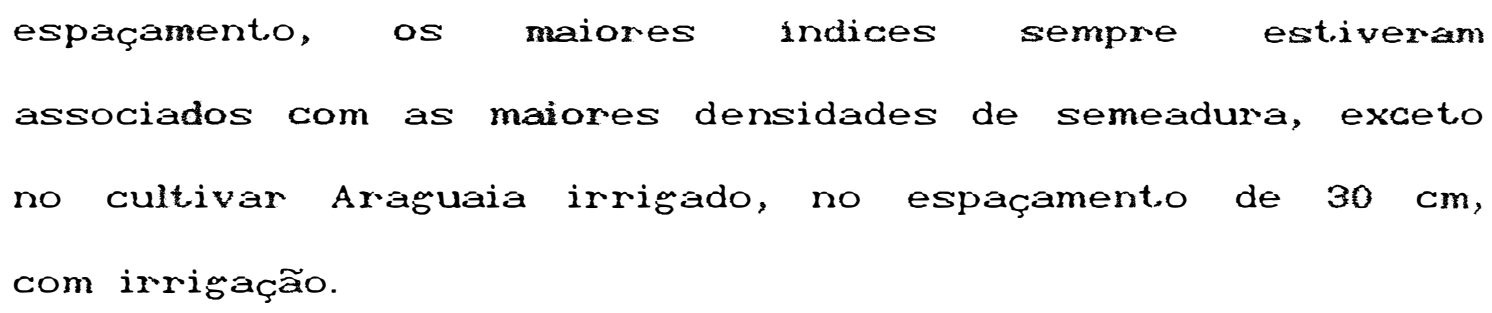


As estrategias para a obtenção de maiores produçóes das culturas são geralmente destinadas para maximizar a interceptação de luz pela realização da cobertura completa do solo, através da manipulação da dersidade de semeadura e do arranjo espacial e promover a rápida expansão da rollia 0 IAF $t$ irequentemente considerado como um indicador da intersidade de competição por luz que ocorre nas plantas individuais dentro de uma população (WATSON, 1958).

Os valores do IAF determinados por ocasião da floração foram submetidos à análise da variância e verificaram-se que, para o cultivar Guarani, houve ereito significativo dos tratamentos sobre esses indices, tanto sem irrisação como em condições irrigadas (Tabela 4), ao passo que, para o cultivar Arasuaia não houve influência. o Indice de srea foliar foi correlacionado linear $e$ regativamente com o espaçamento independente das condições serem irrigadas ou rão (Tabela 9 ). A relação entre IAF e a dersidade de semeadura foi linear e positiva, sem irrigaçăo, e quadrática, com ixriğação, sendo o valor de IAF maximo estimado com 110 plantas por $\mathrm{m}^{2}$.

Foram estudadas as correlaçóes entre 0 rendimento de srä́os e o lAF e a materia seca por perfilho determinados em t.odas amostragens, durante todo o cialo dos cultivares. A correlacäo entre estes parametros e a produção de grãos do cultivax Axasuaia foi sisrificativa e 


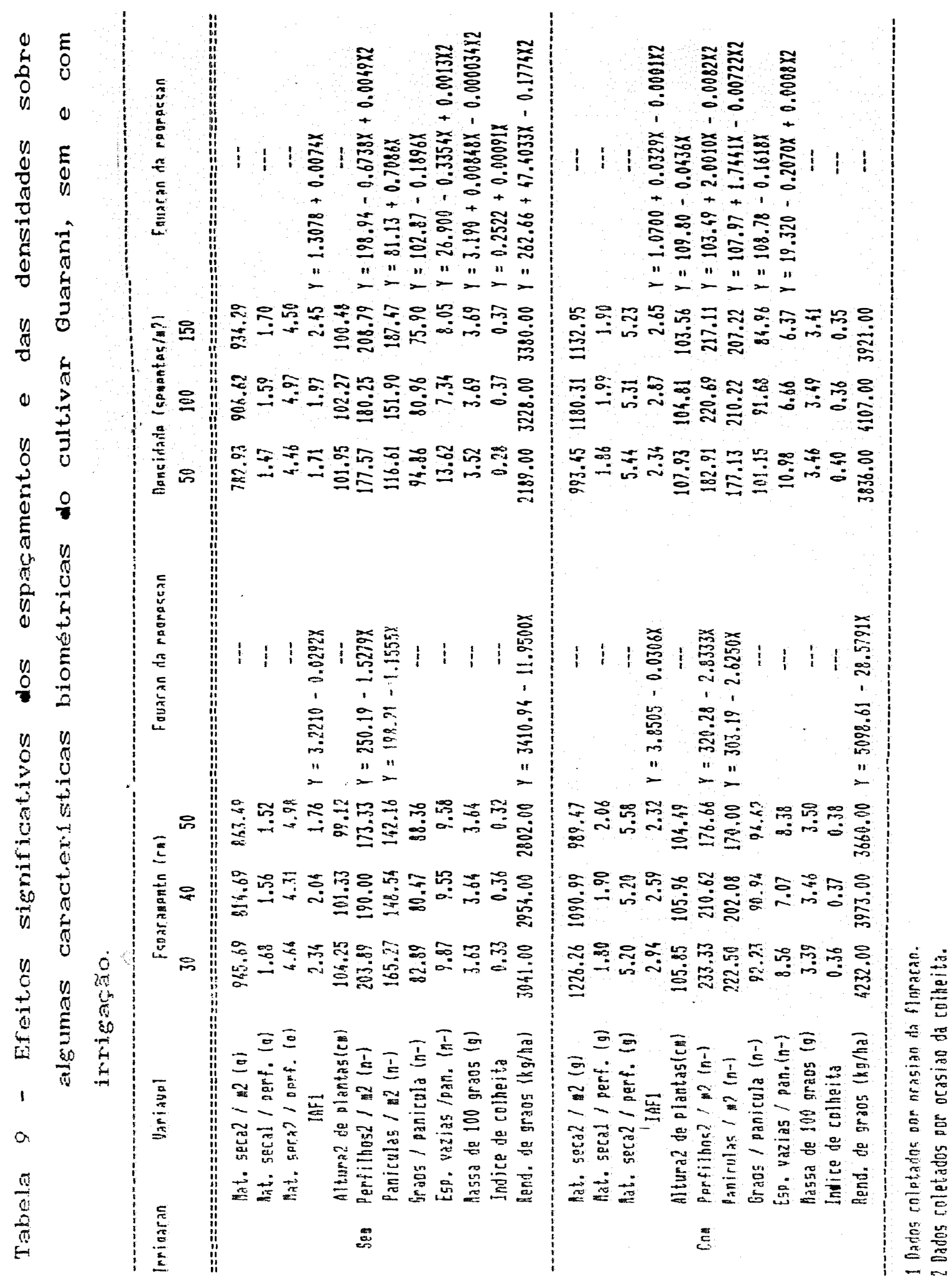


positiva, obtendo-se os coeficientes mais allos 0,48 e 0,44 para IAF e MS, respectivamente, aos 61 dias após a emergência, nos tratamentos sem irrigação, e 0,71 e 0,52 aos 101 dias, em condiçöes irrigadas. Para o cultivar Guarani, a correlação entre est.es parâmet.ros $e$ o rendimento de grãos também foi signiricativa, apresentando os mais elevados coeficientes 0,86 e 0,49 , para IAF e MS, respectivament.e, aos 54 dias após a emerøência, sem irrigação, e 0,62 e 0,43 aos 74 dias, com o emprego da irrisação. Isto mostra que o indice de área foliar e a materia seca pr perfilho são correlacionados significativamente com a produç ăo de grãos com maiores coeficientes de correlação aos 30 e 10 dias antes da floração dos cultivares Araguaia e Guarani, respectivamente, quando o forneciment.o de água $e$ proveniente apenas das precipitaçơes pluviais, e no final da tloração, em condiçōes de boa disponibilidade de ásua $\Leftrightarrow$ plantas dos dois cultivares de arroz. Estudando as relaçöes entre rendimento de srãos, componentes do rendimerto e algumas caracteristicas moriorisiológicas selecionadas, FINHEIRO et alii (1985) obtiveram as melirores correlaçóes com o número de paniculas por $\mathrm{m}^{2}$, indice de área foliar na floraço e larourua das follas, na ausEncia de dericisncia hidrica.

A duraga da area foliar (DAF) expressa a magritude e pexsisténcia da ثrea foliar durante o periodo 
de crescimento da cultura, e foi chamada por WATSON (1947) de "Loda oportunidade para assimilação" que a cultura processa durante o periodo em questão. Houve incremento na DAF nos dois cultivares quando o espaçamento foi reduzido e a densidade de plantas aumentada. São apresentadas na Figura 6 as correlações entre DAF e rendimento de grãos. As relações entre DAF e produção de orăos do cultivar Guarani foram lineares positivas e signiricativas, independent.e do emprego da irrigação, enquant.o que para o cultivar Araguaia as correlações nas análises individuais não foram significativas. Observa-se na Figura 6 que, sem irrigação, o coeficiente angular da ret.a é o dobro daquele em condições irrigadas. Com isso, havendo pequeno aumento na DAF do cultivar Guarani sem imigação proporciona grande incremento no xendimento de grãos, enquanto que com irrigação há tendência do rendimento de grãos se estabilizar com o aumento da DAF. A correlação entre estes parämetros foi maior nas condições irrigadas ( $r=0.905$ ) do que naquelas onde houve menor disponibilidade de água as plantas $(x=0.833$. Assim, nos tratamentos irrigados, onde a área foliar era maior e as folhas perduraram por mais tempo, apresentando consequentemente maior DAF, os rendimentos foram maiores.

Na análise conjunta, as produçẽes dos dois cultivares foram altamente correlacionadas linearmente com a DAF. Isto mostra que maiores rendimentos de grãos desses 

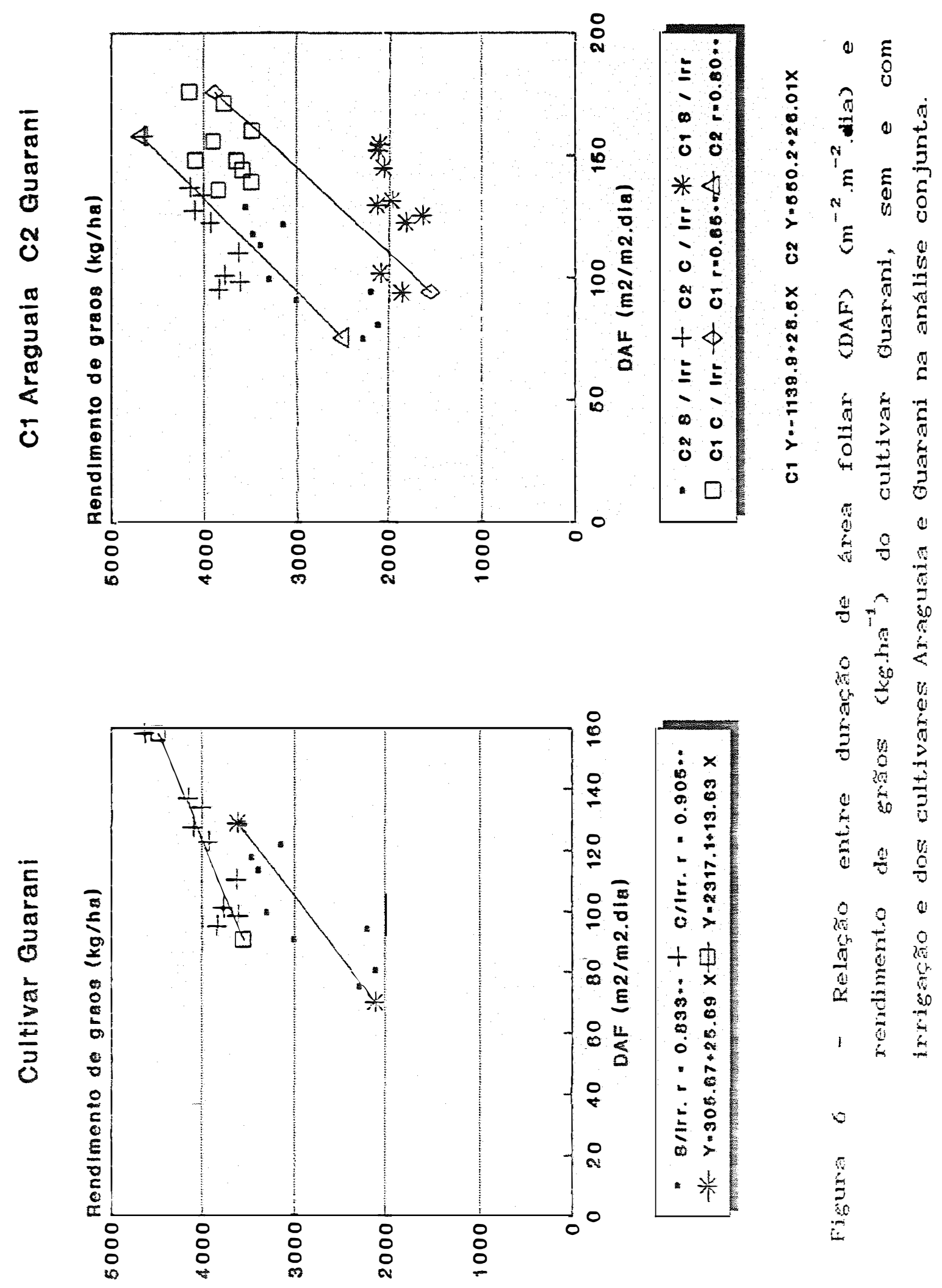
cultivares são obtidos com o aumento da DAF através do uso de irrigação suplementar. A relação entre rendimento de grãs e DAF pode ser explicada em função da proporção da radiação interceptada, pois folhas maiores, mais eretras e abundantes e que permaneçam verdes por mais tempo interceptam mais radiação, desde que não haja autossombreamento. A produção biológica total pode ser estimada pelo produto da duração da área foliar pela taxa de fotossintese média da cultura por unidade de área foliar (MACHADe, 1985 ).

A traxa de crescimento da cultura (TCG), t.ambém chamada de taxa de produção de matéria seca, capacidade fotossintética, tasa de produção de fotossintetizados ou produtividade primária, avalia o crescimento do vegetal, relacionando a quantidade de material orgânico acumulado em runção da área de solo disponivel por unidade de tempo. Inicialmente, as t.axas de crescimento da cultura foram pequenas, aumentando rapidamente até atingir o máximo entre $t 5$ e 100 dias após a emergencia das plantas do cultivar Araguaia, e entre 70 e 80 dias no cultivar Guarani, declinando posteriormente

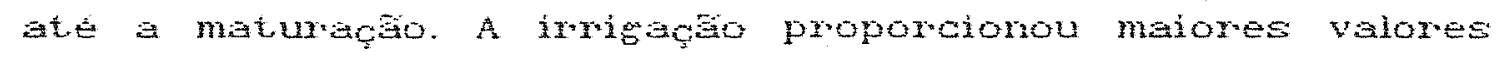
da TCG CFiguras $T$ e 8 , indicando que ambos cultivares foram mais precoces quanto ac desenvolvinento e acumulo de materia seca, em condiçóes tavorecidas em relação à disponibilidade de agua às plantas. Os valores máximos 


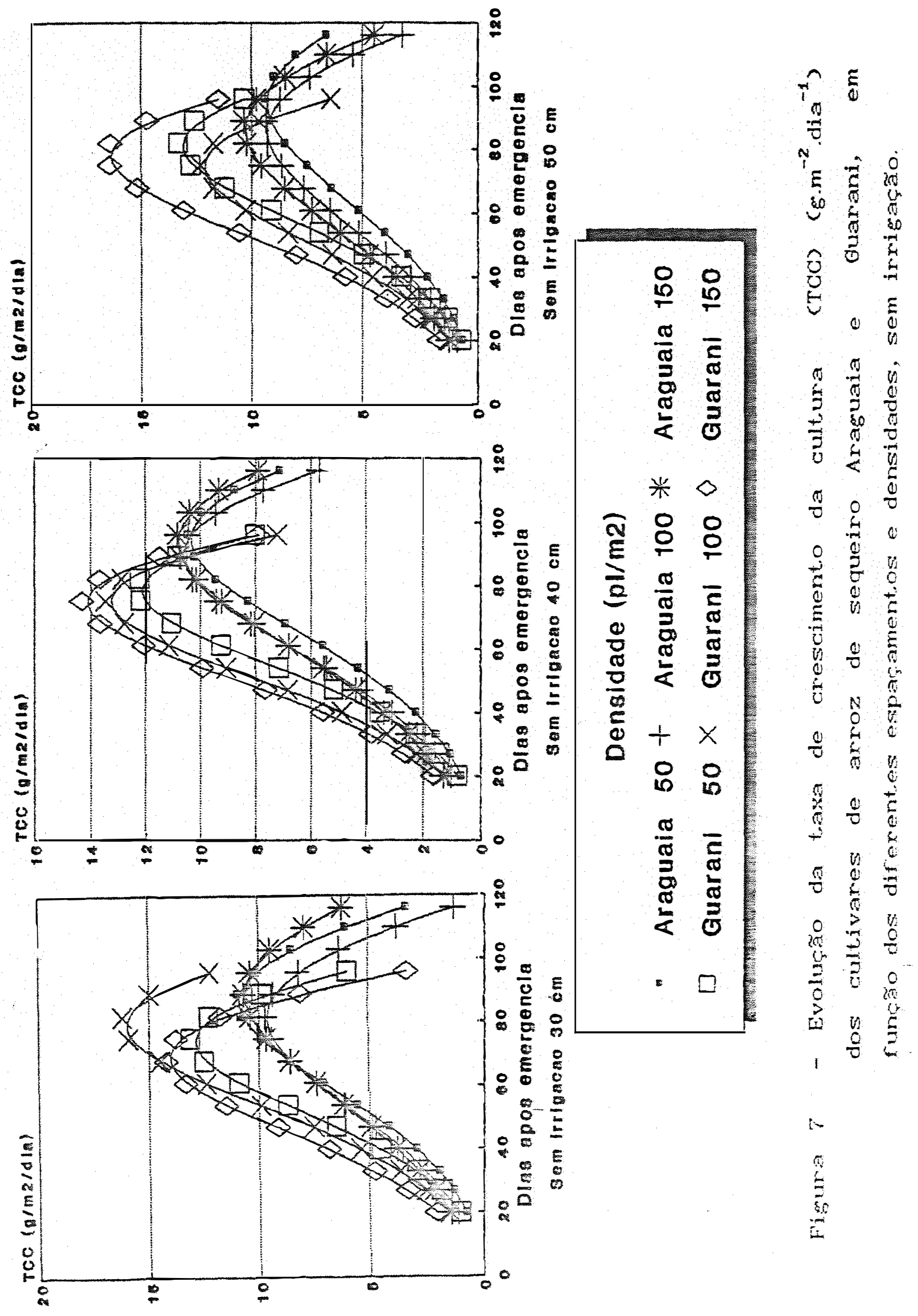




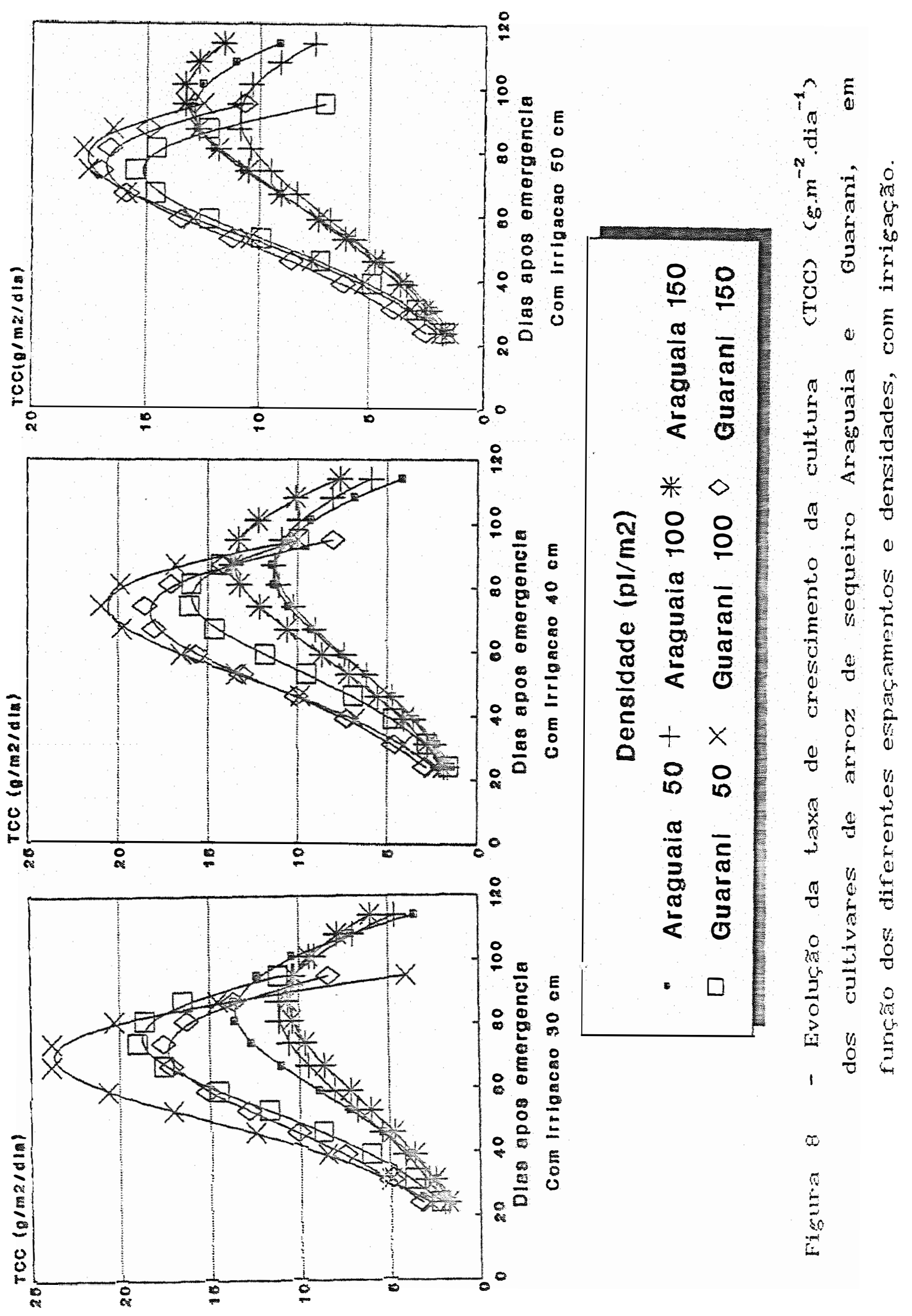


obtidos foram de 10,92 e 13,67 i de matéria seca.m ${ }^{-2}$ de terreno.dia ${ }^{-1}$ no cultivar Araguaia, e de 16,45 e 23,45 \& de matéria seca.m ${ }^{-2}$ de terreno.dia ${ }^{-1}$ no cultivar Guarani, sem e com irrigação, respectivamente. Tais valores foram obtidos no inicio e no final da floração dos cultivares Araguaia e Guarani, respectivamente, e as maiores diferenças da TCC em função dos espaçamentos e das densidades foram atingidas nesse estádio. Independente do uso da irrigação, os valores máximos da TCC do cultivar Araguaia foram observados no espaçamento de $30 \mathrm{~cm}$ com a densidade menor, e no espaçamento de $40 \mathrm{~cm}$ com 150 plantas por $\mathrm{m}^{2}$. No cultivar Guarani, os valores máximos da TCC foram obtidos com o espaçamento e densidade maiores, sem irrigação, e no menor espaçamento e população de 100 plantas por $\mathrm{m}^{2}$, com irrigação.

Do estádio inicial de crescimento das culturas ate a máxima interceptaça da radiaçáo pelas folhas, a TCC aumenta atê um valor máximo em função do IAF. Maior será o rendimento da cultura quanto mais rápido a cultura atingir o IAF máximo, e quanto mais tempo a area foliar permanecer ativa CWATSON, 1952; MACHADO, 1985; EERNARDES, 19873.

A TCi, para uma cultura, pode ser expressa como o produto do IAF pela taxa de assimilação líquida (TAL), ou seja, o IAF pode ser interpretado como um coeficiente de ajuste entre TCG e TAL. Na equação, o IAF 
pode ser substituido pela duração da área foliar (DAF), possibilitando a aplicação da equação por periodos mais longos. Ist.o significa que a taxa de crescimentio ou produção biologica de uma cultura pode ser alterada por fatores que afetam a eficiência ou a dimensão do sistema assimilador CLOOMIS \& WILLIANS, 1969; MACHADO, 1985; MAGALHAES, 1985; EERNARDES; 1987 ).

At.é a floração, as maiores diferenģas encontradas na TCC em runção dos espaçamentos e das densidades de semeadura foram devidas, principalmente, as diferenças no IAF, enquanto que, a partix dai, a TAL (Figuras 9 e 10 ) teve grande influencia nas diferenças obtidas na TCG, pois oscilaram bastante.

O conceito de TAL roi introduzido por ERIGGS et diri $\left(1920_{t}\right)$ A taxa de assimilaça líquida (TAL), também denominada de taxa unitánia da iolna ou taxa de assimilação aparente, demonstra o ganho liquido de assimilados, geralmente fotossintéticos, por unidade de area foliar e tempo. Ela inclui também o ganho em minerais, mas este representa uma fraçäo muito pequena, pois os minerais constituem apenas $5 \%$ ou menos da materia seca total (GAFDNER et airi, 1985). A TAL diminui durante a ontogenese do vesetal, devido ao autossombreamento que provocado pelo aumento do numero e tamanho das follas e pelo ângulo que as folhas fazem com a radiaça so solar incidente. Entretanto, é mostrado nas figura 9 e 10 que, 


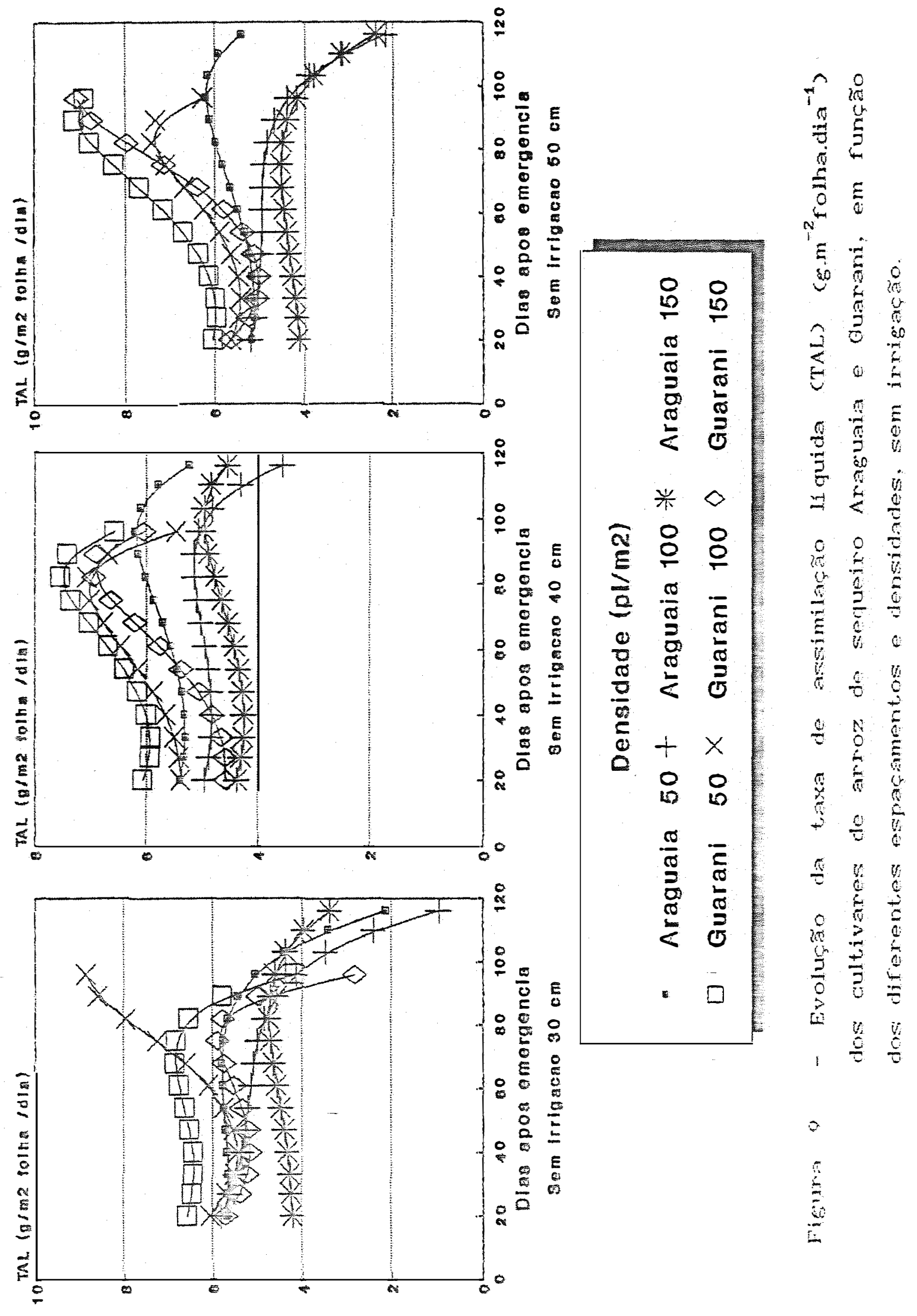




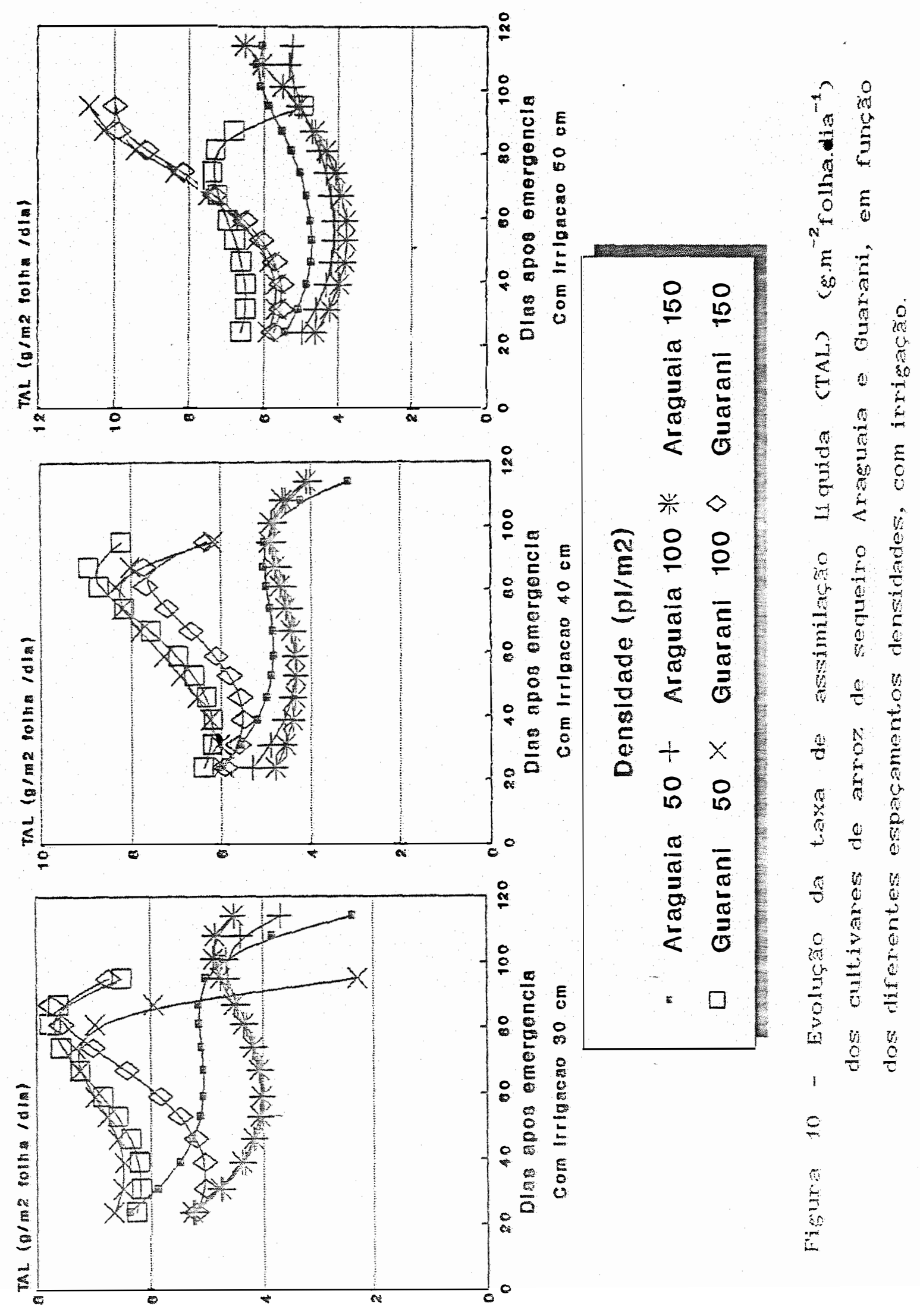




\begin{abstract}
em muitos tratamentos, houve aumento da TAL na fase final de crescimento das plantas de arroz, especialmente no cultivar Guarani. Como a TAL é a relação entre TGC e IAF, os pesultados obtidos se devem à redução do laf após o rlorescimento, em função do autossombreament.o. De modo geral, independente do emprego da irrigagäo e do espaçamento usado, as menores deridades de semeadura propiciaram maiores valores de IAL, até por ocasiäo da noraçă A partir dai, pela razão mencionada, os vesultados tornam-se de dificil conclusão. Assim, verifica-se que a TAL ná foi disetamente relacionada com rendimento de sxãos.
\end{abstract}

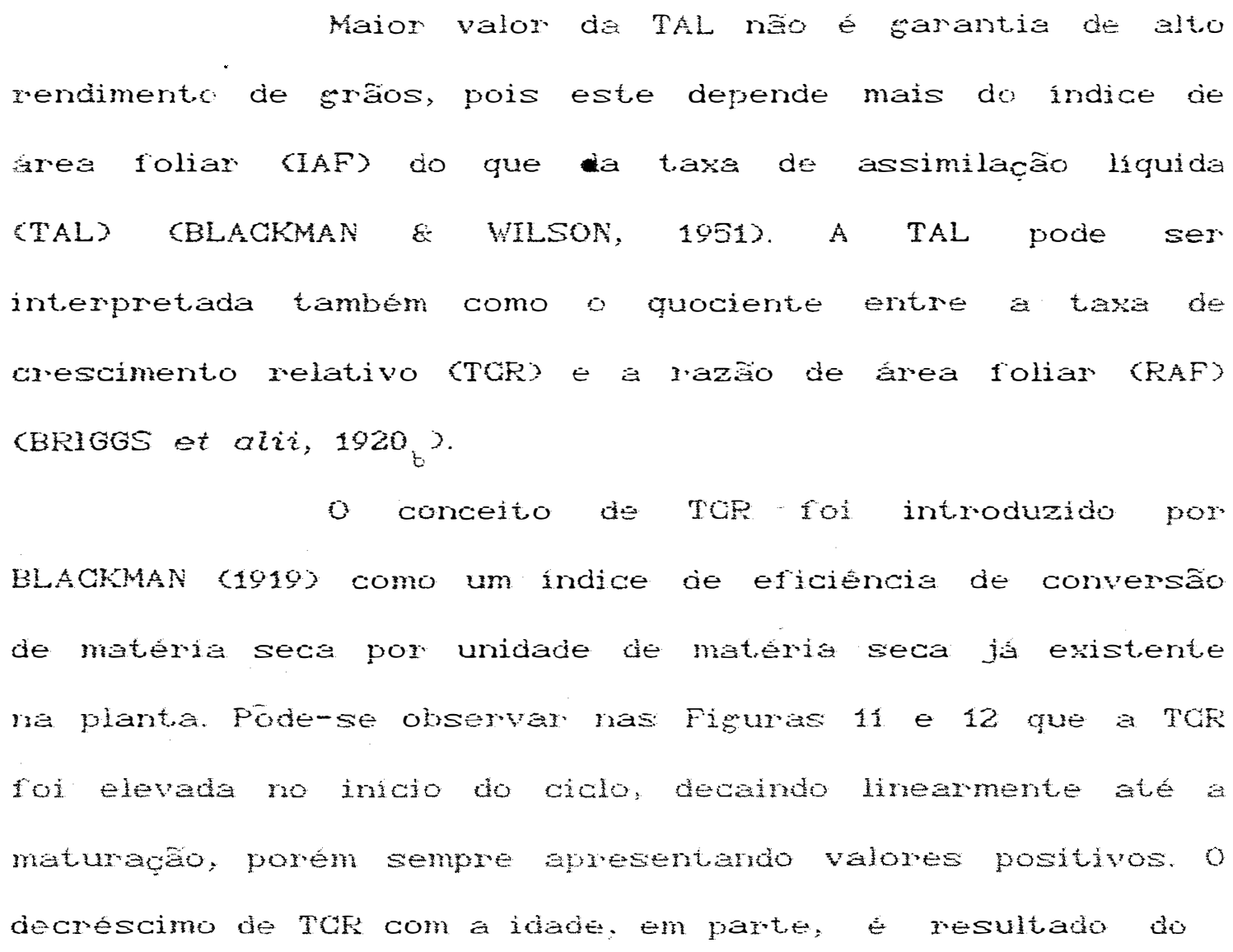



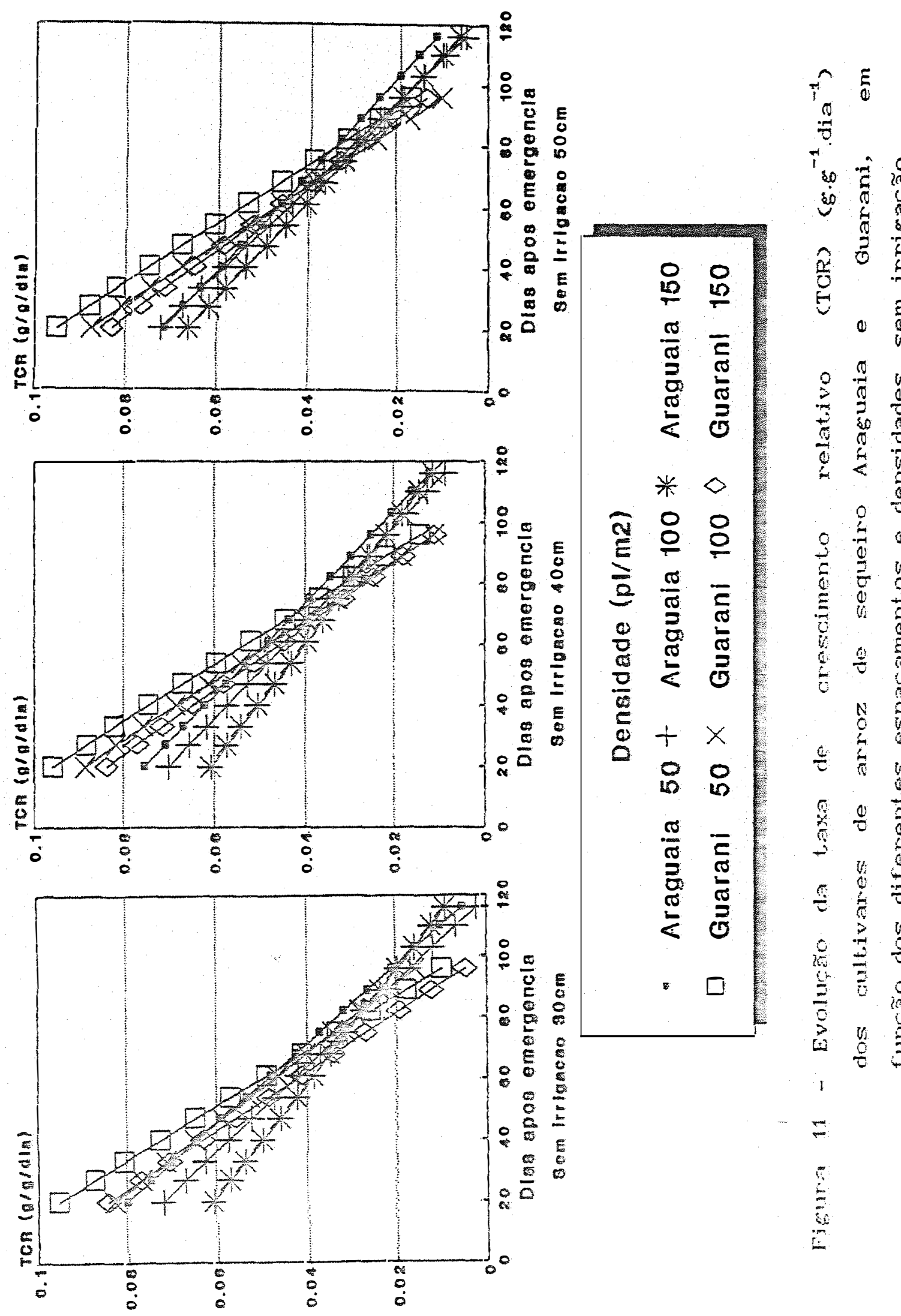

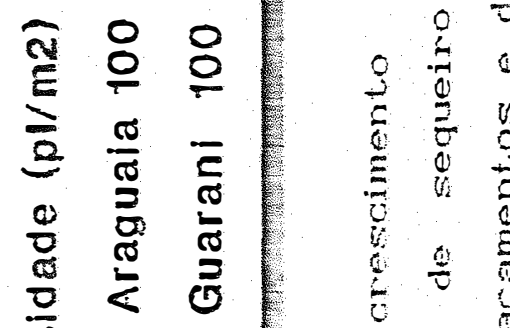
$e_{0}^{\infty}+x$

in 0

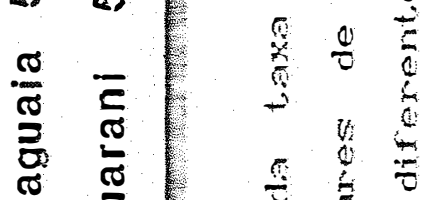

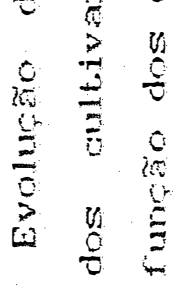

$\frac{5}{5}$ 

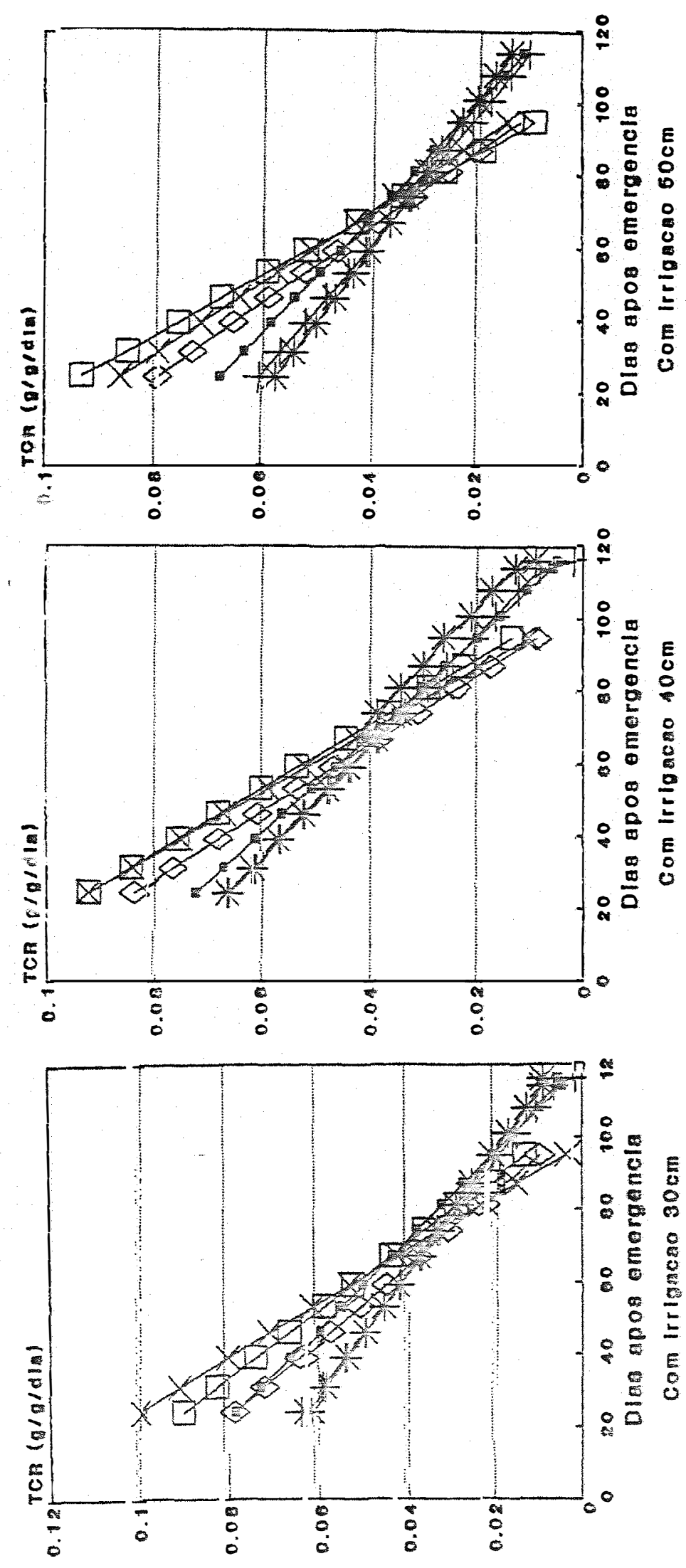

$\frac{y}{0}$

त.

\& 5

$\begin{array}{ll}0 & 0 \\ 2 & 2 \\ \frac{1}{3} & \frac{1}{2} \\ \frac{\pi}{2} & \frac{\pi}{2} \\ \frac{\pi}{2} & 0\end{array}$

E)

$=0$

类 0

$\frac{\pi}{4} \frac{\pi}{6}$

$\begin{array}{lll}3 & 0 \\ 0 & 0 & 0 \\ 0 & 0 & 0 \\ 0 & 0 & 0 \\ 0 & 0 & 0 \\ 0 & 0\end{array}$

$\frac{0}{2}<\frac{5}{5}$

c) $1 x$

12 12

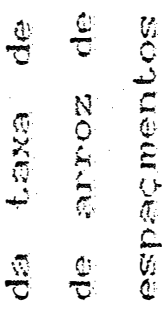

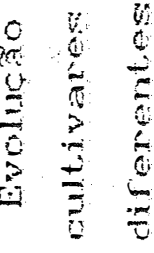

N

5 
aumento gradativo de tecidos não assimilatórios CWILLIAMS, 1946). O comportamento observado parece ser típico de espécies com crescimento tipo determinado. Praticamente, não houve diferenças entre os tratamentos com e sem irrigação, entretant.o o cultivar Guarani apresent.ou maiores valores de TCR, em todos os tratamentos. De modo geral, com as menores densidades obtiveram-se maiores TCR at.é próximo da floração, e as maiores diferenças foram observadas na fase inicial de crescimento das plantas.

A razão de área foliar (RAF) é conceituada como o quociente entre a superficie foliar cárea Iesponsável pela interceptação de energnia luminosa e $\mathrm{CO}_{2}$ ? - a matéria seca da planta (resultado da fotossintese). Ela avalia o esenvolvimentio da área foliar relacionada :om o desenvolvimento da planta toda e expressa a área roliar util para a fotossintese. Ou seja, RAF é a área foliar, em $\mathrm{dm}^{2}$, que estia sendo usada pela planta para produzir 1 grama de matéria seca.

Assim como a TCR, a RAF, que é uma componente morfo-fisiológica, apresentou forte tendencia de decréscimo com a ontogenia das plantas cFiguras 13 e 14. No cultivar Araguaia, quando irrigado, a RAF apresentou declinio pouco acentuado até, aproximadamente, 45 dias apos a emergencia des plantulas, a partir dai, decresceu continuamente até a maturação. O comportamento da RAF no cultivar Guarani foi semelhante ao do cultivar 

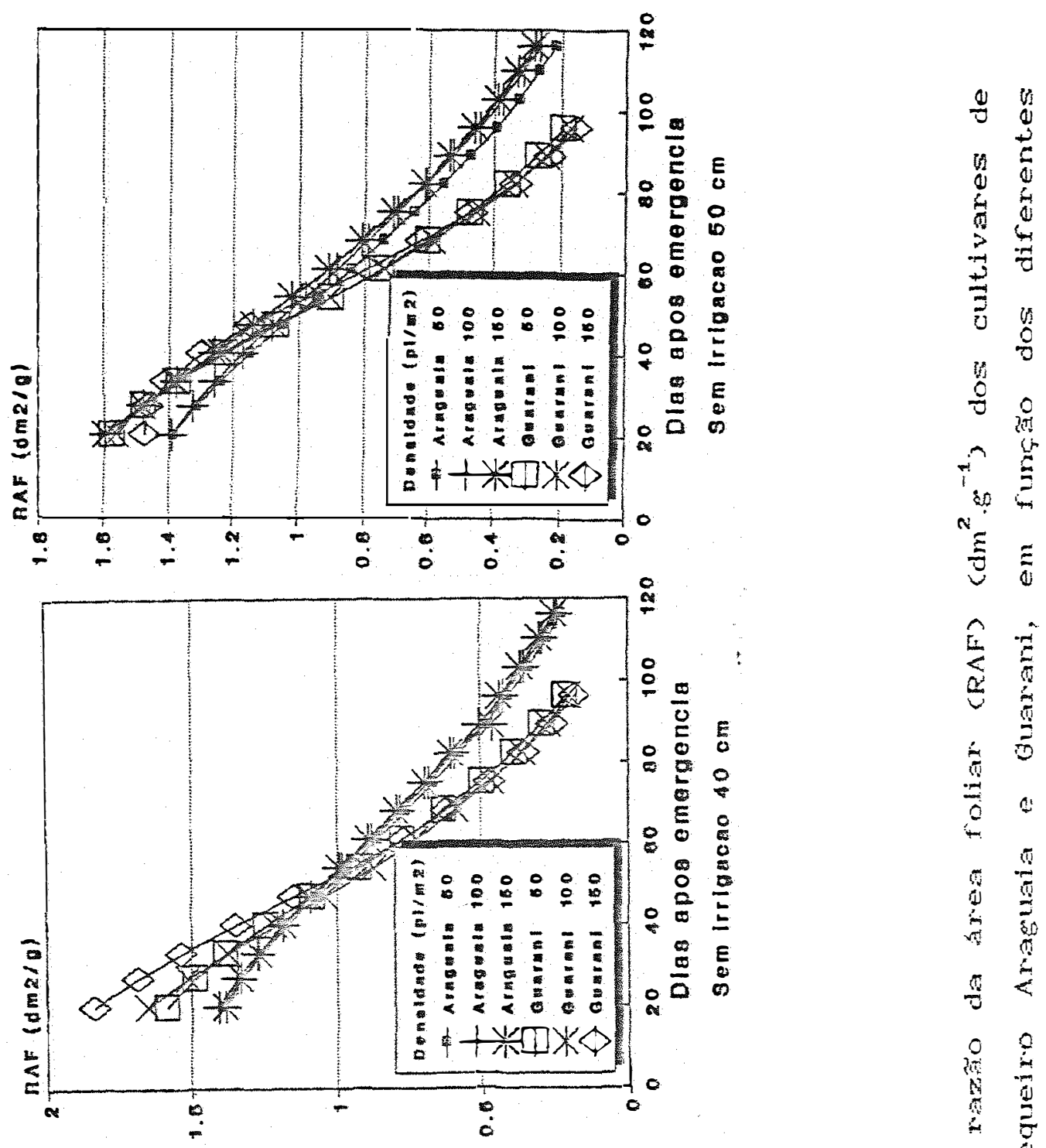

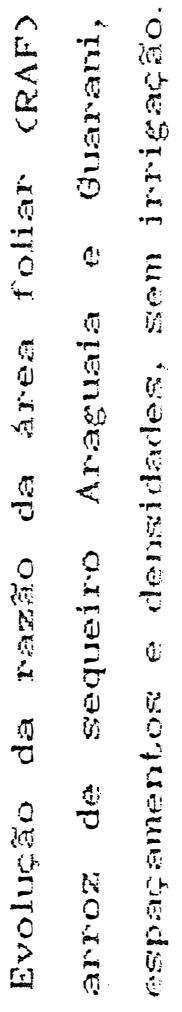
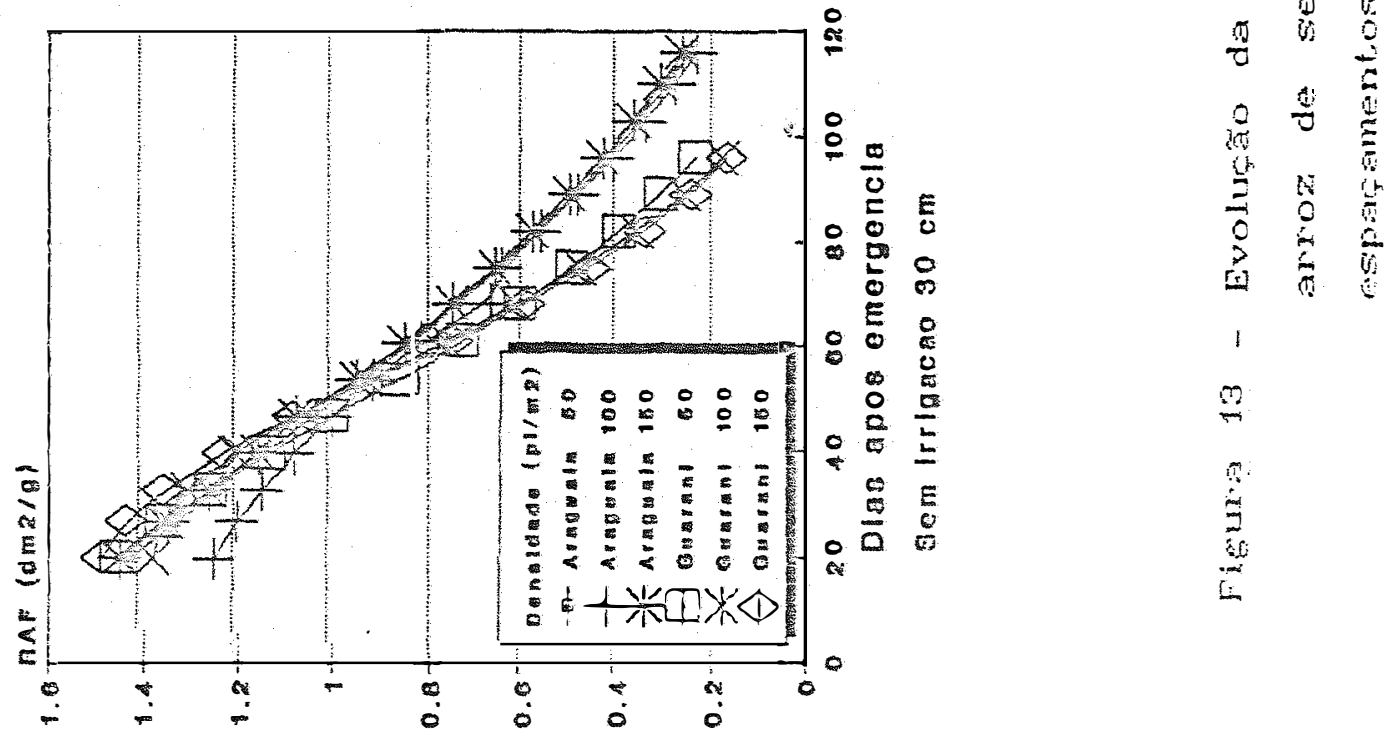

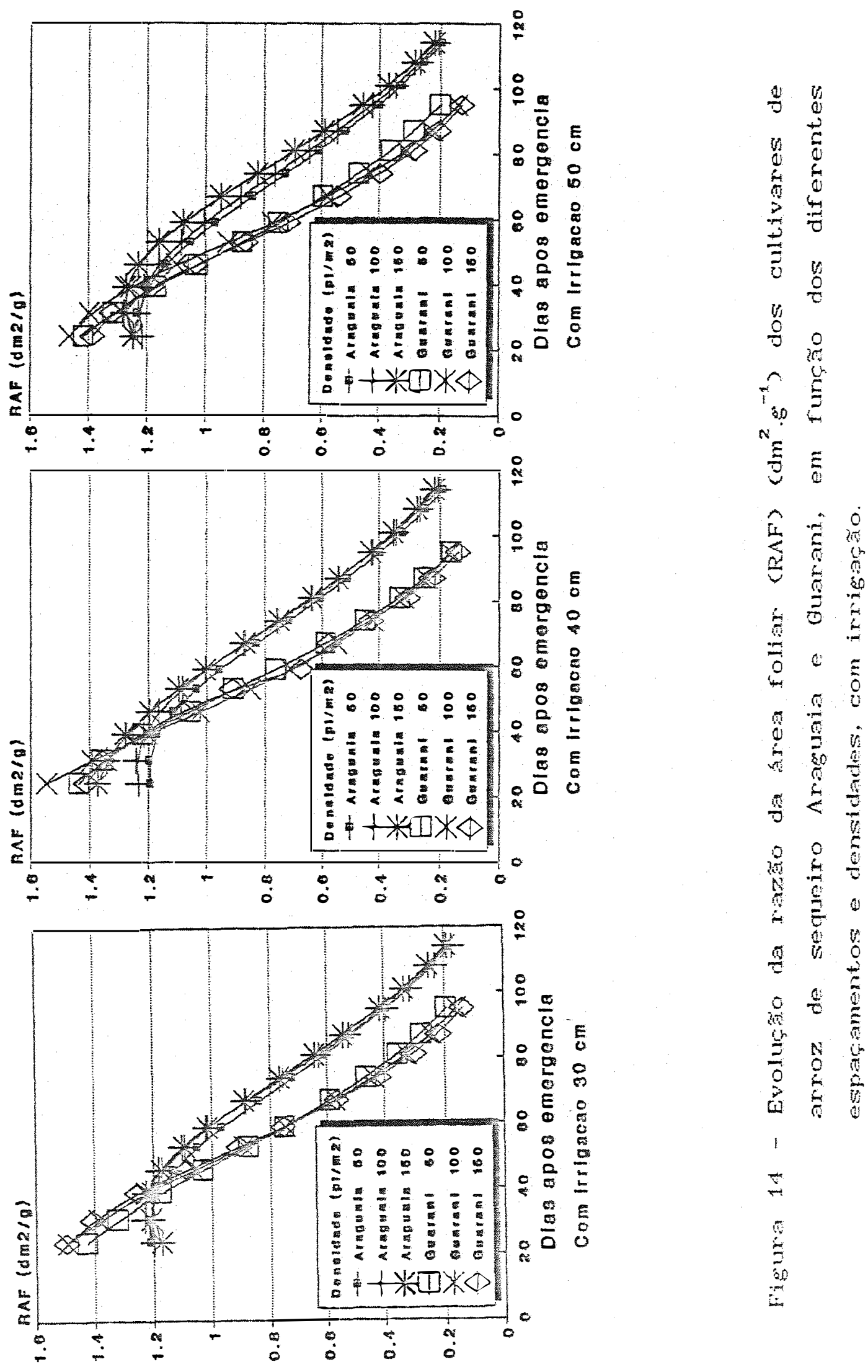

$\stackrel{5}{5}$ 


\begin{abstract}
Araguaia, quando a irrigação não foi empregada, ou seja, houve" decréscimo cradativo desde a fase inicial de crescimento até o final do ciclo.
\end{abstract}

As populações de plant,as praticamente influenciaram o comportamento da RAF apenas nos estádios iniciais de crescimento. O cultivar Guarani apresentou, nestes estádios, RAF superiox ao Araguaia. Os maiores valores da RAF no cultivar Araguaia foram obtidos no espaçamento de $50 \mathrm{~cm}$, enquanto que no cult.ivar Guarari no de $40 \mathrm{~cm}$, ambos na população de 150 plantas por $\mathrm{m}^{2} \mathrm{e}$ sem o emprego da irrigação. O decréscimo observado na RAF, à medida que a plant.a cresce, se deve à interferência das folhas superiores sobre as inferiores, ou seja, aut.ossombreament.o e a tendência da área foliar útil para a fotossintese diminuir a partir de certa fase. isto é observado mais facilmente no cultivar Araguaia nas condiģes irrigadas a partir des 45 diss apos a emenostencia das plântulas (Figura 14). A méxima RAF no início do ciclo das plantas indica que inicialmente a maior parte do material fotossintético foi corvertido em folla, visando maior captạ̧ão da xadiạ̣̄̃o solar disponivel. Posteriormente, houve aumento da biomassa não jötossintetizante, ocasiorando decréscimo də RAF.

$$
\text { A taxa de crescimento foliar relativo }
$$

(TCFR), usada por BUTTERY (1969) e BUTTERY \& BUZZELL (1972), avalia o relativo crescimento da parte área da 
planta, em lermos de área foliar formada por unidade de tempo, correlacionada à área foliar inicial. A TCFR também declinou linearmente com a idade das plantas, atingindo valores negativos em t.odos os tratamentos cFiguras 15 e 163. Com o emprego da irrigação, o decréscimo de TCFR foi mais acentuado em ambos cultivares. Assim como a TGR, houve uma tendência de TCFR estar inversamente relacionada com a densidade de semeadura. No cultivax Araguaia, os espaçamentos mais amplos proporcionaram menores reduções nas TCFR durante o crescimento das plantas. Maiores diferenças na TCFR na fase inicial de crescimento são verificadas no cultivar Araguaia, especialmente nos menores espaçamentos.

A altura de plantas determinada por ocasião da colheita, somente foj influenciada pelos tratamentos no cultivar Guarani, quanòo a irrigação foi empregada cTabela 4). A aitura de plantas reduziu linearmente com o aument.o da densidade (Tabela 9). Isto mostra que em densidades maiores o cultivar Guarani apresentou pequena dominância apical e consequentemente maior perfilhamento. 0 acamamento das plantas dos cultivares de arroz de sequeiro é relacionado à população de plantas por área e ̇̀ altura das mésmas. Entretanto; neste trabalho näo roi possivel determinar a influência dos espạamentos e das densidades sobre o acamamento, pois apenas algumas plantas de cultivar Guarani apresentaram pequeno acamamento, por 

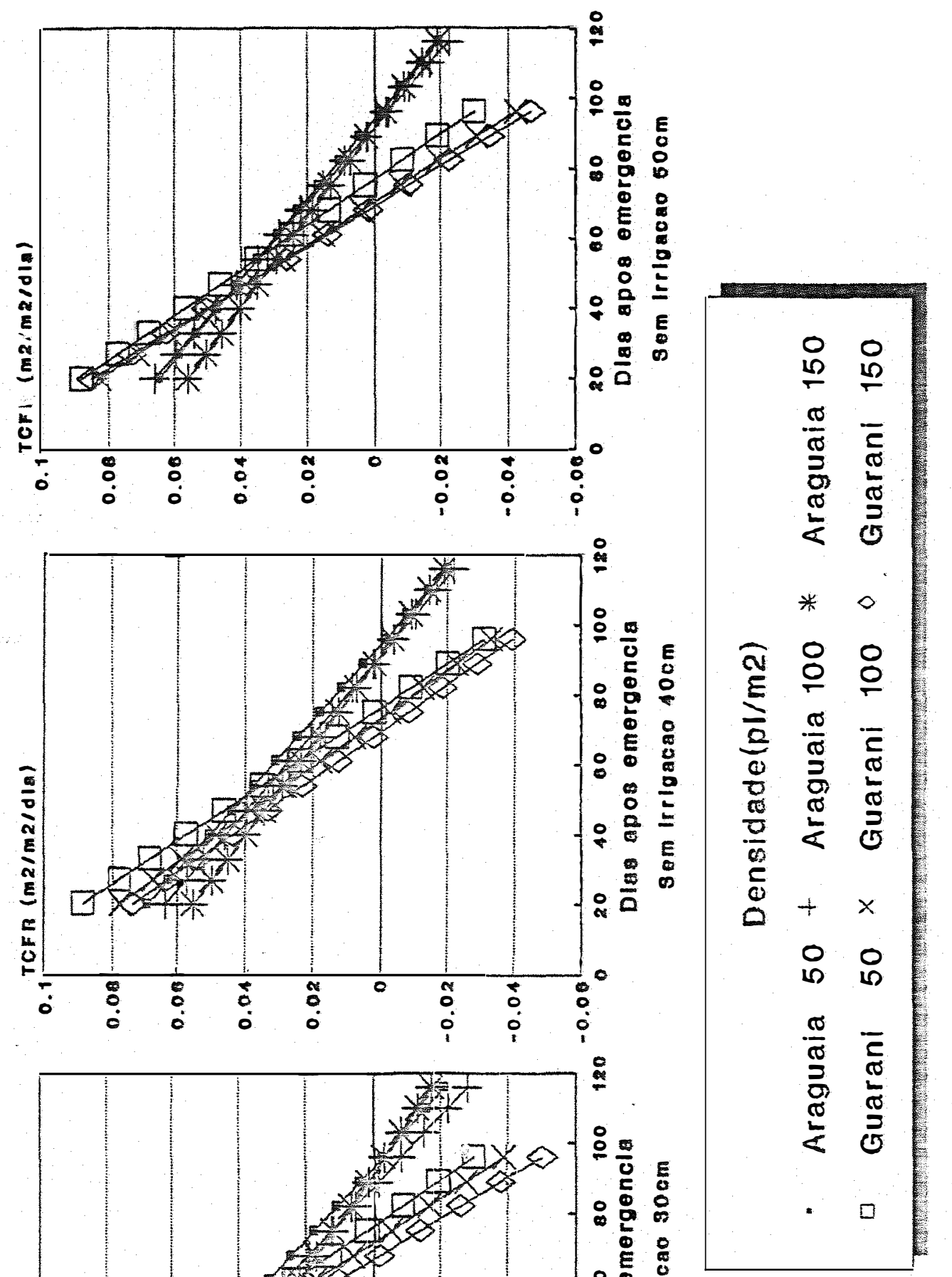

${ }^{n} \frac{E}{6}$

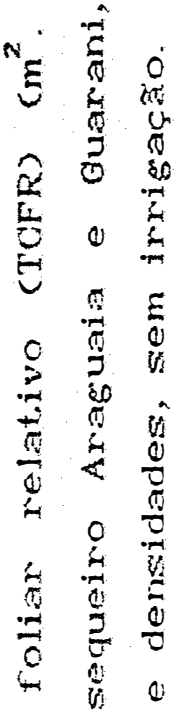

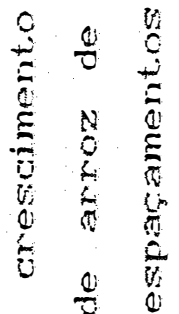

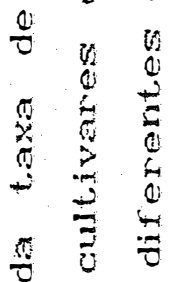

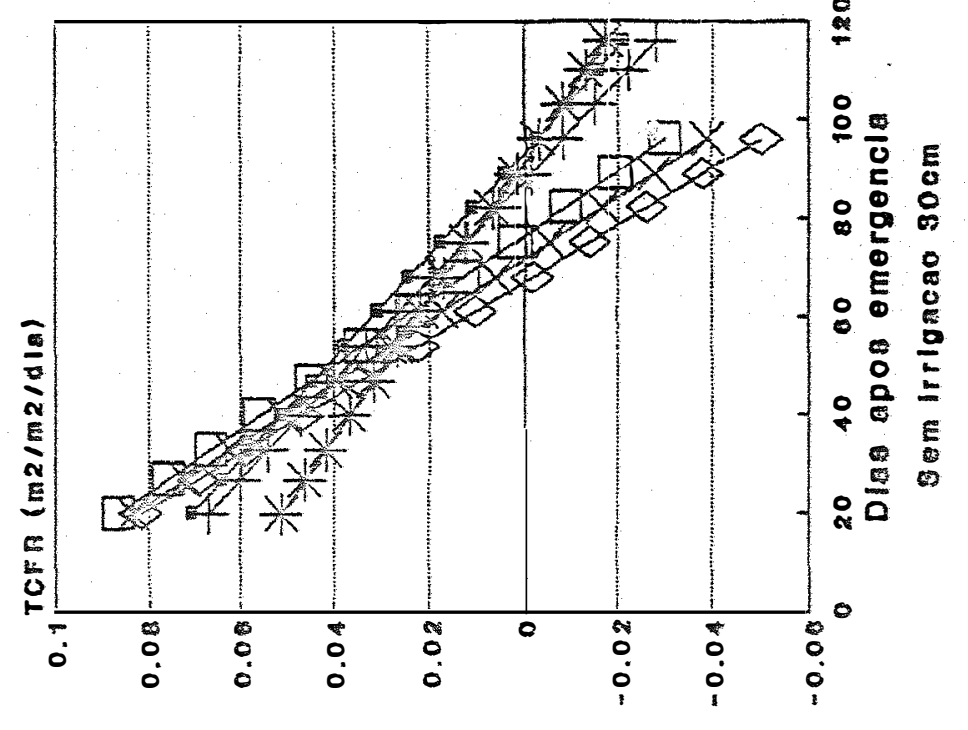

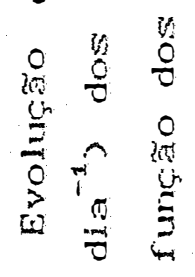

in

5 

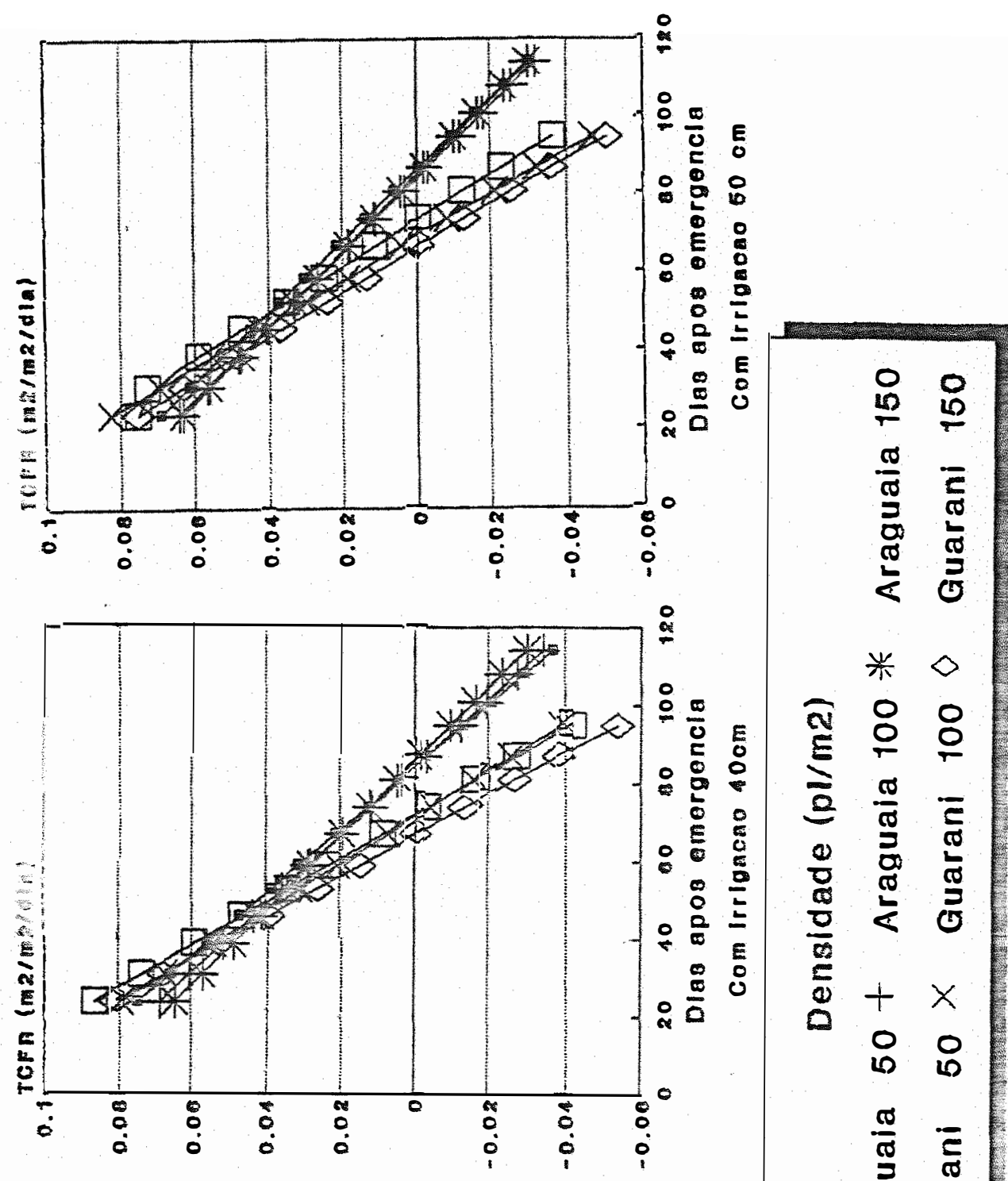

$\stackrel{2}{\frac{1}{2}}$

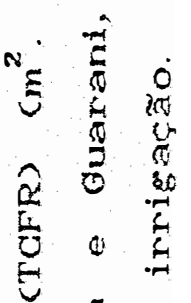

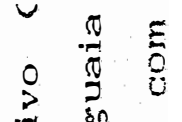

$\rightarrow$ \&

$\frac{+\pi}{2} \sum_{2}^{\frac{\pi}{2}}$

$\rightarrow$ O

* 0

$\stackrel{\pi}{=}=$

촐 웅

$=0$

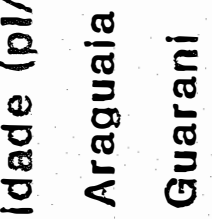

$+x$

$\begin{array}{ll}+ & x \\ 0 & 0 \\ 0 & 0\end{array}$

$\begin{array}{lll}0 & 0 & 0 \\ c & 0 & 0 \\ 0 & N & 0 \\ 0 & 0 & 0 \\ 4 & 0 & 0 \\ 0 & 0 & 0 \\ 0 & 0 & 0 \\ 0 & 0 & 0\end{array}$

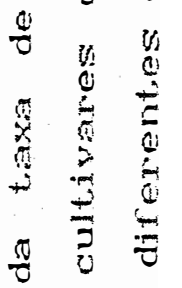

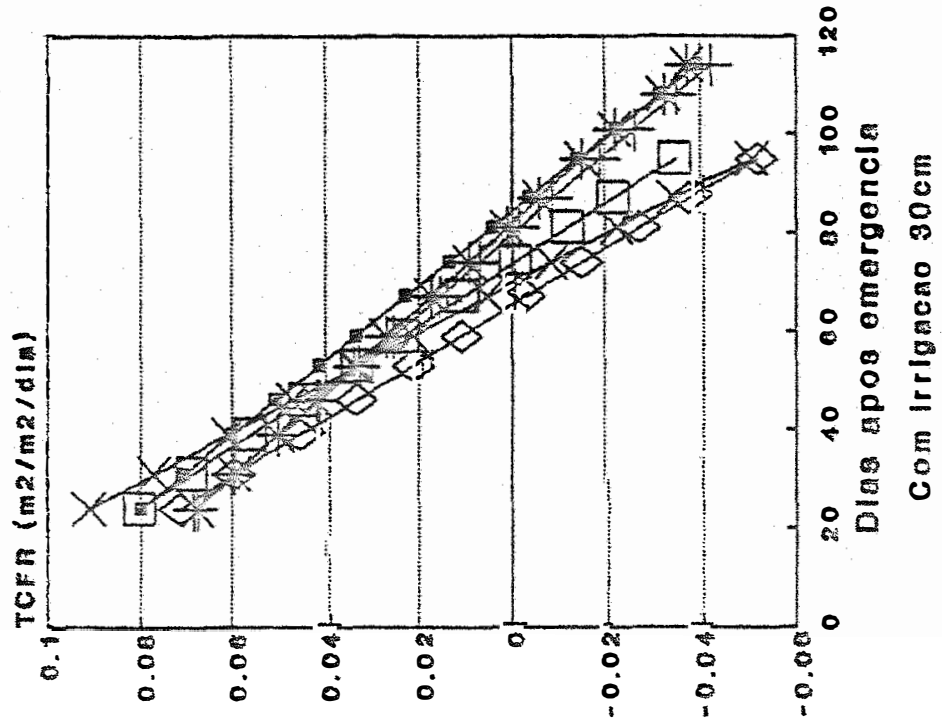

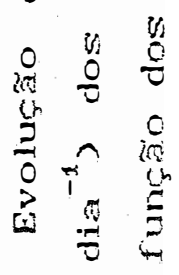

0

$\frac{7}{5}$ 
ocasião da colleita, especialmente no experimento irrigado.

o número de perfillo por $\mathrm{m}^{2}$ do cultivar Guarani. foi influenciado significat.ivamente pelos espaçamentos e pelas densidades de semeadura. enquanto que no cultivar Araguaia houve efeito significativo da interação entre espaçamento e densidade, quando a irrigação não foi empregada e, apenas das densidades, nas condições irrigadas (Tabela 4). 0 número de perfilhos do cultivar Guarani reduziu linearmente com o aumento dos espaçamentos, independent,e das condiçöes serem irrigadas CTabela 92. Quanto às densidades, as respostas foram quadráticas, sendo o menor perfilhamento estimado com 68 plantas por $\mathrm{m}^{2}$, quando a irrix̧ação não foi usada e um maior perfihliment.o com a população de 122 plantas por $\mathrm{m}^{2}$, com irrigação.

$$
\text { Na análise. conjunta, a interação entre }
$$

espaçamento e densidade influenciou significativamente o número de perfiltos por $m^{2}$ do cultivar Araguaia, ao passo que no cultivar Guaxani os efeitos desses tratameritos foram independentes (Tabela 5). Desdobrando-se o efeito da in

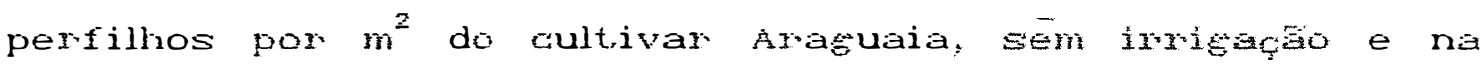
análise conjunta, veririca-se na Tabela 10 que no menor espacament.o o aumento da densidade de semeadura resultou em respostia quadrática, sendo os menores perfilhament.os 


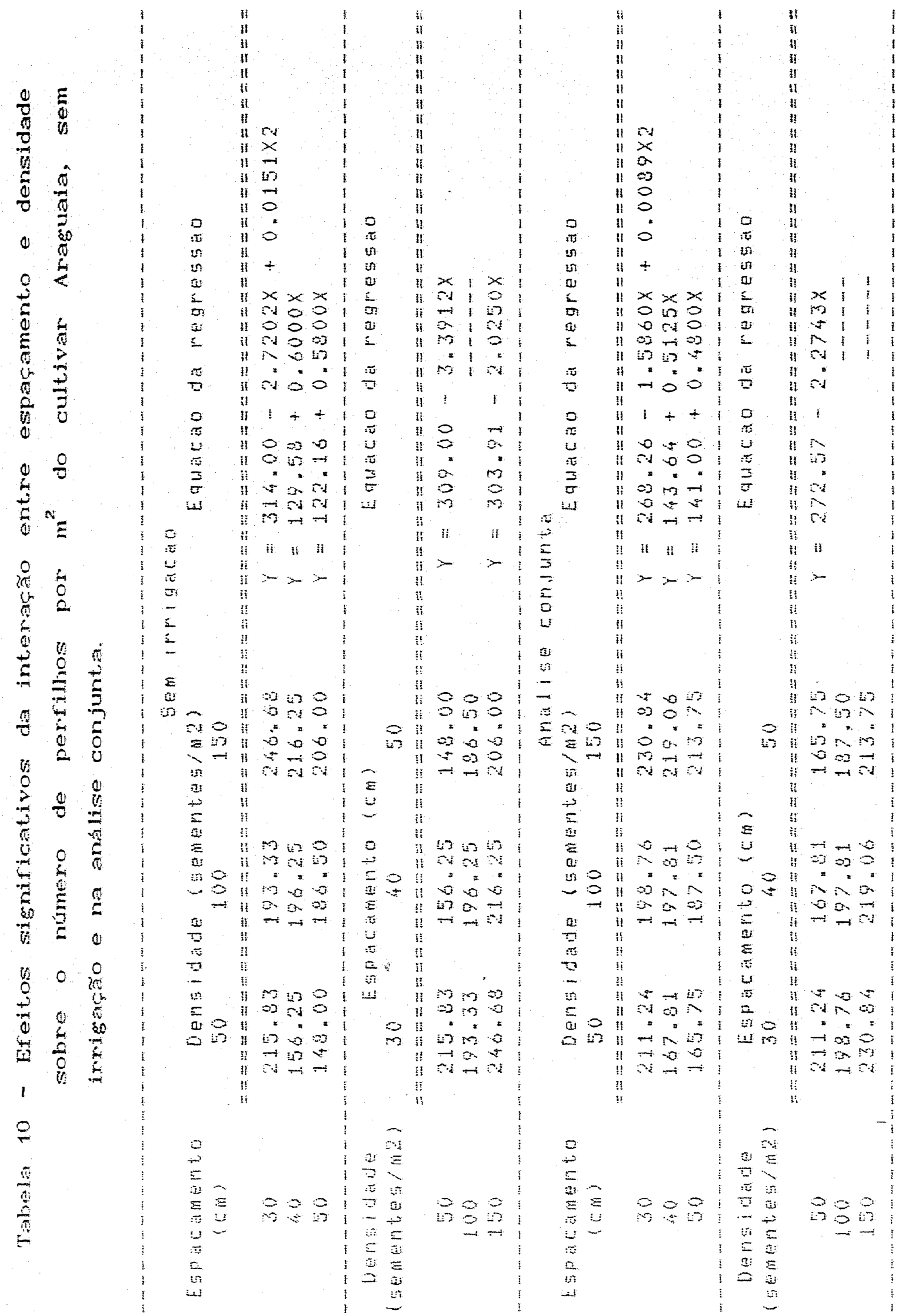




\begin{abstract}
estimados com 90 plantas por $\mathrm{m}^{2}$. Erquanto que nos espaçamentos maiores houve aumento linear do número de perfilhos à medida que as densidades aumentavam. Observa-se também que não se empregando a irrigração, o número de perfilhos declinou linearmente nas populações de 50 e 150 plantas por $\mathrm{m}^{2}$ com o aumento dos espaçamentos, ao passo que, na análise conjunta, esses efeitos só se verificaram na densidade menor.
\end{abstract}

Nas Figuras 17 e 18, acham-se as determinações do número de perfilhos por $\mathrm{m}^{2}$ dos dois cultivares, em função dos tratamentos, realizadas ao longo de todo o ciclo. Verificou-se que o numero de perfilhos de ambos cultivares, por ocesião da colheita, é reduzido à medida que o espaçamento aumenta e a densidade é diminuida. Iniciaimente, as diferenças no perfilhamento são grandes e, posteriormente são reduzidas com a idade das plantas, até se estabilizarem proximo do ilorescimento. Esse estudio é firequentemente denominado de perfilhamento efetivo ou útil. Nesta ocasião, o IAF e a TCC são máximos, havendo, a partix daí, šrande influência do autossombreamento. Nas densidades menores: 0 pextilhamento aumentou até este periodo, enquanto gue nas maiores densidades o perfilhamento é máximo na taixa de 35 $\Rightarrow 45$ dias e, posteriormente tendeu $\Rightarrow$ reduzir, indicando que muitos perilhos morrem antes de completrarem o ciclo. 0 decréscimo no perfihamento é devido à competição por 
.66.

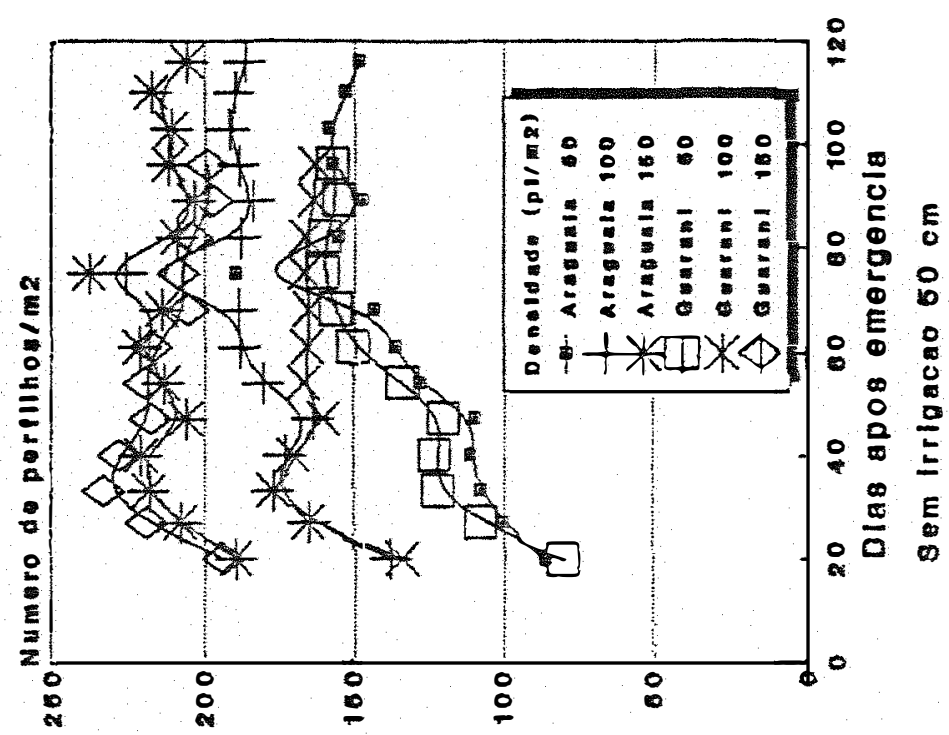

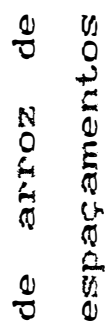

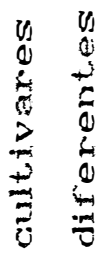

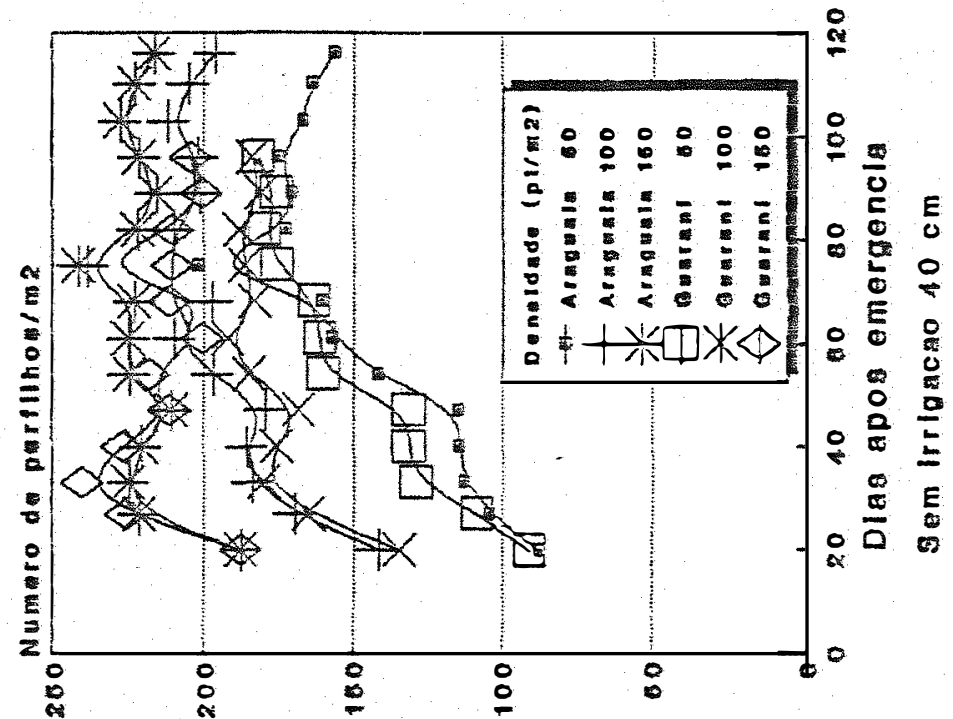

y
0
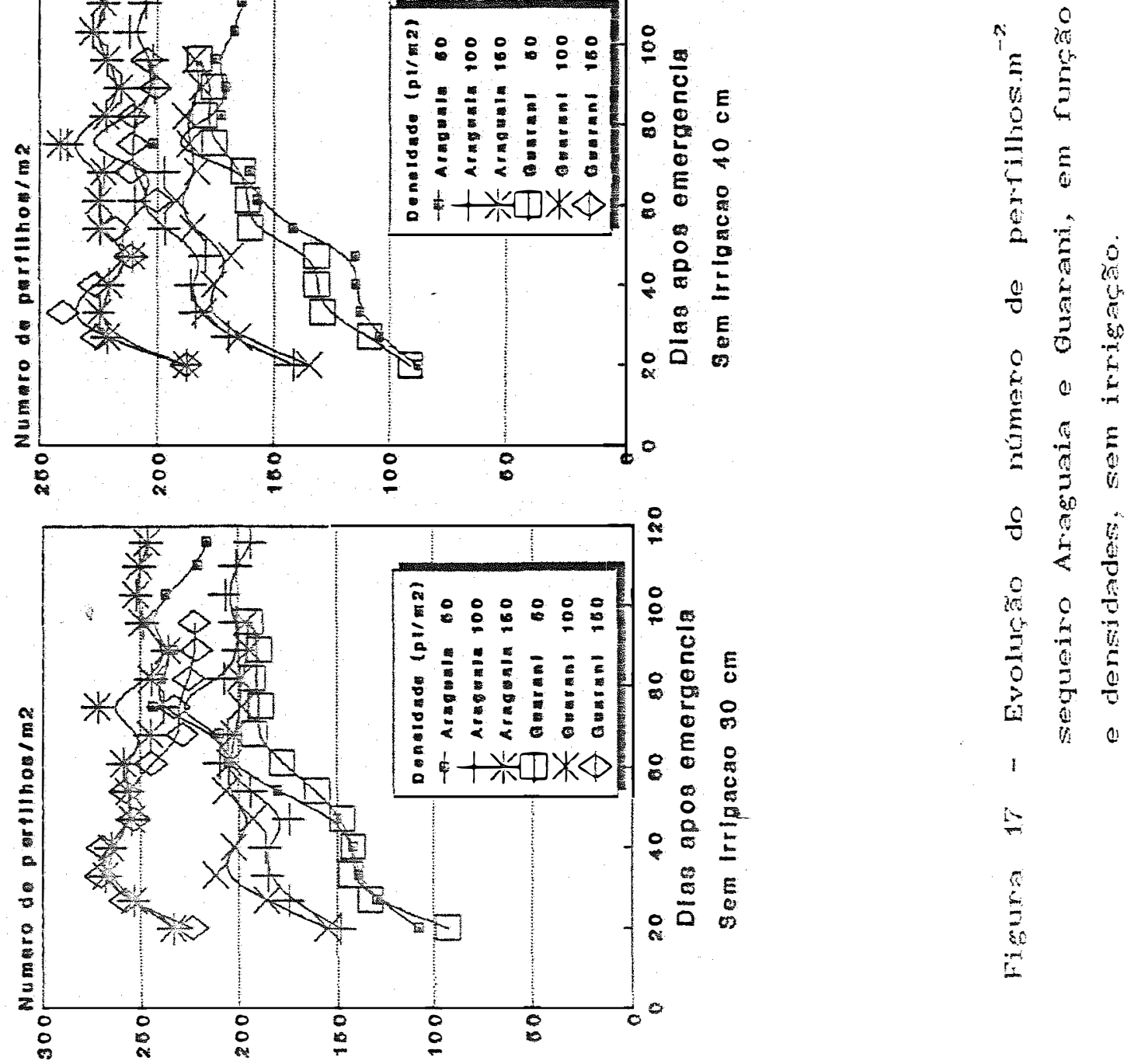

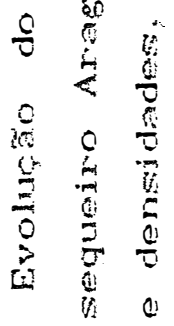

8 

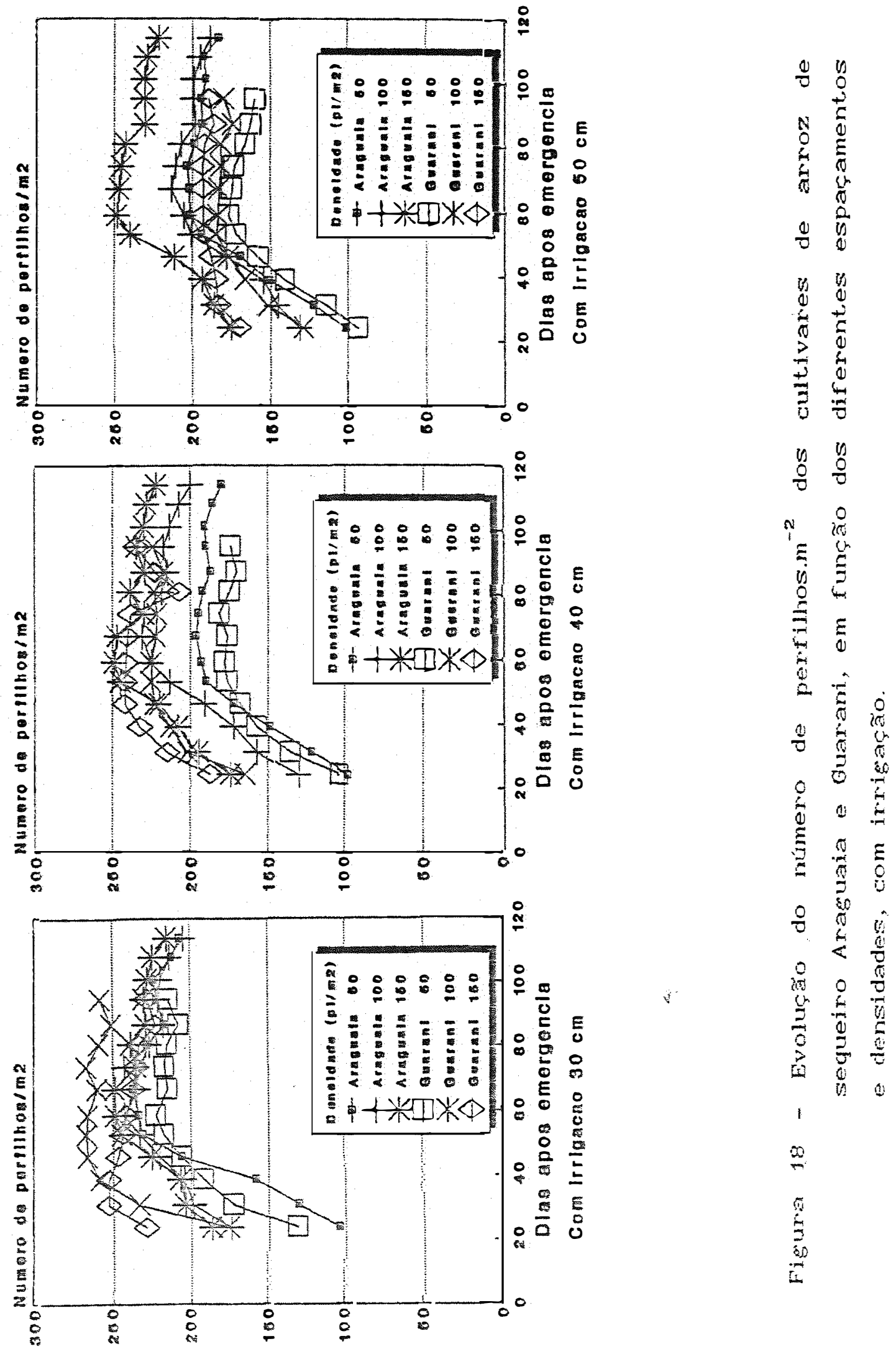


\begin{abstract}
luz e nutrientes, causando a morte de alguns perfilhos que emergiram mais tarde (ISHIZUKA \& TANAKA, 1963 ). Entretanto, o aumento do número de perfilhos verificado nas menores densidades não é suficiente para garantir maiores rendimentos de grãos, pois nestas menores populações de plantas são observados menores valores nos componentes do rendimento. Além disso, conforme as observações de GASTAL (1974) e de SOARES et alii (1979), a população de plantas aquém da ideal favorece a formação de perfilhos improdutivos. Isto ocorre em virtude de períilhos que se desenvolvem tardiamente podem não produzir panículas ou apresentar paniculas com número de espiguetas e massa de grãos menores.
\end{abstract}

Como o índice de área T̃oliar na cultura do arroz é determinado pela multiplicação da área foliar media de um perfilho, em $\mathrm{m}^{2}$, pelo número de perrihhos por $\mathrm{m}^{2}$, observa-se nas figuras $4,5,17$ e 18 que 0 segundo componente teve maior influéncia na determinação do IAF. Esse resultado apresentáa discordancia daqueles obtidos por CHANG et alii (1972) que relatam que esta arirmativa válida para os cultivares semi- anãos, altamente pextilhadores.

MURATA $(1969)$ expressa i capacidade
produtiva ou potencial de produção em cereais como o
produto dos sesuintes componentes: o numero de paniculas
por $\mathrm{m}^{2}$, o numero de espiguetas por panicula e o tamamo


potencial do grão. Segundo PINHEIRO et alii (1985), a importáncia relativa dos componetes do rendimento sobre o rendimento de grãos não $e$ a mesma em condições distint.as de regime hidrico.

Houve efeito significativo do espaçament.o e da densidade sobre o número de paniculas por $\mathrm{m}^{2}$ no cultivar Guarani e apenas do espaçamento, no cultivar Araguaia, sem irrigação (Tabela 4). Com o aumento do espaçamento, houve redução linear no número de panículas nos dois cultivares, independente do empreso da irrigação. - número de panículas do cultivar Guarani cresceu linearmente com o aumento da densidade, quando a irrigação não foi usada, e apresentou resposta quadrática, quando esta foi empregada, sendo máximo o valor estimado com a população de 120 plantas por $\mathrm{m}^{2}$ (Tabela 9). Os efeitos dos espaçamentos sobre o número de panículas por $m^{2}$ estão de acordo com os obtidos por SANTOS et alii (1988), porém apresentam discordância quanto à influéncia das densidades de semeadura. Os efeitos dos espaçamentos e das densidades sobre est.e componente de rendimento foram maiores no cultivar Guarani que no Araguaia. Quando o espaçament.o ĩoi aumentado em $10 \mathrm{~cm}$ houve redução de 11 e 26 panículas no cultivar Guarani, sem e com irrigação, respectivamenté. Nesse cultivar hí incremento de 70 paniculas quando se aumenti a populaçăo em 100 plantas por $\mathrm{m}^{2}$, nas condiçöes não irrigadas (Tabela 9$)$. 
Na ausência de deficiencia hídrica, PINHEIRO et alii (1985) verificaram que o número de paniculas por $\mathrm{m}^{2}$ foi uma das caracteristicas que melhor correlacionou com o rendimento de grãos de 49 cultivares de arroz.

Observourse, na análise conjunta CTabela 5), que o número de panículas do cultivar Araguaia foi influenciado significativament,e pelo espaçamento e pela densidade, enquanto que no cultivar Guarani houve também efeitos das interações entre irrişaçăo e espaçament.o e entre irrigação e densidade. As análises de rescressão mostraram que houve correlaçăo linear nesat,iva entre o espaçamento e o numero de paniculas por $\mathrm{m}^{2}$ e lirear e positiva, com as densidades de semeadura (Tabela 7). Na análise conjunta, verifica-se também que o efeito da densidade sobre o número de paniculas é maior no cultivar Guarani, havendo incremento de 50 paniculas por $\mathrm{m}^{2}$, quando se aumenta a população em 100 plantas por $\mathrm{m}^{2}$, enquanto que com o mesmo aumento da densidade o incremento foi de 14 panículas no cultivar Araguaia CTabela 73.

o número de Exãos por panícula somente foi influenciado pela densidade de semeadura no cultivar Guarani, tanto nas análises individuais como na conjunta (Tabelas 4 e 5). Houve correlaçäo linear negativa entre as densidades e o número de grãos por parícula CTabela $?$ e 9). Resultados semelhantes foram obtidos por SANTOS et 
alii (1988) com cultivar precoce. Identificando os componentes do rendimento, através dos quais o IAF exerce influência sobre o rendimento de grãos de arroz de sequeiro, PINHEIRO et alii (1990) observaram que o numero de grãos por panícula associou-se com o rendimento com maior coeficient.e de correlação, na ausência de deficiência hídrica.

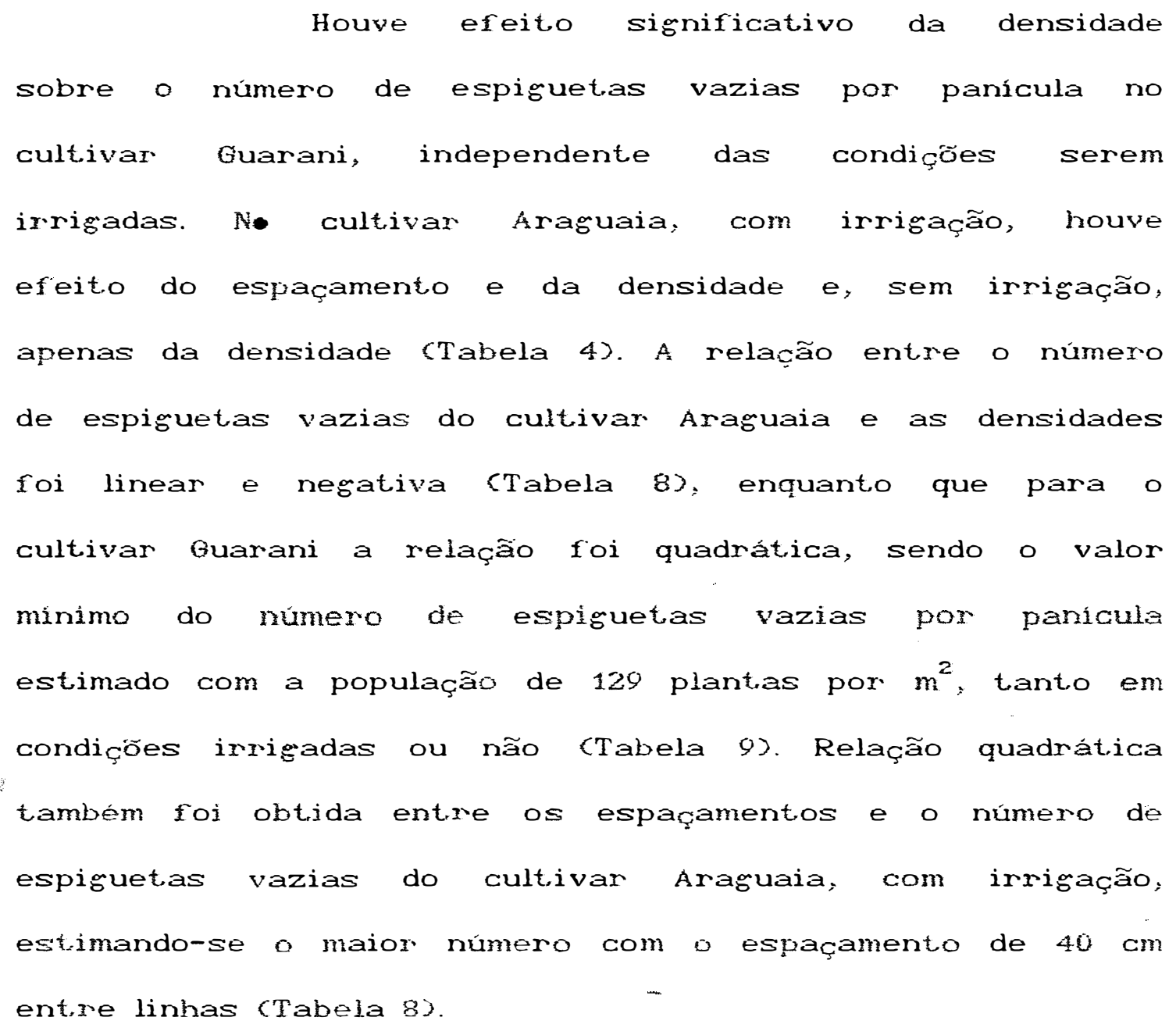

A densidade de semeadura influeraciou significativamente a massa de 100 gräros do cultivar Araguaia, com irrigaçäo, e do cultivar Guarani, sem 
irrigação (Tabela 4). A relação entre a densidade e a massa de 100 grãos foi linear positiva para o cultivar Araguaia (Tabela 8) e quadrática para o Guarani, estimando-se a maior massa de 100 grãos com a população de 125 plantas por $\mathrm{m}^{2}$ (Tabela 9 ).

Na análise conjunta, a massa de 100 grãos do cultivar Araguaia foi influenciada pela interação entre irrigação e densidade. Para o cultivar Guarani houve efeito da densidade, bem como da interação entre irrigação e densidade (Tabela 5). A análise de regressão (Tabela 7) indicou que houve efeito quadrático da densidade sobre a massa de 100 grãos do cultivar Guarani, havendo maior massa com a população de 110 plantas por $\mathrm{m}^{2}$. No estudo desenvolvido por PINHEIRO et airi (1985), a massa de 100 grãos foi correlacionada positivamente com o rendimento de grãos apenas em condições de déficit hídrico.

Em condiçôes de menor disponibilidade de ásua às plantas; 0 indice de colheit.a (IC) foi influenciado significativamente pelo espaçamento, no cultivar Araguaia, e pela densidade, no cultivar Guarani (Tabela 4). A relação entre o espaçamento e o IC no cultivar Araguala foi linear e positiva (Tabela \&). Resultado semelhante foi obt.ido no cultivar Guarani na relação entre este indice e a densidade de semeadura (Tabela 9).

As interaçōes entre irrigação e espaçamento 
e entre irrigação e densidade afetaram o IC do cultivar Araguaia e Guarani, respectivamente, na análise conjunta (Tabela 5).

O Indice de collieita (IC) expressa a eficiência da translocação dos produtos da fotossintese para as partes economicamente importantes da planta. Segundo DONALD \& HAMBLIM (1976), o sucesso do aumento de rendimento de grãos em cereais, especialmente arroz trigo, está relacionado com os maiores IC dos cultivares modernos, com pequena variação no rendimento biológico, em comparação com os cultivares tradicionalmente usados pelos agricultores. CHANLER JUNIOR (1969) menciona que, enquanto os cultivares tradicionais de arroz irrigado apresentam IC de 0,23 a 0,37 ; 0 IC dos cultivares modernos de alto rendimento varia de 0,47 a 0,57 . Neste trabalho, os IC dos cultivares Araguaia e Guarani variaram de 0,37 a 0,54 e 0,34 a 0,37 para as condições não irrigadas e irrigadas, respectivamente. 0 cultivar Guarani por apresentar maior crescimento inicial, porte mais alto, folhas mais longas e decumbentes, perfilhos mais abertos, mostrou-se mais competitivo que o cultivar Araguaia, expressando um menor IC, tanto em condiçōes irrigadas como sem irrigação. Segundo JENNINGS \& JESUS (1968), plantas mais competitivas investem mais na produção de colmos e folhas, e menos em grãos; portanto apresentam menor indice de colreita. 
MURATA \& MATSUSHIMA (1975) mencionam que havendo deficiencia hídrica no inicio da formação da panicula, na divisão de redução ou no florescimento, o rendimento de śrãos é reduzido por falta de espiguetas férteis, mesmo que a fotossintese na fase de amadurecimento se realize em condições ótimas. Nesta situação, o indice de colheita cai e boa part.e dos carboidratos permanece nas folhas e colmos da planta. Por ser de ciclo médio, o cultivar Araguaia foi mais influenciado pela deficiência hídrica que o Guarani, com isso apresentou maior variação no IC, quando se compara as condições irrigadas com as sem irrigação.

$\mathrm{Na}$ Figura 19, encontram-se as relações entre IC e rendimento de grãos. Nas análises individuais, a análise de regressão mostrou efeito significativo apenas no cultivax Guarani, em condiçত̃es não irrigadas, no qual houve relação linear e positiva entre o IC e o xendimento de grãos. Isto mostra que para o cultivar de ciclo curto aument.ando-se o IC, ou seja, maior eficiência na t.ranslocação dos produtos da fotossintese para os grãos, há incremento na produgão de grãos. O que ratifica os resultados obtidos por diversos pesquisadores CDONALD, 1968; JENNINGS \& AQUINO, 1968; SING \& STOSKOPF; 1971; DONALD \& HAMBLIM, 1976), os quais indicam que o sucesso no aumento do rendimento de srãos em cereais estáa relacionado com os maiores indices de colheita. $\mathrm{Na}$ arálise conjunta, 


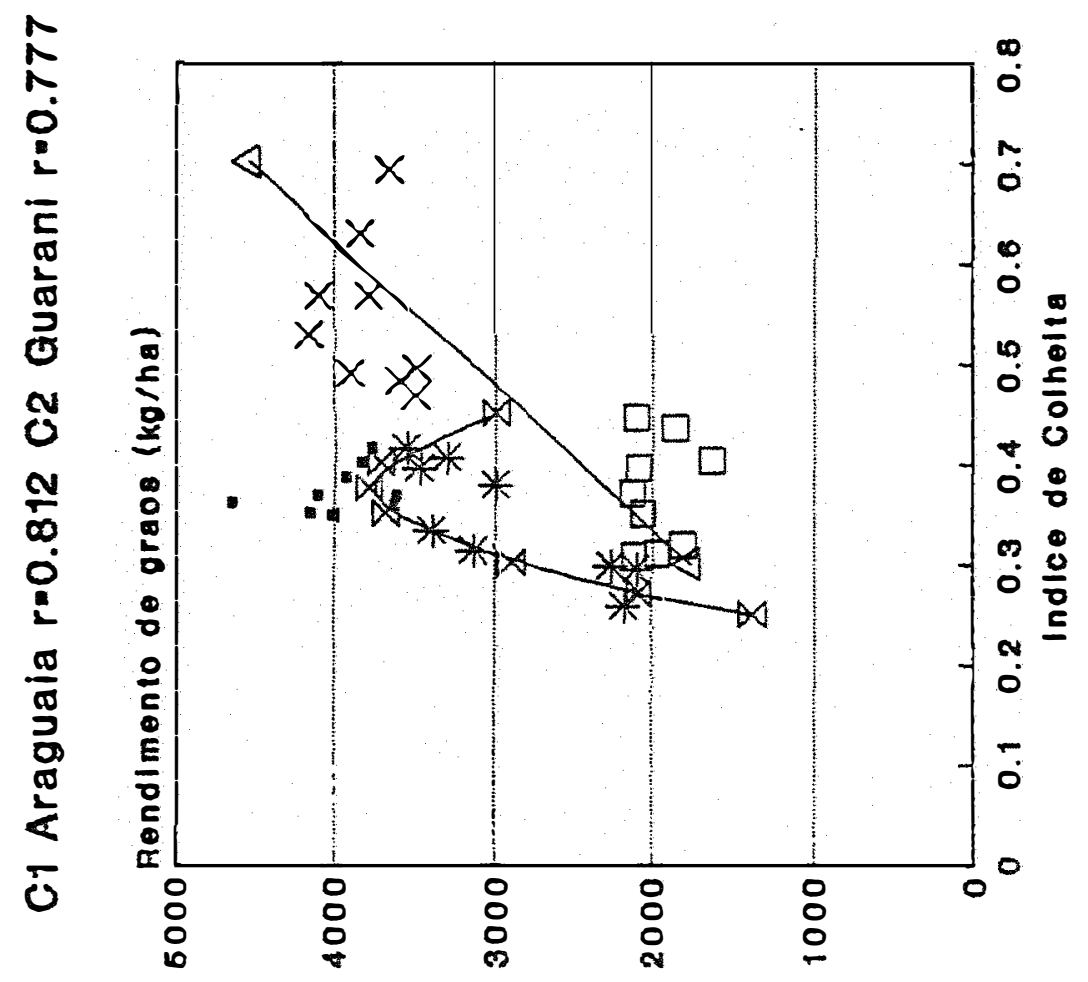

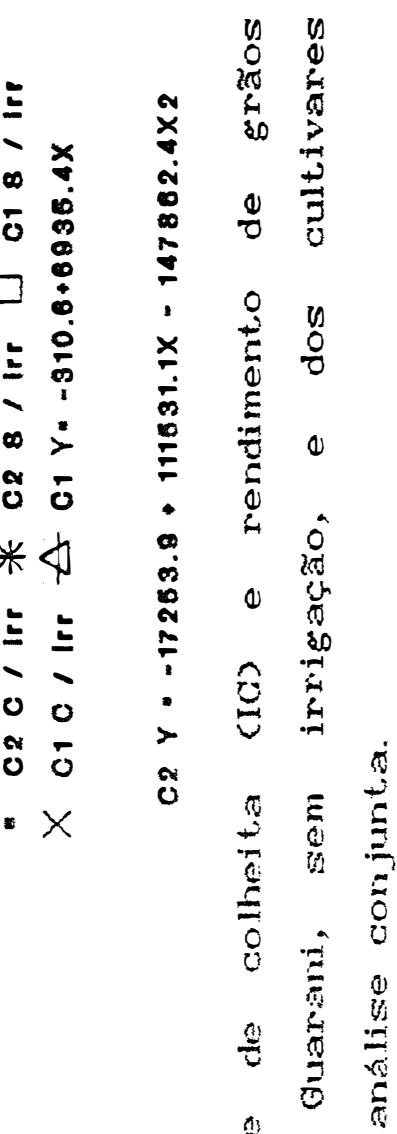

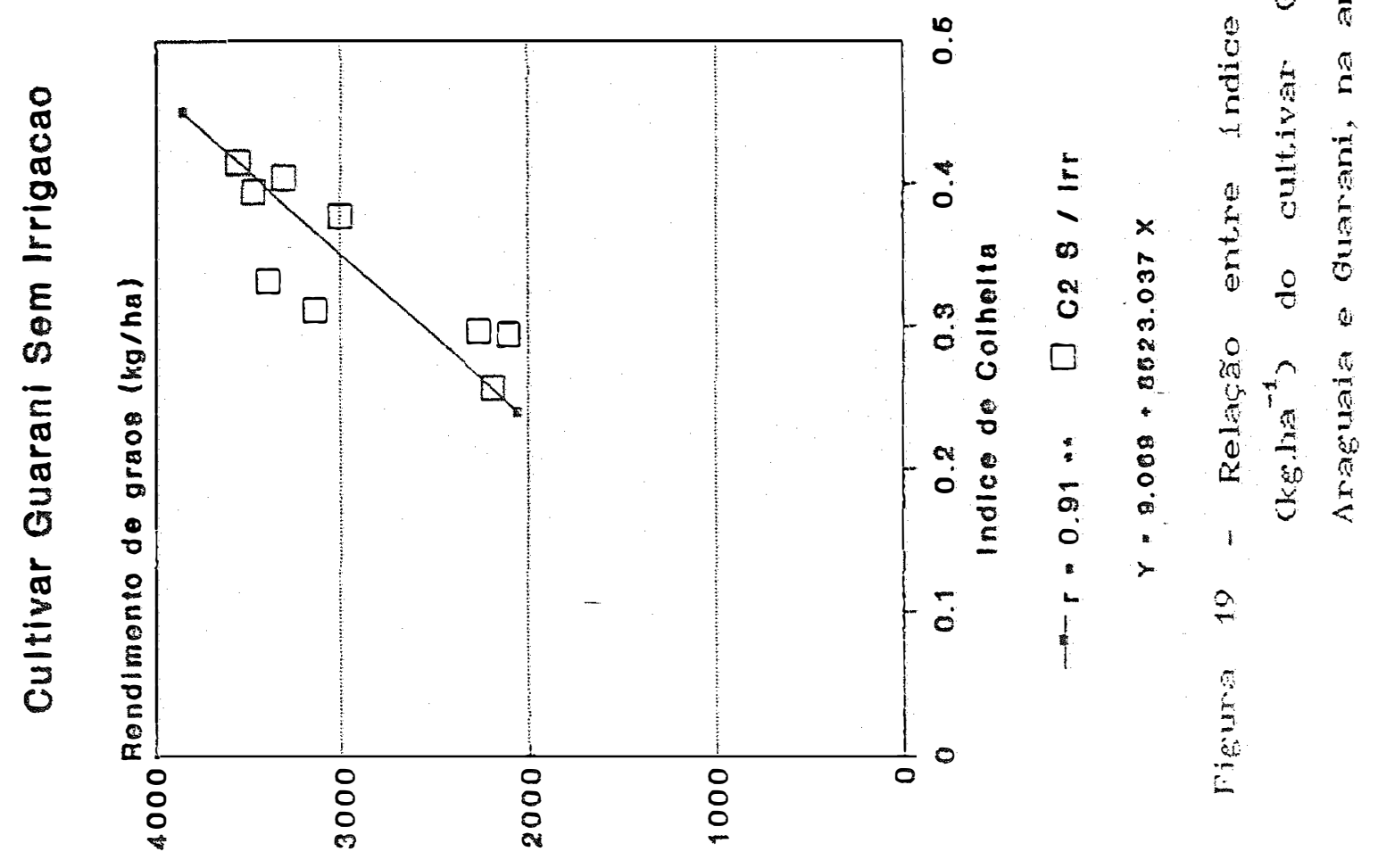


as análises de regressão mostraram que houve correlação linear positiva entre o IG e o rendimento de grãos do cultivar Araguaia e quadrática no cultivar Guarani, estimando-se a maior produção de grãos com IC igual a 0,38. Entretanto, no cultivar Araguaia os efeitos observados se devem especialment.e à suplement.ação hídrica, ao passo que, no cultivar de ciclo curto houve influéncia marcante dos espaçament.os e das densidades estudados, em condições de menor disponibilidade de água às plantas.

O rendimento de grãos do cultivar Araguaia, com irrigação, foi influenciado pelo espaçament.o e, do cultivar Guarani, pelo espaçament.o e pela densidade de semeadura, quando a irrigação não foi empregada, e pelo espaçamento, com irrigação cTabela 4). A análise de regressão mostrou que houve correlação quadrática entre os espaçamentos e o rendimento de grãos do cultivar Araguaia, sendo a maior resposta estimada com o espaçamento de $40 \mathrm{~cm}$ entre linhas (Tabela 8). Isto se deve aos valores máximos de MS e IAF obtidos com este espaçamento. No cultivar Guarani, o rendimento de grãos declinou linearmente com o aumento dos espaçamentos, sendo mais afetado quardo a imrigaçäo foi usada, havendo redução de $285 \mathrm{~kg} / \mathrm{ha}$ no rendimento de srã̃os quando o espaçamento foi aumentado em $10 \mathrm{~cm}$ cTabela 9). O sendimento de srãos do cultivar Guarani aument.ou em 8,5 e $15,6 \%$ quando o espaçamento entre linhas soi reduzido de $50 \mathrm{~cm}$ habitualmente 
empregado na lavoura de arroz de sequeiro, para $30 \mathrm{~cm}$, sem e com irrigação, respectivamente. Enquanto que, no cultivar Araguaia o incremento foi de $11,4 \%$ com a redução de $50 \mathrm{~cm}$ para $40 \mathrm{~cm}$, na presença de irrigação.

A relação entre o rendimento de grãos do cultivar precoce e a densidade foi quadrática, sendo que a maior produção de grãos foi estimada com 133 plantas por $\mathrm{m}^{2}$. Valores ligeirament.e superiores aos obtidos por OLIVEIRA et alii (1977) com o cultivar Batatais. Os efeitos dos tratamentos verificados sobre o rendimento de grãos do cultivar Guarani se devem aos maiores valores de IAF (Figura 4 e 5 ) e TCG (Figura 7 e 8 ) determinados no menor espaçament.o, bem como, nas populações de 100 e 150 plant.as por $\mathrm{m}^{2}$. Ademais, os t.ratament.os influenciaram também várias caractetísticas biométricas, tais como: redução do número de panículas por $\mathrm{m}^{2}$ à medida que o espaçamento era aumentado; incremerto no indice de colheita com o aumento da densidade; menor número de espiguetas vazias por panícula e maiores valores para o número de perfillios e de paniculas por $\mathrm{m}^{2}$ e tambem da massa de 100 grãos com a população entre 120 e 130 plantas por $\mathrm{m}^{2}$. Os resultados obtidos corrirmam aqueles verificados por SANTOS et alii (1988) que os efeitos do espaçamento entre linhas sobre o rendimento de crãos de arroz de sequeiro são muito maiores do que os da dersidade de semeadura. 


\begin{tabular}{|c|c|c|c|c|c|c|c|c|}
\hline \multirow[b]{2}{*}{ rendimento } & \multirow[b]{2}{*}{ de } & $\mathrm{Na}$ & análise & \multicolumn{2}{|c|}{ conjunta } & \multirow{2}{*}{$\begin{array}{l}\text { CTabela } \\
\text { ciclo }\end{array}$} & 5), & 0 \\
\hline & & grãos & do & cultivar & de & & médio & foi \\
\hline influenciado & & selo & spaçá & mento, & obt & ndo-se & resp & osta \\
\hline
\end{tabular}
com $39 \mathrm{~cm}$ (Tabela 7). Para o cultivar Guarani, houve efeito significativo do espaçamento, da densidade e da interação entre espaçament.o e densidade sobre o rendiment.o de grãos (Tabela 5). Desdobrando-se os efeitos dos tratamentos sobre o rendimento de grãos do cultivar Guarani, verifica-se, na Tabela 11, que nos espaçamento de 30 e $40 \mathrm{~cm}$ o aumento da densidade de semeadura resultou em respostas quadráticas, obtendo-se as produções máximas com 117 e 127 plantas por $\mathrm{m}^{2}$, respectivamente. Enquanto que, D maior espaçamento houve aument.o linear do rendiment.o de rãos à medida que a densidade crescia. Dentro de cada ensidade de semeadura, efeitos lineares negativos ignificativos dos espacamentos sobre o rendimento de srãos foram observados com as populações de 10 e 150 plantas por $\mathrm{m}^{2}$. Efeitos da interaçăo entre espaçamento e densidade sobre o rendiment.o de grãos foram também obtidos pOT SANTOS et alii (1988), em condiçóes de irrigação suplementar e aplicação de inseticida, com o cultivar precoce IAG 165. A maiör respostra verificada por esses autores, espaçamento de $50 \mathrm{~cm}$, pode ser devida à maior susceptibilidade do cultivar 引 brusone. Como o aumento do espaçamento reduz a intensidade dos sintomas de brusone 


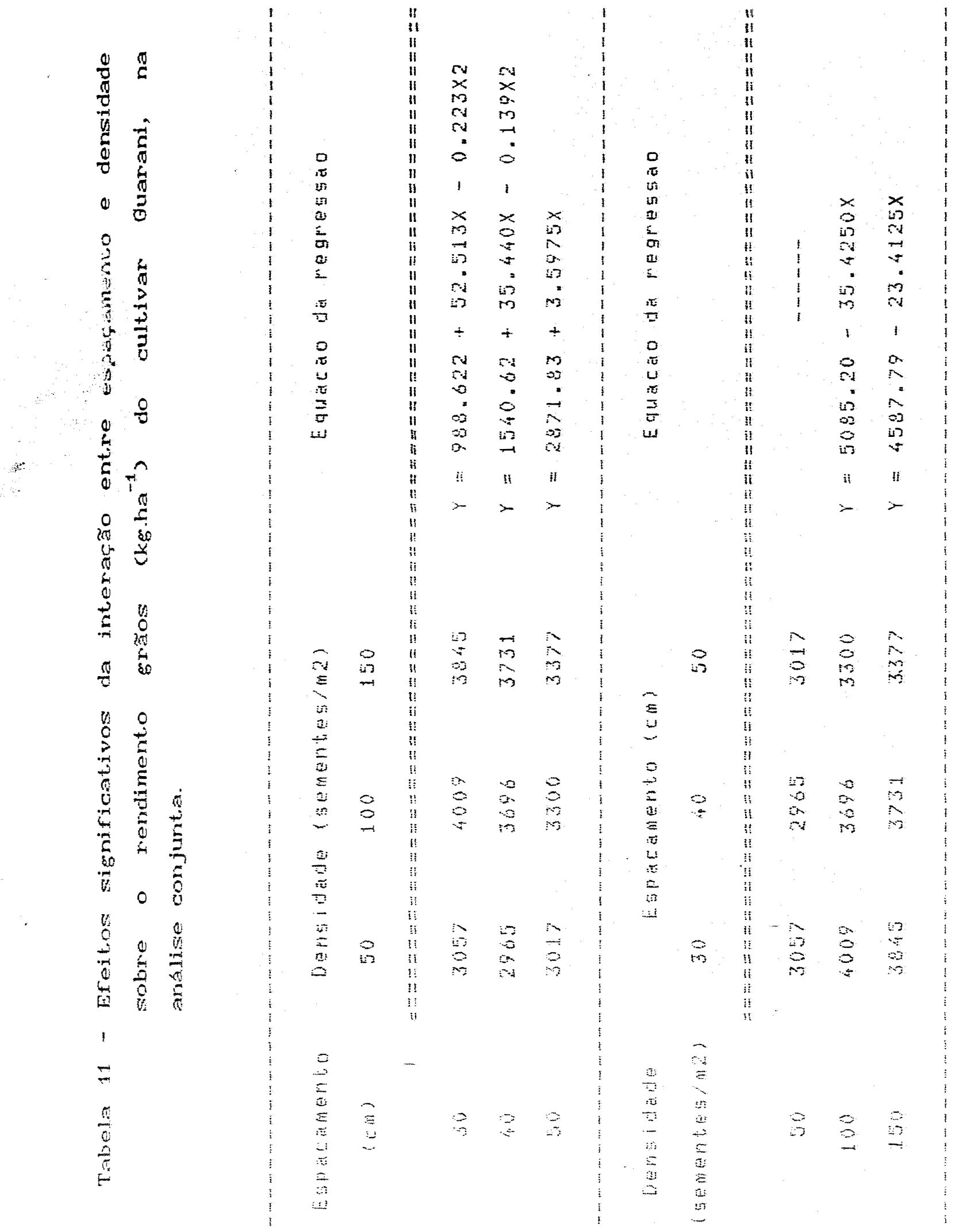




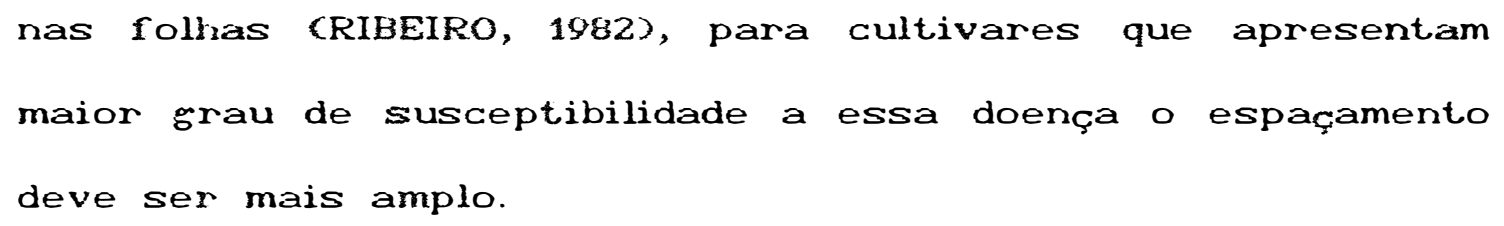




\begin{abstract}
população de 130 plantas por $\mathrm{m}^{2}$. Ao passo que, para o cultivar Araguaia, independente da irrigação, o espaçamento deve ser de $40 \mathrm{~cm}$. Como a população de plantas apresentou menor influencia sobre o rendimento de grãas do cultivar Araguaia que o espaçamento, esta pode variar de 100 a 150 plantas por $\mathrm{m}^{2}$, pois possibilitou a obt.enção de maiores valores de IAF e TCC.

o Guarani, por demonst.rar ser um cultivar mais competitivo que o Araguaia, apresentou menor IC e seu rendimento de grãos foi mais influenciado pelos efeitos do espaçamento e da derısidade de semeadura. O que corrobora com as conclusões relatadas em vários estudos CDONALD, 1968); JENNINGS \& AQUINO, 1968; JENNINGS \& JESUS, 1968; PEREIRA, 1989 ).
\end{abstract}




\section{CONCLUSÕES}

A irrigação proporciona incrementos de 90 e $35 \%$ no rendimento de grãos dos cultivares Araguaia e Guarani, respectivamente.

A complementação hídrica afeta significativamente todas as caracteristicas biometricas estudadas, exceto o numero de perfilhos por $m^{2}$ no cultivar Araguaia.

Considerando-se os parametros de avaliaçäo da análise de crescimento estudados, a irrigação aument.a a produção de matéria seca total (MS), o indice de área foliar (IAF), a taxa de crescimento da cultura (TCC) e a duração de area foliar (DAF) nos dois cultivares.

A medida que o espaçament.o aument.a, decrescem O IAF, a DAF e a TCC em ambos cultivares.

O IAF e a materia seca por perfilho säo conpelacionados significativamente com o rendimento de sräos com maiores coeficientes de correlaça aos 30 e 10 dias antes da floraçäo dos cultivares Axaguaia e Guarani, respectivamente, quando ha menow disponibilidade de ásua as plantas, e no final da floração, com irrisaçäo. 
O cultivar Guarani t.em maior MS, pois apresenta maiores valores de TCC, taxa de assimilação liquida (TAL) = taxa de crescimento relativo (TCR), parâmetros indicativos de capacidade de acúmulo de biomassa. Atinge rapidamente o ponto de máximo IAF, com alta capacidade de aproveit.amento da área disponível.

A produção de grãos do cultivar Guarani aumenta quando o espaçamento é reduzido até $30 \mathrm{~cm}$ e a população é ao redor de 130 plantas por $\mathrm{m}^{2} ; \mathrm{e}$, seu indice de colneita (IC) é correlacionado linear e positivamente com o rendimento de grãos, sem irrigação, e relação quadrática, na análise conjunta.

o cultivar Araguaia apresenta maior rendiment.o de grãos no espaçament.o de $40 \mathrm{~cm}$, independent.e da densidade de semeadura e dà irrigação.

A redução do espaçament.o de $50 \mathrm{~cm}$, comumente utilizado, para $30 \mathrm{~cm}$ entre linhas possibilita incrementos de 8,5 e $15,6 \%$ no rendimento de grãos do cultivar Guarani, sem e com irrigạ̧ăo, respectivamente. Ao passo que, no cultivar Araguaia, com irrigaçăo, o aumento é de $11,4 \%$, quando a distáncia é reduzida para $40 \mathrm{~cm}$.

o Guarani mostra ser um cultivar mais
competitivo que o Araguaiz, apresentando menor la e maior
influencia da populaça de plantas sobre o rendimento de
sraos.




\section{REFEREANCIAS BIBLIOGRÁAICAS}

ANDRADE, D.; GALVAO, J.D.; BRANDAO, S.S.; GOMES, F.R.

Efeito do espaçamento entre fileiras e densidade de plantio sobre a produgão de arroz de sequeiro. Experientiae, Viçosa, 11(3): 135-61, 1971.

BERNARDES, M.S. Fotossintese no dossel das plantas cultivadas. In: CASTRO, P.R.C.; FERREIRA, S.O. \& YAMADA, T., ed. Ecofisialosia da produção agricola. Piracicaba, Associação Brasileira para a Pesquisa da Potassa e do Fosfato. 1987. p.13-48.

BLAGKMAN, V.R. The compound interest law and plant growth. Annals of Botany, Oxford, 33: 353-60, 1919.

BLACKMAN, G.E. \& WILSON, G.L. Physiological studies in the analysis of differential effects of light intensity on the net assimilation rate, leaf area ratio an relative srowth rate of different species. Annals of Botany. Oxford, 15(59): 373-408.1951.

BRIGS, G.E.; KIDD, F.; WEST, C. A quantitative analysis of plant growth. Part I. Annals of Applied Biology, Cambridge, 7: 103-23, $1920_{a}$.

BRIGS, G.E.; KIDD, F.; WEST, C. A quantitative analysis 
of plant growth. Parth II. Annals of Applizd Biolosy, Cambridge, $7: 202-23,1920_{6}$.

BUENO, L.G.; NEIVA, L.G.S.; PURISSIMO, G. Informacoes serais sobre urroz de sequeiro. Goiania, EMGOPA, 1981. 80p. (EMGorA. Gircular Técnica, 1).

BUTTERY, B.R. Analysis oì the growth of soybeans as affected by plant population and fertilizer. Canadian Journal of Plant Science, Ot.tawa, 49: 675-84, 1969.

BUTTERY, B.R. \& BUZZELL R.I. Some differences between soybean cultivars observed by growth analysis. Canadian Journal of Plant Science, Ottawa, 52(1): $13-20,1972$

GASTRO JUNIOR, L.G. de \& PORTES E GASTRO, T. de A. Programa computacional para análise de crescimento de plantas. Série Documento. Goiania, 1990. (No prelo).

GHANDLER JUNIOR, R.F. Plant morphology and stand geometry in relation to nitrogen. In: EASTIN, J.D.; HASKINS, F.A.; SUlLIVAN, G.T.; BAVEL, G.H.M. van. ed. Physiological aspects of crops yield. Madison, American Society of Agronomy, 1969. p.265-89.

CHANG, T.T.; LORESTO, G.C.; TAGUMPAY, O. Agronomic and growth characteristics of upland and lowland rice varieties. In: INTERNATIONAL RICE RESEARCH INSTITUTE. ed. Rice breeding. Los Baños, IRRI, 1972. p.645-61.

DONALD G.M. In search of yield. Journal of the Australian Institute of Agricultural Science, 28 : 
$171-9,1962$

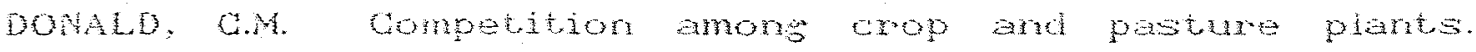

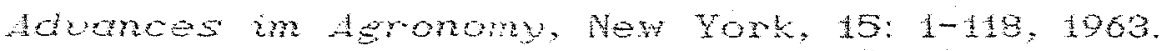

DONALD, G.M. The breeding or urop ideotypes. Euphytica, Wagenirisen, 17: $385-403,1908$.

DONALD, C.M. Th HAMBLIN, J. The biolosical yield and harvest index of cereals as agronomic and plant. breedins criteria. Advarces in deronomy, New York, 38 : $361-405,1970$.

DUNGAN, W.G. The relationship bet.ween population and yield. Agronomy Journal, Madison, 50: 82-4, 1958.

DUNCAN, W.G. Cultural manipulation for hisher yields.

In: EASTIN, J.D.; HASKINS, F.A.; SULLIVAN,G.T.; BAVEL,

G.H.M. van, ed. Physiolosical aspects of crop yield. Madison, American Society of Agronomy, 1969. p.327-39.

DUNGAN, W.G. A theory to explain the relationship between corn population and sxain yield. Crop science, Madison, 24: 1141-45, 1984

EMPRESA BRASILEIRA DE PESQUISA AGROPECUARIA. CEntro Hacioral de Pesquisa de Arroz e Feijão, Goiania. Aracuaia; cultivar de arroz de sequeiro para Goias. Goiânia, 1986 a. Folder.

EMPRESA BRASILEIRA DE PESQUISA AGROPECUARIA. CEntro Naciomal de Pesquisa de Arroz e Feijão, Goisnia. Guarani: cultivar de arroz de sequeiro para o Mato Gosso, Goias, Minas Gerais e Mato Grosso do Sul. 
Coínia, $1980_{\text {z }}$. Folder.

EMPRESA DE PESQUISA AGROPECUARIA DO ESTADO DO MATO GROSSO.

Cuiabá, MT. Kedução no custo de produção de arroz através de práticas adequadas. 1982. 2p. CEMPA. Imforma, 001 .

ENGLEDOW, F.L. \& WADHAM, S.M. Investigation on yield ir cereals. Institute Japanese Agriculture Science, 13: $390-439,1923$

FAGERIA, N.K. Adubação e nutrição mineral da cultura do arroz. Rio de Jareiro, Campus, 1984. $341 \mathrm{p}$.

GARDNER, F.P.; PEARCE, R.B.; MITCHELL, R.L. PhYsiology of crop plants. Ames, lowa state University Press, 1985. $327 \mathrm{p}$.

GASTAL, F.L. da G. Densidade de semeadura em arruz. A Granja, Port.o Alegre, 30(318): 27-8, 1974.

GUIMARTES, E.P.; MORAIS, O.P. de; BARROS, L.G. de; NEIVA; L.C. da S.; SUARES; A.A.; BAZON, R.; PRABHU, A.S.; PINHETRO, E. da 5 . Desenvolvimento, avaliạăo $E$ larçamento da cultivar precoce Guarani para o arroz de sequeiro. Pesquise Agropecuaria Erasileira, Brasilia, $2 \cdot(03): 900-74,1989$

HOLLIUAY: R. Fiant population and crop yield. Nature, Lonùn, $190: 22-4,1900$.

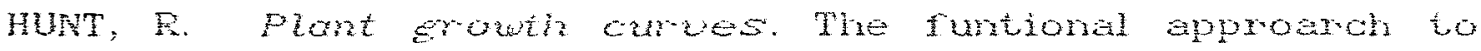
plart growth aralysis. Lorion, Edward Amroud. 1982. 2480 
INSTITUTO AGRONOMICO DO PARANA, Londmina, PR. Cuztura do arroe no Estado do Paraná. Londrina, i98• 6́p. IAPAR. Cincular, 19).

ISHZUKA, $Y$. TANAKA, A. Studtes on the nutrio-physiolosy of the rice plant. Tokyo, Yokendo, 1963. $307 \mathrm{p}$.

JENNINGS, P.R. \& JESUS, J. de. Studies on competition in rice. I- Competition in mixt,ures de varieties. Evolution, New York, 22: 119-24, 1968.

JENNINGS, P.R. \& AQUINO, R.G. Studies on competition in rice. III-The mecanism of competition among phenotypes. Evolution, New York, 22: 529-42, 1968.

KIM, S.C. \& MOODY, K. Study on the residual effect of plant. spacino and weedins t.reatment on the weed flora. Research Report of the Office of Rural Development, 22: $76-81,1980$.

KUSSOW, W.R.; CORUM, K.R. \& DALL'AQUA, F.M. Interpretação aśro-econômica de ensaios de adubação. Goiânia, EMBRAPA - CNPAF, 1976. 49p. CEMBRAPA-CNPAF Boletim técnico, 43.

KVET, J.; ONDOK, J.P.; NECAS, J.; JARVIS, P.G. Methods of srowth analysis. In: SESTAK, Z; CATSTY, J. \& JARVIS, P.G., ed. Plant photosynthetic production. Manual of methods. Haia, Dr. W. Junk, N.V. Publishers, 1971. p.343-91.

LOOMIS, R.S. \& WILLIANS, W.A. Produtivity and the 
morphology ot crop stands: pattern with leaves. In: EASTIN, J.D; HASKTNS, F.A.; SULLIVAN, C.T.; BAVEL, C.H.M. van, ed. physialoerial aspecis of crop yiseld. Madison, American Society ot Asronomy, 1969. p.27-47.

MACHADO, E.G. Eficiencia sotossintética. In: SEMINARIO DE BIOTECNOLOGIA AGRICOLA, Piracicaba, 1985. Anais. Piracicaba, FEALQ, 1995 . p.175-200.

MAGALHAES, A.C.N. Análise quantitativa do crescimerito. In: FERRI, M.G., ed. Fisiologia Fegetal. São Paulo, Editora Pedagogica e Universitária, EDUSP, 1985. p. $333-50$

MATSUSHMA, S. Hater and physiology or indica rice. Proceedine Crop Science Society, Tokyo, 102: 9, 1968.

MERGADO, B.L. \& LUBIGAN, R.T. Biology and control of Paspalum distichrm L. 3. Competition with lowland rice. In: University of Philippines Weed Science Report for 1977-78. Los Baños, University of Philippines Press. 1979.

MITCHELL, R.L. Crop growth and culture. Ames, Iowa Stat.e Universit.y Press, 1979. 349p.

MURATA, Y. Studies on the photosynthesis of rice plants and its culture significance. Bulletin of the National Institute of Agricultural Science Série D, Tokyo, 9: $1-169,1961$.

MURATA, Y. Physiological responses to nitrogen in plants. In: EASTIN, J.D.; HASKINS, F.A.; SULLIVAN, G.T.; BAVEL, 
C.H.W. van. ed. Physiolosicat aspects of crop yield. Madison, Ameriazn Society of Agronomy, i9o9. p.235-59.

MURATA, $Y$. M MATSUSHTA, S. RICE. In: EVAHS, L.T., ed. Grop physiobosy London, Cambridge University Press, 1075. p.73-99.

MEGTON, JE. Q BLACMAN, G.E. Penetration Ot SOlar raciation through leas caropies ot different structure. Annals of Botany, Oxford, 34: 329-48, 1970.

NICHIPOROVICH, A.A. Photosynthesis and the theory of obtaining hioh crop yields. 15th Timirjazev Lecture, USSR Academy of Science, 1956. CTranslated and Review by BLACK, J.N. WATSON, J.D.) Field Crop Abstract, Aberytwyth, 13: $390-439,1960$.

OLIVEIRA, A.B. de; BRANDAO, S.S.; CONDE, A.R.; DEL GIUPCE, R.M. Espaçamento entre fileiras e densidade de plantio em duas cultivares de arroz, sob irrigaçäo por aspersáo. Revista Ceres, Viçosa, 24(135): 427-44, 1977.

PEREIPA, A.P. A APPUDA, H.V Ajuste pratico de curvas na pesquisa biolopica. Campinas, Fundagio Givaill, 1937. $50 \mathrm{p}$

PEREIRA, A.R. Competiçáo intra-espedifla entre plantas cultivadas. O Aeronomico, Campiras, 41(1): 5-11, 1989.

PEREIRA, A.R. \& MACHADO, E.C. Análise quantitativa do crescimento de comunidade vesetais. Campinas, IAC, 1987. 33p. \{IAC Boletim Técnico, 114 \}. 
PINHEIRO, B. da S.; STEINMETZ, S.; STONE, L.F.; GUIMARAES, E.P. Tipo de planta, regime hidrico e produtividade do arroz de sequeiro. Pesquisa Aeropecuária Brasileira, Brasilia, 20(1): 87-95, 1985.

PINHEIRO, B. dá S. \& GUIMARAES, P.E. indice de áreá roliar e produtividade do arroz de seque "o. I. Níveis Limitantes. Pesquisa Aeropecuaria Brasibira, Brasilia, $25(6): 863-72,1990$.

PINHEIRO; B. da S; MARTINS, J.F. da S.; ZIMMERMANN, F.J.P. Indice de area foliar e produtividade do arroz de sequeiro. Ir. Marifestaçáo atraves dos componentes de producäo. Pesquisa Amopecuamia Erasileira, Erasilia, 2566): 873-79, 1990.

PITELLI: R.A. DOMINGUE: E.; PEDROSO, P.A.: HAAG: H.P. Matointerfersmaia em arroz de sequeiro. I. Efeitos do espagamento nas concentraçes de rutrientes no arroz e nas plantas daninhas. Annais da Escola Superior "Luiz de Quevor". Piracicate, sicil: 237-76, 1984.

RAUFORV. P.I. Growtin analysis formulae. Their use and abuse. Crop science, Madisor, 7: 171-5, 1967.

RIBEIRO, A.S. Eieitos do espaçamento entre linhas sobre a intensidade de brusone em arroz. Fesquisa Arropecuaria Emasileira: Brasilia, $17(11)$ : $1601-4,1982$.

SANTOS: A.B. dOS; FERREIRA: E.; AQUNNO: A.RL. de: SANT'ANA, E.P.: BALDT, A.F. POPulagáo de plantas e controle de pragas em arroz de sequeiro com 
complementaçäo hídrica Pesquisa Agropecuária Brasileira, Brasilia, 23(4) 397-404, 1988.

SARKAR, F.A. Study of a varietal resporse to plantirix geometry ard weedire in tramsplanted rice. Allahabad Farmer, 50: $357-8,1979$

SINGH, 1.b. \& STOSKOFF, N.C. Hervest index in cereals. Aeronomy Joumal, Madisor, 63: 224-6, $19 ? 1$.

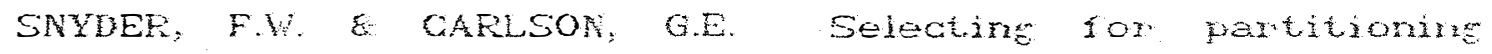
of photosymbetid products in cropsi Anomes in Aeroromy, Hew Yojk, 37: 47-72, 1984.

SOAFES P.C.: MOFAIS OP.; SOUZF AF. DEL GUUME. EM prepard do solo, epoce e dersidade de semedurie Informs Aeropecubrio, Eelo Horizomle, 565: $3=-9$ 1075

SOEFAL, O.M. E OLIVETA, JMS. Espacamento $x$ densidade

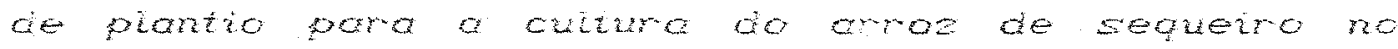

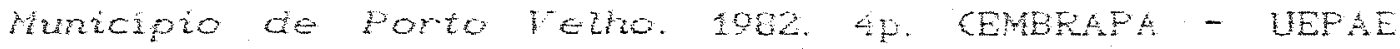

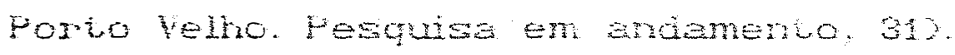

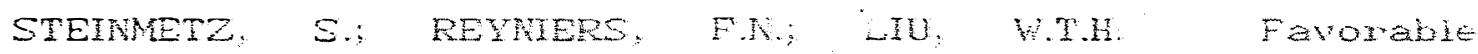

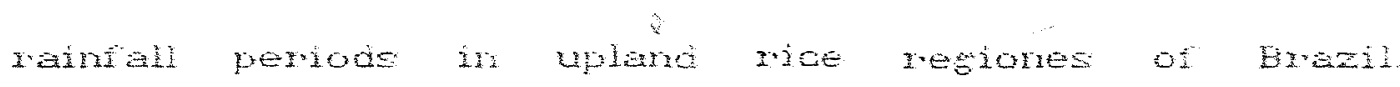

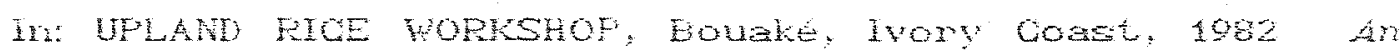

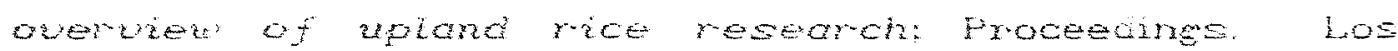
Danos. IFFi, $1084.9275-81$

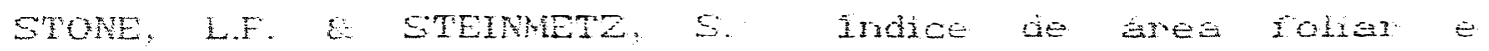

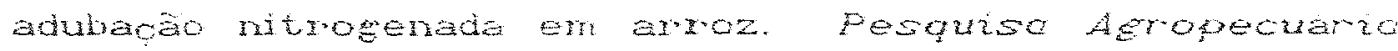
Brasileiro, Brasilid: 16(1): 25-8, 1979. 
STONE, L.F.; OLIVEIRA, A.B. de; STEINMETZ, S. Deficiencia hidrica e resposta de cultivares de arroz de sequeiro ao nitrogénio. Pesquisa Agropecuára Brasileira, Brasilia, 14(3): 295-301, 1979.

STONE; L.F.; PORTES, T.A.; MOREIRA, J.A.A. Ereitos da tensão da água do solo sobre a produlividade e crescimento do feijoeiro. II. Crescimento. Pesquiso Asr-pecuária Erasibeira: Brasilia, 2365): 503-10, 1988.

TAKEDA: T. Studies on the photosynthesis and production of dry matter in the community of rice plants. Japanese Joumal Botany, 17(3): 403-37, 1901.

TSONODA: S. A levelopmental aneivsis of yieldins ability in varieties of field crops. I. Lear area per plant and lear area ratio. Japthese Journal Breedinz. Tokyo, $161-8,1059$.

VERNON, A.J. E ALISON, J.G.S. A methol ố calculating net assimilation rate. Nature, London, 200: 814, 1963.

WATSON, D.J. Comparative physiological studies on the erowth of field crops. I. Variation in net assimilation rate and leaf between species and varieties, and withir and between years. Annals of Botany, exrord, 11 $41-76,1947$.

WATSON, D.J. The hysiolosical basis of variation in yield. Advances in Aeronomy, New York, 4 : 10s-45, 1052.

WATSON, D.J. The dependence of net assimilation rate on 
leaf area index. Annats of Botany, Oxford, 22: 37-54, 1958.

WILEY, R.W. \& HEATH, S.B. The quantitative relationships between plant population and crop yield. Advances in Agronomy, New York, 21: 281-321, 1969.

WILLIAMS, R.F. The phyiology of plant srowth with special reference to the concept of net assimilation rate. Annals of Batany, Oxiord, 11: 41-72, 1940.

MAGUISHI, A.; HASHIZUME, A.; TAKEICHI, $Y$ Studies on the control of parenial weeds in paddy fields. Competition between Cyperus serotinus Rotib and rice. Chiba-kem Aenicultural Experimentai Station. Research Bulletin no 171976.

SHIDA. S. Fhysiological aspects of grvar yiela. Annul Review of Plant Dhusioloey. Palo Alto, 23: 437-64, 1972

YOSHIDA, S. Fice. In: ALVIA, P.T. E KOZLWSH, T.T.ed. Ecophysiolosy of tropical crop. Nev York Aandemic Press, 1977. p.57-87. 